\title{
Female social relationships among wild Assamese macaques (Macaca assamensis)
}

\author{
Dissertation \\ for the award of the degree \\ "Doctor rerum naturalium" (Dr.rer.nat.) \\ of the Georg-August-Universität Göttingen
}

within the doctoral program Biology

of the Georg-August University School of Science (GAUSS)

submitted by

Sally Macdonald

from Aberdeen, United Kingdom

Göttingen, 2014 


\section{Thesis Committee}

Prof. Dr. Julia Ostner, Junior Research Group Social Evolution in Primates, Courant Research Centre Evolution of Social Behaviour, University of Göttingen

Prof. Dr. Peter Kappeler, Department for Sociobiology/Anthropology Johann-FriedrichBlumenbach Institute for Zoology \& Anthropology, University of Göttingen \& Behavioral Ecology and Sociobiology Unit, German Primate Center GmbH

\section{Members of the Examination Board}

First Reviewer:

Prof. Dr. Julia Ostner

Second Reviewer:

Prof. Dr. Peter Kappeler

\section{Further members of the Examination Board}

Dr. Antje Engelhardt, Junior Research Group on Primate Sexual Selection, Reproductive Biology Unit, German Primate Centre GmbH

Dr. Bernhard Fink, Junior Research Group Evolutionary Psychology, Courant Research Centre Evolution of Social Behaviour, University of Göttingen

Prof. Dr. Julia Fischer, Cognitive Ethology Lab, German Primate Center GmbH

Prof. Dr. Eckhard Heymann, Behavioral Ecology and Sociobiology Unit, German Primate Center $\mathrm{GmbH}$ 
This thesis is dedicated to Marlies Heesen and Miranda Swagemakers, two fantastic, female friends I couldn't have done it without. 



\section{Table of Contents}

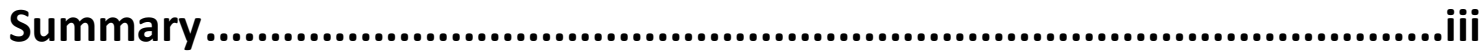

Zusammenfassung..................................................................................

Chapter 1 - General Introduction ...................................................... 1

Chapter 2 - The Structure and Stability of Female Social Relationships in

Assamese Macaques (Macaca assamensis) ............................................17

Chapter 3.1 - The Absence of Grooming for Rank-Related Benefits in Female

Assamese Macaques (Macaca assamensis)

Chapter 3.2 - Social Relationship Strength and the Equality of Grooming Reciprocity

in Female Assamese Macaques (Macaca assamensis)

Chapter 4 - Primate Social Networks.

Chapter 5-General Discussion

References

Acknowledgements

Curriculum Vitae 



\section{Summary}

It has been repeatedly shown that strong, affiliative social relationships (hereafter "social relationships") are extremely important for human health and well-being. Increasingly there is evidence that non-human species also form social relationships that share important characteristics of human social relationships: specifically differentiation in strength, stability and equality, and that these relationships play an important role in non-human fitness and wellbeing. However, there have been strong criticisms of this work by some, who claim the apparent similarities between human and non-human social relationships may be by-products of very different, simpler processes. In addition, not all aspects of the proposed, shared characteristics have been thoroughly compared with their human equivalent. Investigations of non-human social relationships are also generally hindered by a lack of consensus on how best to quantitatively assess non-human social relationships. The overall aim of this thesis was to establish the characteristics of social relationships among wild, female Assamese macaques and consider how closely they resemble the characteristics of strong social relationships among humans and other non-human species. Specifically I addressed the criticisms and gaps in our understanding of the characteristics of non-human social relationships. In addition, I evaluated and made use of new quantitative measures of social behaviour, provided by Social Network Analysis (SNA) and considered whether these measures are helpful in improving our assessment of non-human social relationships.

Data for this thesis were collected from a single group of wild Assamese macaques living within Phu Khieo Wildlife Sanctuary $\left(16^{\circ} 5^{\prime}-35^{\prime} \mathrm{N}, 101^{\circ} 20^{\prime}-55^{\prime} \mathrm{E}\right)$, located in Chaiyaphum province, north-eastern Thailand. The sanctuary covers $1573 \mathrm{~km}^{2}$ and is part of the regions contiguous ca. $6500 \mathrm{~km}^{2}$ Western Isaan Forest Complex. Data were collected over two one-year sampling periods (period 1: Oct. 2007 - Sep. 2008, period 2: May 2010 - Apr. 2011). During this time the group consisted of 49-53 individuals in total, 12 adult females in sampling period 1 and 15 adult females in sampling period 2. All adult females in the group were subject to regular focal observations, during which all social interactions were recorded using continuous sampling and general activity was recorded using instantaneous sampling. In total over 2100 hours of behavioural observations were collected.

Analysis of this data revealed that female Assamese macaque social relationships do share some important characteristics of strong human social relationships. The social relationships were found to be strongly differentiated in strength, with females tending to only form a few stronger than average social relationships. Social relationships were also found to 
remain stable throughout the year, despite significant changes in the time females allocated to other behaviours, such as feeding and resting, associated with changes in the female breeding cycle. In addition, analysis also provided some initial evidence that these social relationships remain stable for several years. Females were also found to exchange services in an equitable manner, however unlike human social relationships, social relationships strength did not influence the content or time frame over which services were exchanged. SNA was found to provide useful measures for quantifying the structure of female Assamese macaques social relationships and to provide other potentially useful measures for future studies of non-human social relationships.

These results provide a valuable contribution to our understanding of both non-human and human social relationships. They provide us with a fuller picture of the social lives of Assamese macaques in general, showing that strong, social relationships are an important feature of female social lives in this species, while dominance rank plays a relatively limited role in female behaviour. They also provide further support for the "valuable" relationship approach to understanding non-human social relationships, as opposed to the biological market approach suggested by some. Lastly, by providing further evidence that social relationships among nonhuman species share important characteristics with strong human social relationships these results also have implications for our understanding of the evolutionary origins of human social relationships, particularly the original functional benefits these relationships evolved to provide. In the future, we can further deepen our understanding of non-human social relationships by continuing to investigate which characteristics these relationships share with strong human social relationships. At the same time, we should also attempt to identify and investigate characteristics of social relationships which may be more meaningful specifically for non-human species. Lastly, we should begin to turn our attention to the many weak and dynamic social relationships that exist in groups of non-human species and the potential benefits that they may provide. 


\section{Zusammenfassung}

Es wurde wiederholt gezeigt, dass enge, affiliative soziale Beziehungen (im Folgenden "soziale Beziehungen") äußerst wichtig für die Gesundheit und das Wohlbefinden des Menschen sind. Eine steigende Zahl von Befunden deutet darauf hin, dass nicht-menschliche Arten Sozialbeziehungen führen, die wichtige Eigenschaften menschlicher sozialer Beziehungen teilen, insbesondere Differenzierung in Stärke, Stabilität und Gleichwertigkeit, und dass diese Beziehungen eine wichtige Rolle für die Fitness und das Wohlbefinden dieser Arten spielen. Allerdings wurden diese Arbeiten von einigen stark kritisiert und es wird argumentiert, die scheinbaren Gemeinsamkeiten zwischen menschlichen und nicht-menschlichen sozialen Beziehungen könnten Begleiterscheinungen anderer, einfacherer Prozesse sein. Zudem wurden nicht alle Aspekte der vorgeschlagenen, gemeinsamen Eigenschaften vollständig mit den menschlichen Entsprechungen verglichen. Untersuchungen nicht-menschlicher sozialer Beziehungen werden außerdem grundsätzlich durch einen Mangel an Übereinstimmung darüber, wie nicht-menschliche soziale Beziehungen am besten quantitativ zu bewerten sind, erschwert. Das allgemeine Ziel dieser Doktorarbeit war, die Eigenschaften sozialer Beziehungen zwischen frei lebenden weiblichen Assam-Makaken zu ermitteln und sorgfältig zu prüfen, inwiefern diese den Eigenschaften enger sozialer Beziehungen zwischen Menschen und anderen nichtmenschlichen Arten gleichen. Ich habe mich im Speziellen mit den Kritiken und den Wissenslücken hinsichtlich nicht-menschlicher sozialer Beziehungen befasst. Des Weiteren habe ich die neuen Möglichkeiten, die die soziale Netzwerkanalyse bietet, um soziales Verhalten zu messen, beurteilt und genutzt, sowie geprüft, ob diese Messmethoden unsere Bewertung nichtmenschlicher Beziehungen verbessern können.

Die Daten dieser Arbeit stammen von einer einzelnen Gruppe Assam-Makaken, die in ihrem natürlichen Lebensraum im Phu Khieo Wildlife Sanctuary $\left(16^{\circ} 5^{\prime}-35^{\prime} \mathrm{N}, 101^{\circ} 20^{\prime}-55^{\prime} \mathrm{O}\right)$ in der Provinz Chaiyaphum im Nordosten Thailands leben. Das Schutzgebiet umfasst $1573 \mathrm{~km}^{2}$ und ist Teil des ca. 6500 km² umfassenden, zusammenhängenden Western Forest Complex. Die Daten wurden in zwei einjährigen Beobachtungszeiträumen erhoben (Zeitraum 1: Oktober 2007 September 2008; Zeitraum 2: Mai 2010 - April 2011). Während dieser Zeit bestand die Gruppe aus insgesamt 49-53 Individuen, davon 12 adulten Weibchen im ersten und 15 adulten Weibchen im zweiten Beobachtungszeitraum. Alle adulten Weibchen wurden regelmäßig mittels der Fokustiermethode beobachtet, währenddessen alle sozialen Interaktionen kontinuierlich und allgemeine Aktivitäten nach einer zeitabhängigen Regel aufgezeichnet wurden. Insgesamt wurden über 2100 Stunden an Verhaltensbeobachtungen gesammelt. 
Die Analyse dieser Daten zeigte, dass die sozialen Beziehungen weiblicher AssamMakaken wesentliche Charakteristika enger sozialer Beziehungen von Menschen teilen. Wie beim Menschen unterschieden sich die Sozialbeziehungen weiblicher Assammakaken deutlich in ihrer Stärke, wobei Weibchen dazu neigen nur wenige überdurchschnittlich enge soziale Beziehungen zu bilden. Außerdem blieben soziale Beziehungen über ein ganzes Jahr stabil, trotz signifikanter Veränderungen in der Zeit, die Weibchen für andere Verhaltensweisen, wie z.B. Fressen und Ruhen, aufwandten, wie sie mit Veränderungen im weiblichen Reproduktionszyklus einhergehen. Weiterhin konnte gezeigt werden, dass die sozialen Beziehungen über mehrere Jahre stabil bestehen bleiben. Ich konnte nachweisen, dass Weibchen Leistungen balanciert austauschen, allerdings wurden die Art und der Zeitrahmen, über den Leistungen ausgetauscht wurden, im Gegensatz zu sozialen Beziehungen beim Menschen nicht durch die Stärke sozialer Beziehungen beeinflusst. Der Einsatz der sozialen Netzwerkanalyse in meiner Arbeit zeigte, dass diese nicht nur nützliche Messwerte liefert, um die Struktur der sozialen Beziehungen weiblicher Assam-Makaken zu quantifizieren, sondern auch andere, potentiell nützliche Messwerte für zukünftige Studien nicht-menschlicher sozialer Beziehungen.

Diese Ergebnisse liefern einen wertvollen Beitrag für unser Verständnis sowohl nichtmenschlicher als auch menschlicher Sozialbeziehungen. Sie geben uns einen tieferen Einblick in das Sozialleben von Assam-Makaken im Allgemeinen, in dem gezeigt wird, dass feste soziale Beziehungen eine wichtige Größe des weiblichen Soziallebens dieser Art sind, während die Rangordnung eine untergeordnete Rolle im weiblichen Verhalten spielt. Sie unterstützen den "Ansatz der wertvollen Beziehungen", der genutzt wird, um nicht-menschliche soziale Beziehungen zu verstehen, und nicht den Ansatz der, von einigen vorgeschlagenen, biologischen Markttheorie. Schließlich haben diese Ergebnisse Auswirkungen auf unser Verständnis des evolutionären Ursprungs menschlicher sozialer Beziehungen, insbesondere für ihren ursprünglichen funktionalen Nutzen, da sie Hinweise darauf geben, dass soziale Beziehungen nicht-menschlicher Arten wichtige Eigenschaften mit engen zwischenmenschlichen Beziehungen gemeinsam haben. In Zukunft können wir unser Verständnis nicht-menschlicher Sozialbeziehungen vertiefen, indem weiter untersucht wird, in welchen Eigenschaften sich diese sozialen Beziehungen ähneln. Zeitgleich sollten wir versuchen, Eigenschaften, die insbesondere für nicht-menschliche Arten von größerer Bedeutung sein könnten, zu ermitteln und zu untersuchen. Schließlich sollten wir beginnen, unsere Aufmerksamkeit auf die vielen schwachen und dynamischen sozialen Beziehungen zurichten, die in Gruppen nicht-menschlicher Arten existieren, und ihren potentiellen Nutzen zu erforschen. 
Chapter 1

\section{General Introduction}



It has been repeatedly shown that having strong, affiliative social relationships (hereafter "social relationships"), be it with family members, romantic partners or close friends, is extremely important for maintaining health and well-being in humans (House 2001; Holt-Lunstad et al. 2010). Increasingly it is being suggested that non-human species also form strong social relationships, similar to those seen among humans (Silk 2002b; Massen et al. 2010; Dagg 2011), and that these relationships could play an important role in individuals' fitness and well-being (Alberts 2010). Support for this idea has gradually begun to grow as studies from a wide range of species provide evidence that non-human social relationships share some important characteristics of human social relationships, (Moses and Millar 1994; Kimura 1998; Connor et al. 2000; Silk et al. 2006a; Langergraber et al. 2009; Lehmann and Boesch 2009; Mitani 2009; Silk et al. 2010b; Stanley and Dunbar 2013), and that these relationships are related to significant improvements in both individual's reproductive success (Moses and Millar 1994; Silk et al. 2003; Cameron et al. 2009; Silk et al. 2009; Frére et al. 2010; Schülke et al. 2010) and their survival (Silk et al. 2010a). However, there have been some strong critics of this work, who argue that our current approach to studying animal sociality in general is overly anthropomorphic and anthropocentric (Barrett 2011) and that on closer inspection some of the characteristics which non-human social relationships appear to share with human social relationships do not hold (Henzi et al. 2009). They argue that in order to properly assess the similarities and differences between human and animal social relationships we must attempt to take a much more detached, "action centred perspective" of animals social behaviour which focuses more on the here and now consequences of an individuals' interactions (Barrett et al. 2007; Barrett 2011).

In addition to these criticisms, a persistent problem in attempts to effectively study animal social relationships is the lack of an established consensus on how best to measure and quantify positive social interactions, relationships and social structures (Silk 2002a; Silk 2007; Silk et al. 2013). Social network analysis (SNA), an approach used in human social sciences to investigate and quantify human social relationships, has been widely promoted in recent years as a useful source of quantitative tools which may help improve our ability to accurately assess animal social behaviour (Croft et al. 2008; Wey et al. 2008; Krause et al. 2009; Brent et al. 2011a; Jacobs and Petit 2011; Sueur et al. 2011a). SNA provides a range of different measures which capture various properties of a social network, i.e. a group of socially interconnected individuals, at various different levels of analysis, i.e. at the group, sub-group and individual levels. These measures promise to provide quantitative improvements in our analysis of animal social behaviour. However, SNA is still relatively new to researchers in this field, and as such has not yet been widely used. Therefore it still remains to be seen exactly how useful the approach will be in providing meaningful improvements to our analysis of animal social behaviour. 
The overall aim of this thesis is to investigate the characteristics of female social relationships among wild Assamese macaques (Macaca assamensis), and by doing so, providing a contribution to the ongoing debate regarding the similarities and differences of the characteristics of human and non-human social relationships. I will make use of a range of methods throughout the thesis, including SNA measures. In addition, I will specifically review the use to date of SNA in primatology, with the aim of contributing to debates on the usefulness of SNA in the study of animal social behaviour and how best to quantify social relationships both in primates and other non-human species. In this general introduction I will provide an overview of our current understanding of the characteristics of strong human social relationships and what evidence we currently have that non-human social relationships share any of these characteristics. I will also discuss both the criticisms and difficulties of our current approach to studying social relationships in non-human species. Lastly, I will finish by providing a brief summary of the chapters within this thesis and how each of them will contribute to the thesis's overall aim.

\section{Human Social Relationships}

The strength of the connection between strong social relationships and health was first established among humans during the late 1970's and early 1980's through a number of prospective mortality studies which linked various measures of the quantity and quality of social relationships among random samples of adults, from various communities, to their rates of mortality in the following nine to twelve years (Berkman and Syme 1979; House et al. 1982; Welin et al. 1985). These studies showed that individuals who scored lowest on these measures, i.e. had the fewest social relationships and/or spent the least amount of time engaged in social activities, had significantly higher risk of death during the follow up period. The findings have since been widely replicated in studies conducted in wide range of countries and cultures (HoltLunstad et al. 2010). Subsequent studies have also extended this work to show that the benefits of strong social relationships provide are not only limited to reduced mortality, but also to the development and/or progression of a range of specific physical and mental illnesses, including cardiovascular disorders (Horsten et al. 2000; Knox et al. 2000; Kuper et al. 2002; Everson-Rose and Lewis 2005; Wang et al. 2005), cancer (Costanzo et al. 2005), schizophrenia (Erickson et al. 1989; Hultman et al. 1997; Patterson et al. 1997; Salokangas 1997; Norman et al. 2005) and depression (Peirce et al. 2000; Vanderhorst and McLaren 2005; Mechakra-Tahiri et al. 2009) as well as cognitive decline during old age (Seeman et al. 2001).

A strong social relationship in the context of this work is generally defined as any relationship that involves regular, positive social contact between two individuals (House 2001). 
This covers a wide range of relationship types including spouse, relative, close friend etc. Each of these types of relationships tend to have several basic characteristics in common. For example they are all stable, long term social relationships (potentially life long relationships in the case of relatives). They also all involve high levels of emotional closeness which is maintained through frequent social contact and communication (Dindia and Baxter 1987; Dainton and Aylor 2002; Laursen and Collins 2003; Roberts and Dunbar 2011a). Without this regular connection the quality of these relationships can deteriorate rapidly (Dindia and Baxter 1987; Harrison et al. 1999; Laursen and Collins 2003; Oswald and Clark 2003; Roberts and Dunbar 2011a; Roberts and Dunbar 2011b). Due to the time and effort required to maintain regular social contact individuals tend to only have a small number of strong social relationships (Zhou et al. 2005). As a result the overall pattern of individuals' social relationships tends to become strongly differentiated, i.e. their social interactions are not evenly distributed between all their social contacts, but instead are consistently skewed toward a few specific individuals. This produces distinctly nested social structures, centered around a few strong social relationships, which are then nested within a larger grouping of increasingly weaker social relationships (Zhou et al. 2005), e.g. from best friends, friends and acquaintances.

In addition to stability and frequent contact, equality in the exchange of support and services, i.e. that no one individual is being taken advantage of by the other, is also an important feature of strong social relationships (Rook 1987; Clark and Ayers 1993; Walker 1995; Horwitz et al. 1996; Hendrix 1997; Komter and Schans 2008). Indeed, equality in the exchange of support and services appears to be important in both weak and strong social relationships. However, there are important differences in how this balance is maintained depending on the strength of the social relationship involved. For example, among strong social relationships it is not necessarily expected that the service provided will be returned exactly in kind, doing so in fact tends to be associated with weaker social relationships (Clark 1981; Törnblom et al. 2012), sometimes also referred to as "exchange" relationships (Clark and Mills 1979). There also seems to be an understanding that within strong social relationships there will be a delay in the reciprocation of a service (Komter and Schans 2008; Törnblom et al. 2012; Xue and Silk 2012). Immediate reciprocation of a favor or close monitoring of assistance given and received is again considered more characteristic of causal "exchange" relationships (Clark 1984; Xue and Silk 2012). Immediate reciprocation has even be found to be considered insulting or inappropriate and ultimately damaging to strong social relationships (Shackelford and Buss 1996).

The characteristics discussed here are not meant to represent an exhaustive list of the characteristics of strong human social relationships. It could even be argued that many of them represent a very modern, "WEIRD" (western, educated, industrialised, rich and democratic, 
Henrich et al. 2010) notion of what friendship, marriage, or family life should look like. However, studies from a range of continents and cultures including Africa (Hendrix 1997; Zhou et al. 2005), South America (Hendrix 1997; Zhou et al. 2005) and South and Central Asia (Hendrix 1997; Kulik 2002; Zhou et al. 2005; Xue and Silk 2012), as well as Europe and North America suggest that there is some safety in considering these broad, general characteristics as important in strong social relationships among humans in general. Therefore, in the next section of the introduction I will focus on examining to what extent these specific characteristics of strong human social relationships have been found among non-human species.

\section{Animal Social Relationships}

Around the same time that researchers in the human social sciences were beginning to establish the importance of strong social relationships for human health and well-being, researchers studying animal social behaviour, particularly primatologists, began to suggest that non-human species may also establish, strong, long term, social relationships which provide them with important benefits (Kummer 1978; Cheney et al. 1986). This also coincided with the first suggestions that a complexity of social life may be driving the evolution of intelligence among non-human species (Jolly 1966; Humphrey 1976). In the years that followed the idea that nonhuman species form and actively maintain valuable social relationships and that these relationships provide them with important fitness benefits became increasingly embedded into research of non-human social behaviour. The social brain hypothesis was set out by Dunbar (1998), proposing that the need to build and maintain valuable social relationships, was an important factor driving the expansion of the brain in a range of species (Dunbar 1998; Dunbar and Bever 1998; Shultz and Dunbar 2006). Among primatologists the socioecological model was set out in an attempt to understand how variation in the style of female primate social relationships, i.e. despotic vs. egalitarian, individualistic vs nepotistic, tolerant vs intolerant, may allow females to maximize their access to food (van Schaik 1989; Sterck et al. 1997). In addition researchers increasingly made use of terms such as "friendship" to describe certain non-human social relationships (Smuts 1985; Silk 2002b; Massen et al. 2010; Dagg 2011). More recently, researchers have begun to focus on establishing the characteristics of non-human social relationships, producing evidence that they are differentiated in strength, stable over long periods of time and equitable (Silk et al. 2006a; Silk et al. 2006b; Langergraber et al. 2009; Lehmann and Boesch 2009; Mitani 2009; Silk et al. 2010b; Silk et al. 2012; Stanley and Dunbar 2013). Further evidence has also been produced that strong social relationships are related to important fitness benefits, such as increased infant survival (König 1994; Moses and Millar 1994; Silk et al. 2003; Weidt et al. 2008; Cameron et al. 2009; Silk et al. 2009; Frére et al. 2010) or 
increased number of infants sired (Schülke et al. 2010), as well as increased life span (Silk et al. 2010a). Here I will take a closer look at the characteristics of non-human social relationships and consider just how closely they can match those of strong human social relationships.

\subsection{Differentiation in strength}

Differentiation in the strength of social relationships between individuals, i.e. that individuals associate and/or interact with some individuals more frequently than others, is a relatively easy phenomenon to find among non-human animals and has been reported in a wide range of species. In a large number of species variation in the strength of social relationships is based solely on association data, i.e. variations in the amount of time individuals spend within a certain distance or category of grouping with other individuals (e.g. bottlenose dolphin (Tursiops truncatus): Connor et al. 2000; guppies (Poecilia reticulata) and sticklebacks (Gasterosteus aculeatus): Croft et al. 2005; elephants (Loxodonta africana): Archie et al. 2006; mice (Mus domesticus): Weidt et al. 2008; kangaroos (Macropus giganteus): Carter et al. 2009; bats (Myotis bechsteinii ): Kerth et al. 2011; great tits (Parus major): Aplin et al. 2013; giraffes (Giraffa camelopardalis): Carter et al. 2013; feral goats (Capra hircus): Stanley and Dunbar 2013). In other species, particularly non-human primates, differentiation in the strength of social relationships can be based on data from specific social interactions, such as grooming (horses (Equus caballus): Kimura 1998; blue monkeys (Cercopithecus mitis): Cords 2000; yellow baboons (Papio cynocephalus): Silk et al. 2006b; chimpanzees (Pan troglodytes): Langergraber et al. 2009; Lehmann and Boesch 2009; Mitani 2009; male Assamese macaques: Schülke et al. 2010; chacma baboons (Papio hamadryas ursinus): Silk et al. 2010b). Frequently, individuals are found to show strong preferences in their social relationships for kin (Connor et al. 2000; Whitehead 2000; Archie et al. 2006; Silk et al. 2006b; Silk et al. 2010b; Carter et al. 2013; Stanley and Dunbar 2013). However, there are also several examples of strong preferences for non-kin (Kimura 1998; Langergraber et al. 2009; Lehmann and Boesch 2009; Mitani 2009; Schülke et al. 2010; Carter et al. 2013), although it should be noted that kin is often not available in these cases. In some species individuals have also been found to prefer individuals they are most familiar with, e.g. those with whom they have been co-resident with the longest (Krause et al. 2000; Wikberg et al. 2013), individuals of similar physical appearance (Krause et al. 2000; Croft et al. 2005), or individuals which share the same personality traits (Aplin et al. 2013; Massen and Koski 2014). In some species it is even possible to identify nested social structures in the preferred associations of individuals, similar to those described among humans (Connor et al. 2000; Hill et al. 2008). Overall, while it would perhaps be more satisfying if more of this evidence was based on 
interaction data rather than association data, it seems fair to conclude that the ability to form strongly differentiated social relationships is wide spread among non-human species.

\subsection{Stability}

Whether the differentiated social relationships described above remain stable over long periods of time is a much more difficult, and occasionally controversial, topic to address. In general it would perhaps seem relatively safe to assume that many of the differentiated associations and social interactions we see, particularly among long lived animals living among same sex kin, would remain stable over long periods of time. However, there is often a lack of long term data available to properly test this assumption. The long term data which is available provides some evidence that social relationships in general, among both kin (Connor et al. 2000; Silk et al. 2006a; Mitani 2009; Silk et al. 2010b; Moss and Lee 2011; Silk et al. 2012) and non-kin (Connor et al. 2000; Lehmann and Boesch 2009), can remain stable for several years, if not decades. However, important exceptions to these studies have also been found. In one study examining the association preferences of female chacma baboons, Henzi et al. (2009) where able to show that while the female baboons had distinct preferences in their associations, these preferences did not remain stable all year round. Rather they changed cyclically depending on the availability of food in their temperate environment. In a more recent study Brent et al. (2013b) were able to find significant seasonal changes in the social network structure of a freeranging group of rhesus macaques (Macaca mulatta) which coincided with the groups' annual breeding cycle. These results are particularly surprising given that both of these species are a female philopatric, living in what is sometimes described as a female bonded society (Wrangham 1980). As such, these females live in the same group, alongside many of the same females (both kin and non kin) for their entire lives. It therefore seems particularly surprising that their preferred social relationships would be so unstable. Henzi et al. conclude that the cyclic pattern in their data represents females choosing social partners in response to their short term needs, which regularly change in this seasonal environment, rather than long term preferences. They go on to caution that the apparent stability which we see in other species may in fact be a byproduct of stability in the short term needs of individuals brought about by stability in their environmental and/or social conditions. Given these findings it seems that we require more information on the stability of relationships among animals living in more changeable environments in order to properly examine the claim that non-human animals form stable social relationships.

In addition to more studies of species living in changeable environments, I would also argue that we require more studies of stability in which the strength of social relationships is 
established using social interaction rather than association data. Many studies examining the stability of social relationships, including Henzi et al. (2009), establish the strength of social relationships solely on association data. While individuals must of course be within a certain proximity in order to interact, proximity data alone cannot tell us if, when or how often these individuals are actually interacting. It has been shown that patterns in associations and patterns of social interaction are not always closely matched (Barrett et al. 2012). As a result there is a danger that the use of association data alone may provide inaccurate assessments of the stability of social relationships in some species. Overall, I would conclude that there is a strong need for both more studies of the stability of social relationships among species living in more changeable environments and more studies which base their analysis on direct social interactions, such as grooming, before we can make any firm conclusions about the ability of non-human species to form stable social relationships.

\subsection{Equality}

As discussed earlier, equality in the exchange of support and services between individuals is an important characteristic of strong human social relationships (Rook 1987; Clark and Ayers 1993; Walker 1995; Horwitz et al. 1996; Hendrix 1997; Komter and Schans 2008). Among nonhuman species there are a relatively large number of studies examining the exchange of support and services between individuals. They are largely focused on the exchange of grooming (or allopreening among birds) for a wide range of services such as agonistic support (Seyfarth 1977; Schino 2007), feeding tolerance (Ventura et al. 2006; Carne et al. 2011; Tiddi et al. 2012), reduced aggression (Löttker et al. 2007; Kutsukake and Clutton-Brock 2010; Xia et al. 2012), assistance in territory defense (Gill 2012; Radford 2012), opportunities to handle young infants (Henzi and Barrett 2002; Fruteau et al. 2011b) or food (de Waal 1997), as well as the exchange of grooming for itself (Connor 1995; Barrett et al. 2000; Lewis et al. 2007; Gomes et al. 2009; Fruteau et al. 2011a). This work provides evidence that non-human animals can exchange one kind of service for a different kind of service. However there has been no work to date which has examined whether, as in humans, the strength of social relationships between individuals influences the kind of services exchanged. There is a growing body of work specifically examining the influence of the strength of social relationships on the equality of exchanges of grooming for itself (Silk et al. 2006a; Mitani 2009; Silk et al. 2010b). These studies commonly find that the equality of the exchange is positively correlated with the strength of the social relationship of the groomers, that is the stronger the relationship between the two individuals the more balanced their grooming exchange (Silk et al. 2006a; Mitani 2009; Silk et al. 2010b). This work, along with other work examining the exchange of grooming for itself (Connor 1995; Barrett et al. 2000; Gomes et al. 
2009; Fruteau et al. 2011a), provides evidence that equality in the exchange of services, as with human social relationships, is a characteristic of non-human social relationships. However, there has been little work done that can tell us anything about how the strength of social relationships influences the time frame of exchanges among non-human species.

There are two studies, one from primates and one from birds, which do provide some hints on the relationship between social relationship strength and the time frame of exchange in non-humans species. The first is a study examining the exchange of grooming for itself in two species of primate, vervet monkeys (Chlorocebus aethiops) and sooty mangabeys (Cercocebus atys) (Fruteau et al. 2011a). The study examines what influence the frequency with which two individuals groom, which is widely used as an indicator of social relationship strength among primates, has on the exchange of grooming in these species (Fruteau et al. 2011a). Overall, they find that the frequency of grooming has very little influence on the exchange of grooming, with virtually all grooming in both species being immediately reciprocated, in a closely time matched manner, regardless of the frequency with which the two individuals groomed. As such these relationships appear to resemble casual human "exchange" relationships (see section 1) rather than strong, social relationships. However, it is important to note that only two broad categories, "frequent groomers" and "infrequent groomers", were used to differentiate between the strength of social relationships, which may have obscured important variation in social relationship strength. In the second study, Lewis et al. (2007) examined differences in the allopreening of breeding partners and neighbouring birds in the common guillemot (Uria aalge). Common guillemots are colonial biparental birds which remain with the same breeding partner for several years. Their breeding colonies are extremely crowded, so much so that it is possible for individuals both to allopreen and fight with their neighbours while remaining within their own nest. Allopreening between both neighbours and mates was shown to be an important predictor of breeding success in this species, however while allopreening among neighbours, whom have only short term relationships lasting on average 1.5 years, was often directly reciprocated, allopreening among breeding partners, whose relationships last on average 4.94 years, was not. As such, differences in the strength of social relationships in this species appear to have a similar impact on the time frame of the exchange of services, as is seen in humans. There may be many other examples similar to the common guillemot among non-human animals. It is also possible that vervet monkeys and sooty mangabeys are more typical of non-human species in this regard. Ultimately, we will need many more studies, looking more closely at the details of the exchanges among non-human species relative to social relationship strength before we can make any firm conclusions about how similar animal and human social relationships are in this respect. 
Overall, I would argue that the current evidence that equality plays a similar role in strong social relationships in both humans and non-human species is relatively weak. This is largely due to a lack of appropriate studies rather than a mismatch of evidence, therefore it is still entirely possible that strong human and non-human social relationships may be very similar in this regard. However, to truly get a handle on the role of equality in the social relationships of non-human species I would argue that we must begin to shift the focus of our research and consider more closely what influence relationship strength has on the content and time frame of the exchange of services between individuals. Only when we have more studies addressing these questions will we be in a position to make firmer conclusions about the similarity of this characteristic of human and non-human social relationships.

\subsection{Summary}

Taken together, the evidence that characteristics of strong non-human social relationships closely match those of human strong social relationships appears to be mixed. There is good evidence, from a wide range of species that animal social relationships can be strongly differentiated in strength, although more studies based on social interaction rather than association data would be an important improvement. Similarly, studies investigating the long term stability of non-human social relationships would also benefit from more studies based on social interaction data. Perhaps more pressing is the need for more studies of the stability of nonhuman social relationships in changeable environments in order to address the important criticisms raised by Henzi et al. (2009). In addition, while the current literature provides evidence that equality in the exchange of services is in general an important feature of non-human social relationships, there is little work examining the influence of social relationships strength on the content and time frame of exchanges between individuals. Until these topics are properly addressed it will not be possible to make any firm conclusions about the similarity of the role of equality in the social relationships of humans and non-human species. Overall, it seems that there remain many crucial gaps in our knowledge of non-human social relationships which need to be addressed before we can make any solid conclusions on the similarities of the characteristics of human and non-human social relationships.

\section{Criticisms of Anthropocentrism and Anthropomorphism}

In recent years strong criticisms have been raised among some researchers about our current approach to studying animal social lives (Barrett et al. 2007; Barrett 2011). They argue that our current attempts to understand animal social behaviour, and the social cognition which may underlie it, are heavily anthropocentric and anthropomorphic. In order to uncover any true 
commonalties between human and non-human sociality, they suggest that we must take a more detached, "action centred perspective" of animals social behaviour which focuses more on the here and now consequences of an individuals' interactions, rather than placing human sociality at the centre of our thinking, and which acknowledges and actively attempts to minimise our innate tendencies to see human like behaviour in non-human animals (Barrett et al. 2007; Barrett 2011). Barrett and colleague are also chief among those who regularly question the ability, and the need, of non-human animals, specifically primates, to form stable, long term social relationships. They argue that the evidence that such social relationships are strong and enduring over time is weak and that a better understanding of these relationships would come from focusing more on the short term dynamics of social interactions (Henzi and Barrett 1999; Barrett and Henzi 2002; Barrett and Henzi 2006; Henzi et al. 2009). In particular, they strongly advocate the use of the biological market approach to understand animal social interactions (Henzi and Barrett 2002; Barrett and Henzi 2006). This approach places the exchange of services, such as grooming, within the context of a market place, where the supply and demand of different services influences with whom individuals interact and the relative value of a service (Noë and Hammerstein 1994; Noë and Hammerstein 1995; Noë et al. 2001). However, it is important to point out that the biological market approach does not assume a specific time frame within which exchanges must take place, immediate, short term or otherwise (Noë per. com.). Barrett and colleagues go on to propose that it has been variation in the need to deal with an ever changing market of short term interactions within the social environment that has in fact been the driving force behind the increase in brain size that we see among some highly social species (Barrett and Henzi 2006; Barrett et al. 2007), rather than the need to maintain valuable, long term social relationships.

To a certain extent I believe that some of Barrett and colleagues criticisms are justified. I would agree that there is a tendency in the study of non-human social behaviour to attach overly anthropomorphic narratives to results which are not necessarily fully justified by the data, as the example they provide from Cheney and Seyfarth (2005) clearly demonstrates (Barrett et al. 2007, p.566). I would also agree that in some cases conclusions about the long term stability of animal social relationships have been made without properly addressing how short term interactions maybe contributing to these results (Connor et al. 2000; Silk et al. 2006a; Mitani 2009; Silk et al. 2010b; Silk et al. 2012). However, I would argue that these problems are largely caused by the way in which research is being framed and interpreted, and as such does not necessarily require researchers to make major changes in the type of questions which they are asking or the methods that they are using. Rather it requires us to become more careful in the framing of our research and more open-minded and cautious in our interpretations of our results. 
One way in which I believe we can encourage more accurate, less anthropocentric and anthropomorphic interpretations of animal social relationships is by moving away from the use of broad, categorical terms to classify animal social behaviour, and instead move more towards attempts to develop and apply more quantitative measures. There are several broad and general terms widely used to describe animal social structures such as, "despotic" and "egalitarian" which I believe are ultimately unhelpful, and which in their own way encourage anthropocentric and anthropomorphic interpretations of data. I would also argue that even the use of more narrow terms such as "friendship" is extremely unhelpful. The problem is not that these terms tend to originate from the human social sciences and the study of human social behaviour, but that even within these disciplines they often do not have a single, clear definition. As one author in the field puts it "It has become a cliché to begin articles on friendship with a discussion of how its definition varies" Adams et al. (2000). Only by actively avoiding these terms and embracing more quantitative measures can we bring much needed clarity, detachment and consistency to the study of non-human social relationships.

\section{Quantifying Animal Social Relationships}

A persistent problem in the study of animal social relationships has been establishing a consensus on how best to quantify these relationships and their various characteristics (Silk et al. 2013). There are areas of animal sociality, such as dominance for example, where there is a more or less well accepted approach to measuring and quantifying dominance interactions, relationships and the resulting dominance structure (de Vries 1998; de Vries et al. 2006), however there is still much debate over how to measure and quantify positive social relationships. There does appear to be a general agreement on which behaviours are most relevant, e.g. approaches, grooming etc., and how data on these behaviours should be collected (Altmann 1974; Lehner 1998; Martin and Bateson 2007). However, how we then combine this information into meaningful measures of the social relationships, and in turn the social structures they form, is still widely discussed (Whitehead 2008; Silk et al. 2013).

In the last decade there has been a surge in the promotion and use of Social Network Analysis (SNA), a quantitative approach to studying human social behaviour, in the study of nonhuman social behaviour (Krause et al. 2007; Croft et al. 2008; Wey et al. 2008; Krause et al. 2009; Brent et al. 2011a; Pinter-Wollman et al. 2013). This approach represents social interactions between individuals as a series of "nodes" and "edges", where the nodes represent individual animals and the edges represent the social interactions between individuals. These nodes and edges come together to form a network which represents all the social interactions between all individuals within a given group (Croft et al. 2008). A range of measures at different levels of 
analysis, i.e. at the group, sub-group and individual level, can then be applied to these networks in order to investigate various aspects of social interactions of the group, its sub-groups and its individuals (Croft et al. 2008). The approach still remains relatively new to many studying animal social behaviour, yet steadily, more and more researchers, investigating a wide range of nonhuman species, are beginning to make use of SNA and its measures to address questions relating to non-human social relationships in particular, as well as many other related topics (Krause et al. in press).

This is not the first time SNA has been introduced to animal behavioural research. The first attempts to take an SNA approach to the analysis of animal behaviour date as far back as the late 50's (Kummer 1957). The approach went on to grow in popularity during the 60's and 70's, particularly among studies of primate social behaviour (Ploog et al. 1963; Sade 1965; Kummer 1968; Sade 1972; Soczka 1974; Cheney 1978a; Cheney 1978b). This coincided with the arrival of one of the most influential conceptual frameworks proposed for the study of social relationships and social structures in animals presented by Robert Hinde in 1976 (Hinde 1976). The framework broke animal social behaviour down into three distinct, interconnected levels: the interaction level, relationship level and structural level. Like the SNA approach the framework attempts to understand social behaviour by building up from the smallest, basic building blocks, in this case individual social interactions, to form the larger, overall social structure. The challenge of the framework, which still remains, is finding and implementing suitable measures to quantify the content, quality and patterning of social interaction and relationships at each level (Whitehead 2008). SNA had the potential to provide some useful measures which perhaps could have assisted with this challenge, however, due to a lack of the computational power at the time some of the more interesting measures could be burdensome to perform (Sade 1989). It was perhaps as a result of this limitation that, while the Hinde framework persisted, becoming extremely important in providing the conceptual foundations for a wide range of studies of animal social behaviour (Whitehead 2008), SNA began to fade from animal sociality literature. Since the early 2000 's, with the advent of greater computational power and the development of user friendly SNA packages, such as Ucinet (Borgatti et al. 2002), SNA has returned with a bang to animal research. As mentioned above it is now being embraced in a wide range of species and social behaviour topics, however it still remains to be seen whether this time it is here to stay. 


\section{Thesis Aims}

As stated at the outset of this introduction, the overall aim of this thesis is to investigate the characteristics of female social relationships among wild female Assamese macaques, and by doing so, provide a contribution to the ongoing debate regarding the similarities and differences of the characteristics of strong human and non-human social relationships. Specifically I aim to address several gaps in our current knowledge of the characteristics of non-human social relationships identified in this introduction. In Chapter 2 I aim to establish whether female Assamese macaques form differentiated social relationships and how stable these relationships remain through the species annual breeding cycle. In Chapter 3 I aim to establish what services female Assamese macaques exchange, how equitably these services are exchanged and what influence social relationships strength has on the content and time frame of these exchanges. As grooming is by far the most extensively studied cooperative service among non-human species, and particularly among primates, the aim of this chapter ultimately became to understand what grooming is exchanged for, e.g. rank related services or simply itself, how equitably these exchanges are and what influence social relationships strength has on the content and time frame of grooming exchanges. Finally in Chapter 4 I will review the use of social network analysis in primatology in particular, considering its potential usefulness and limitations as a quantitative tool in the study of primate social behaviour. Female Assamese macaques are a suitable species to address these aims for several reasons. Primates, in general, are particularly social relative to other animals, (Mitani et al. 2012). Female macaques, in particular, tend to live their lives in stable, female bonded social groups (Thierry et al. 2004), which arguably provide the perfect conditions under which we might expect stable, long term social relationships to form. In addition, it has already been shown that female Assamese macaques are strictly seasonal breeders (Fürtbauer et al. 2010), as such female Assamese macaques potentially live their social lives in the kind of changeable social environment required to address one of the major criticisms of stable, non-human social relationships. 



\section{Chapter 2}

\section{The Structure and Stability of Female Social Relationships in Assamese Macaques (Macaca assamensis)}

Sally Macdonald ${ }^{a}$, Oliver Schülke $^{b} \&$ Julia Ostner ${ }^{a}$

a Primate Social Evolution Group, Courant Research Centre Evolution of Social Behaviour, Georg-August University, Göttingen, Germany.

${ }^{b}$ Courant Research Centre Evolution of Social Behaviour, Georg-August University, Göttingen, Germany. 



\section{Abstract}

Strong, stable social relationships are very important for human health and well-being. Slowly research is beginning to show that strong, stable social relationships seem to be important for a broad range of non-human species as well. However it has been suggested that the apparent stability of these non-human social relationships may be an artifact of stable environmental or social conditions. The aim of this study is to examine the structure and stability of female social relationship in a seasonally breeding primate, the Assamese macaque (Macaca assamensis). We collected over 2100 hours of behavioural observations from a wild group at Phu Khieo Wildlife Sanctuary, Thailand. Data were collected over two one-year sampling periods (Oct. 2007 - Sep. 2008, May 2010 - Apr. 2011) with all adult female group members included in the study ( $N=12$ 2007-8; $N=15$ 2010-11). We collected detailed data on all social interactions between females including approaches within $1.5 \mathrm{~m}$, body contact and grooming. We also collected data on the general activity of all females in order to allow us to assess how female activity budgets changed over different stages of the breeding cycle. Our results show that females in this group formed strong, differentiated social relationships which remained stable across seasons despite significant seasonal changes in female activity budgets. In addition we were able to show that the structure of the female social network remained largely stable across seasons and provide some initial evidence that relationships between female Assamese macaque can remain stable for multiple years. As such we argue that these social relationships bare some fundamental similarities to human social relationships. 



\section{Introduction}

Affiliative social relationships (hereafter "social relationships") have been found to be extremely important for human health and well-being (Horsten et al. 2000; Knox et al. 2000; Berkman et al. 2004; Costanzo et al. 2005; Friedman et al. 2005; Norman et al. 2005; Vanderhorst and McLaren 2005; Wang et al. 2005; Holt-Lunstad et al. 2010). Increasingly, evidence is building that social relationships also have very important benefits for non-humans species as well (Silk et al. 2003; Cameron et al. 2009; Silk et al. 2009; Frére et al. 2010; Schülke et al. 2010; Silk et al. 2010a). In humans health benefits are particularly associated with having a small number of "meaningful" social relationships, i.e. strong, stable social relationships with a close friend, romantic partner or relative, rather than casual acquaintances (House 2001). Among non-human species we also see individuals from a variety of species focusing their social behaviour on a few preferred individuals (Kimura 1998; Cords 2002; Silk et al. 2006b; Weidt et al. 2008; Cameron et al. 2009; Carter et al. 2009; Langergraber et al. 2009; Lehmann et al. 2010; Silk et al. 2010b; Carter et al. 2013; Stanley and Dunbar 2013). These individuals are often maternal kin (Connor et al. 2000; Whitehead 2000; Cords 2002; Archie et al. 2006; Silk et al. 2006b; Mitani 2009; Frére et al. 2010; Silk et al. 2010b), although social relationships among non-kin have also been reported (Kimura 1998; Silk et al. 2006b; Cameron et al. 2009; Langergraber et al. 2009; Lehmann and Boesch 2009; Mitani 2009; Schülke et al. 2010; Carter et al. 2013). These relationships are often described as "stable" or "enduring" (Moses and Millar 1994; Silk et al. 2006a; Langergraber et al. 2009; Lehmann and Boesch 2009; Mitani 2009; Silk et al. 2010b; Silk et al. 2010a; Silk et al. 2012), with individuals showing specific preferences for certain social partners consistently over multiple years (Lehmann and Boesch 2009; Silk et al. 2010b; Silk et al. 2012). They have also been linked to major fitness benefits, including increased infant survival (König 1994; Moses and Millar 1994; Silk et al. 2003; Weidt et al. 2008; Cameron et al. 2009; Silk et al. 2009; Frére et al. 2010; Schülke et al. 2010) and increased life span (Silk et al. 2010a). However, the apparent stability of these relationships has recently been questioned (Henzi et al. 2009).

In a study examining the stability of the social relationships of female chacma baboons (Papio ursinus), Henzi et al. (2009) investigated female association patterns in two different groups living in seasonal environments. They found pronounced seasonal changes in female associations patterns at both sites. During seasons when food was scarce females showed differentiated preferences in their associations with specific females, resulting in cliquish association patterns. However, when seasons changed and food became more plentiful these preferences disappeared. In addition they could find no evidence that females reformed the partnr preferences they had shown in the previous food scare season in subsequent food scare seasons. They concluded that the associations of the females in these groups were based on the 
short term needs of each female, and as such should be considered as more opportunistic and flexible than the long term, social relationships we find in humans. These findings go against evidence of stable female social relationships presented for this species from another, less seasonal site (Silk et al. 2006a; Silk et al. 2010b; Silk et al. 2012). Henzi et al. (2009) go on to caution that the apparent stability of the social relationships in this and other species may be an artifact of stable environmental or social conditions and should, therefore, be interpreted with care. However, it should also be noted that Henzi et al. analysis was based solely on association data, rather than data on direct social interactions such as grooming. Subsequent analysis of data from one of these same groups of baboons has shown that significant changes in female association patterns do not necessarily lead to significant changes in female grooming patterns (Barrett et al. 2012).

Further evidence of seasonal variability in non-human social relationships comes from a study examining the overall structure of the female social network of two groups of free ranging rhesus macaques (Macaca mulatta) across their breeding cycle (Brent et al. 2013b). This study examined networks based both on proximity and grooming data. This analysis found that during the mating season female social networks were significantly denser (i.e. more interconnected) and centralized than during the birthing season, indicating significant seasonal changes in the structure of the female social networks of these groups, and ultimately the social interactions which these networks are based on. The authors suggest that this variation may result from an attempt by females to compensate for their reduced availability as a social partner brought about by consortships with males during the mating season. Alternatively, they also suggest that females may be attempting to enhance their intra-sex bonds during the mating season as a result of increased female-female competition.

The aim of this study is to build on this work by examining the structure and stability of female social relationships among Assamese macaques (Macaca assamensis). Our analysis is based on a behavioural data set, collected over two one-year sampling periods, recording information both on the associations and direct social interactions (i.e. grooming and body contact) of all adult females within a single habituated group. Like most species of macaques, female Assamese macaques remain to breed in their natal groups while males disperse to breed elsewhere (Thierry 2007). As such females have ample time to develop strong, stable social relationships with other females in their group. In addition, like rhesus macaques, Assamese macaques are seasonal breeders with the majority of conceptions, and subsequent births, occurring within discrete 4 months blocks each year (Fürtbauer et al. 2010). Previous work on this study group has found that this seasonal breeding cycle can bring major changes in the demands, in terms of time and energy, placed on females (Heesen et al. 2013; Fürtbauer et al. in revision). 
Taken together these conditions make Assamese macaques an ideal species to further test whether non-human social relationships remain stable during periods of significant social/environmental change. Before investigating the stability of female social relationships we first establish whether females in this group form strong, differentiated social relationships. We did this by examining the variation in the frequency and duration of three different social behaviours; approaches (within $1.5 \mathrm{~m}$ ), body contact and grooming, among all adult females in the group. In addition we also confirm that the seasonal breeding cycle was associated with significant changes in terms of the demands placed on females' time. This was done by examining the female activity budgets across the three different stages of the breeding cycle, the mating, pregnancy and birthing seasons, for significant changes in the proportion of time spent on four categories of behaviour; feeding, resting, traveling and social. Once all of these factors were established we went onto investigate the stability of both the individual relationships between females and the overall structure of the female social network over time using a range of measures, including measures taken from social network analysis.

\section{Methods}

\section{Study Site and Subjects}

This study was conducted at Phu Khieo Wildlife Sanctuary $\left(16^{\circ} 5^{\prime}-35^{\prime} \mathrm{N}, 101^{\circ} 20^{\prime}-55^{\prime} \mathrm{E}\right)$ located in Chaiyaphum province, north-eastern Thailand. The sanctuary covers $1573 \mathrm{~km}^{2}$ and is part of the contiguous ca. $6500 \mathrm{~km}^{2}$ Western Isaan Forest Complex (Borries et al. 2002). Data were collected from a single habituated group of wild Assamese macaques over two, one year sampling periods, October 2007 - September 2008 (sample 07-08) and May 2010 - April 2011 (sample 10-11). During these sampling periods the group consisted of 53 individuals, 12 of which were adult females, and 49 individuals, 15 of which were adult females, respectively. All adult females were included as subjects in this study. Maternal kin relationships between the adult females are currently unknown.

\section{Data Collection}

Behavioural data were collected using 20 or 30 minute long focal animal sampling (Altmann 1974). Efforts were made to ensure that these focal animal observations were evenly distributed across both time of day and individual females. Due to the dense nature of the forest environment observations could not always be completed for a full 30 minutes, therefore all focal observations longer than 3 minutes were included in this analysis. In total $841 \mathrm{hrsof}$ data were collected in sampling period 07-08 (a mean of 70 $\pm 7.0 \mathrm{hrs}$ per female) and 1360.4hrs in sampling period 10-11 (a mean of $91 \pm 4.6 \mathrm{hrs}$ of data per female). 
All friendly interactions between females lasting for a minimum of ten seconds were recorded using continuous recording (Martin and Bateson 2007). These interactions included approaches (approaches within 1.5m that did not result in aggression or spontaneous submission from either party), body contact (i.e. body contact that did not involve or occur during aggression or spontaneous submission) and grooming. Grooming bouts were considered to have begun when one individual began to groom another individual and were considered finished when grooming between these two individuals stopped for longer than ten seconds.

We also recorded the general activity of the focal females using instantaneous sampling at one minute intervals (Altmann 1974). Four general categories of activity were used; feeding (which included both foraging and handling as well as the ingestion of the food item), resting, travel and social (which included grooming, agonistic and mating behaviour)

\section{Data Analysis}

We used the dyadic composite sociality index (CSI) (Silk et al. 2013) to characterise female social relationships in the study group. The CSI combines relevant positive social behaviours in such a way that it is possible to assess the strength of the relationship between two individuals relative to the strength of the relationships of all other individuals in the group. We chose six correlated behavioural elements to construct this index; the frequency (per hour of observation) of friendly approaches, friendly body contact and grooming, and the duration (minutes per hour of observation) of friendly approaches, friendly body contact and grooming. CSI scores can vary from zero to infinity, with the mean CSI value for a group always having a value of one. As such, a score of one indicates a social relationship of average strength, while scores greater than one indicate a stronger than average social relationship and scores less than one indicate a weaker than average social relationship. Approaches, body contact and grooming are nested behaviors, i.e. one must approach before making body contact and one must make body contact before grooming. Therefore, in an effort to control for pseudoreplication approaches which were followed by body contact or grooming were only included in the analysis if the dyad spent at least 10 seconds in the approach before engaging in the body contact or grooming behaviour. Similarly friendly body contacts were only included in the analysis again if the dyad spent at least 10 seconds in body contact before engaging in grooming.

Both binary and weighted networks were used during our analysis. Networks were constructed using the CSI, as well as for all three social behaviours; approaches, body contacts and grooming. In their weighted form, the connections in these networks represented either the CSI for each dyad or the number of minutes per hour of observation each dyad spent in the given social behavior. In their binary form, a connection in the CSI network simply indicated whether 
these individuals have been seen engaging in any social interactions, while a connection in the behavioural networks indicated whether these individuals had ever been seen engaging in the given social behaviour. We calculated three widely used network level measures to characterise different elements of the female social network; network density, network centralization (both using "sna", Butts 2013) and mean clustering coefficient (using "tnet", Opsahl 2013). Network density in a binary network calculates the proportion of ties present given the number of potential ties in a given network, thereby giving an indication of how densely interconnected a network is. The value of the density score can vary from 0 (a completely unconnected network) to 1 (a network in which all individuals are connected with each other). Network density can also be calculated for weighted networks by dividing the sum of all the edge weights by the number of possible ties in the network. However, the density value returned is equal to the average edge weight in the network (Prell 2012), which is not necessarily very informative of how interconnected a network is, i.e. the number of ties it contains. Therefore, we choose to make use of the binary form of this measure. All other network measures were calculated using weighted networks. Network centralization indicates to what extent the ties in a given network are focused around a single individual. This is done by calculating the average difference in centrality between the most central individual in a network and all other individuals in the network, (for details see Prell 2012). As with network density the value of network centralisation varies from 0 (a network were ties are evenly distributed among all individuals) to 1(a network where all ties are centered around a single individual). Lastly, the mean clustering coefficient gives an indication of how clustered a given network is, a cluster being a highly interconnected sub-group of individuals within a larger network (Scott 2000). The score is calculated by taking the mean of all the clustering coefficients of each individual within a given network, an individual's clustering coefficient being the proportion of the individuals connected to a given individual that are also connected to each other (for details see Croft et al. 2008).

\section{Statistical Analysis}

In order to investigate if and how female social behaviour changes across the breeding cycle we split our data into three blocks, each four months in length, during which the majority of matings (September to December), pregnancies (January to April) and births (May to August) occur. We used Friedman rank sum tests, implement in R 3.0.1 (R-Core-Team 2013), to establish whether there were any significant differences in the mean proportion of time females spent in the four categories of the activity budget; feeding, resting, travel and social, across the different seasons. We also used a Friedman rank sum test to establish if there were any significant difference in dyadic rates of approaches, body contact and grooming across the different 
seasons. Post hoc analysis of significant results were also conducted in R using the "friedman test with post hoc" function (Galili 2010). Row-wise matrix correlations were used to compare dyadic CSI scores across both seasons and across sampling periods. We assessed the relationship between rank and an individuals' number of above average social relationships using a randomisation test constructed in $\mathrm{R}$. In this test the original matrix containing the values for each female social relationship is reshuffled, the number of above average social relationships each female has is then calculated and correlated with her rank position, using a spearman correlation, for 10,000 iterations. The $p$-value represents what proportion of the distribution of the random correlation coefficients generated was greater than or equal/less than or equal to the original observed correlation coefficient depending on the sign of the original correlation coefficient. We compared all network measures across seasons by constructing a bootstrapping test in R 3.0.1. In this test the original data set used to generate each network was resampled (with replacement), a new network was formed based on this resampled data and the relevant network measure calculated, for 10,000 iterations. We then used $95 \%$ confidence intervals to assess whether there was a significant difference between the distributions generated. This process maintains the general topological features of the networks while disrupting other general features such as weight distribution, thereby allowing us to simulate the level of noise in our original sample. 


\section{Results}

Structure of Female Social Relationships

The distribution of the CSI among females in this group is extremely right skewed (Figure 1) with a median CSI value 0.80 . On average females had 4.7 (range 1-10) stronger than average social relationships (i.e. relationships with a CSI greater than 1), and 1.3 (range 0-3) relationships with a CSI value of 2 or greater. In both sampling periods there was no relationship between a female dominance rank and the number of stronger than average social relationships she had (2007-08, rho $=0.07, p=0.83 ; 2010-11$, rho $=-0.08, p=0.33$ ).

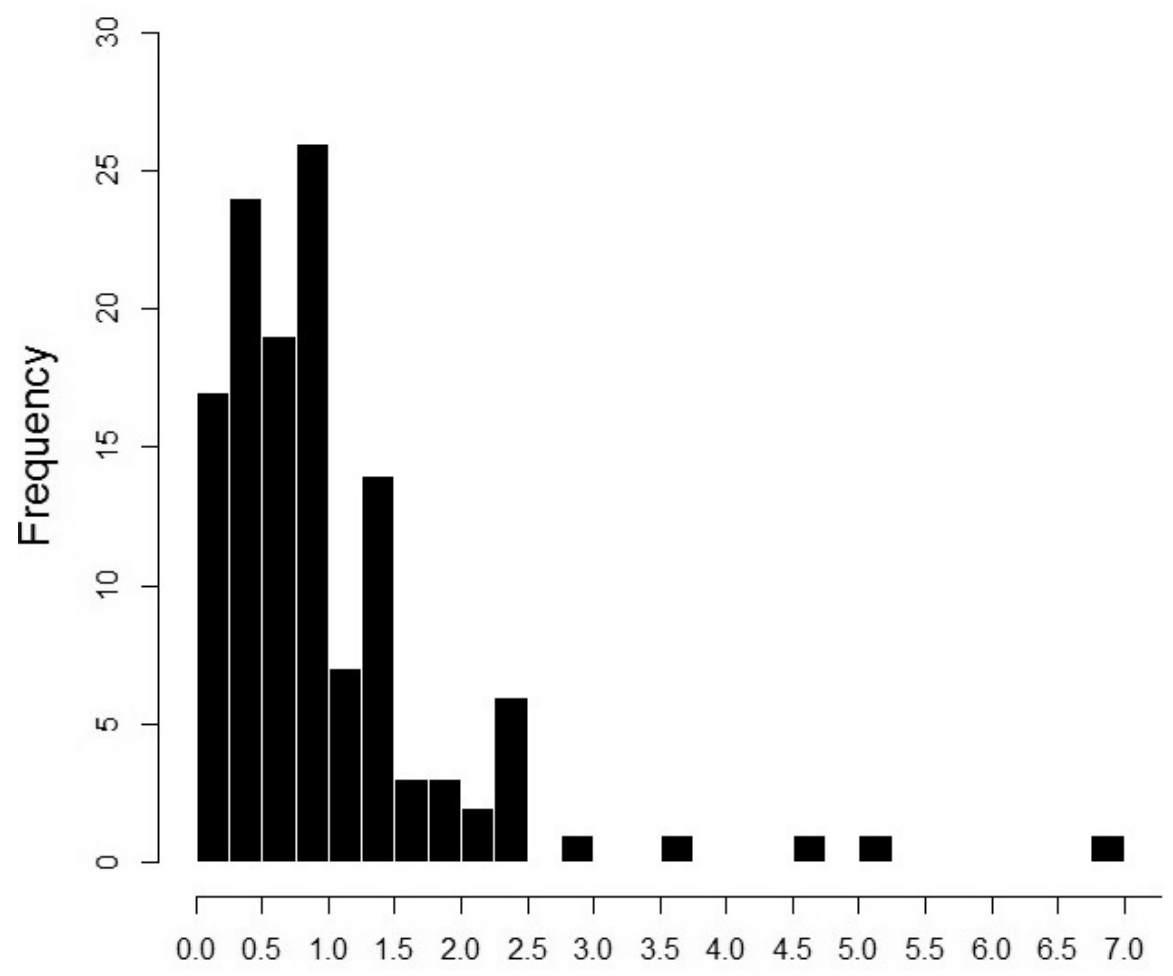

Composite Sociality Index

Figure 1. The distribution of the dyadic composite sociality index calculated for all dyads across both sampling periods.

\section{Structure of Female Social Network}

All networks showed very high network density scores, indicating that individuals in each network were highly interconnected (Table 1, Fig.2). The network centralisation scores for each network were in general low, with somewhat higher scores in the grooming networks, indicating that social interactions in general were not highly focused around a single individual (Table 1). The mean clustering coefficients of all networks were extremely high, indicating again that the 
individuals in these networks were highly interconnected and as a result there is no obvious clustering in the networks (Table 1, Fig. 2).

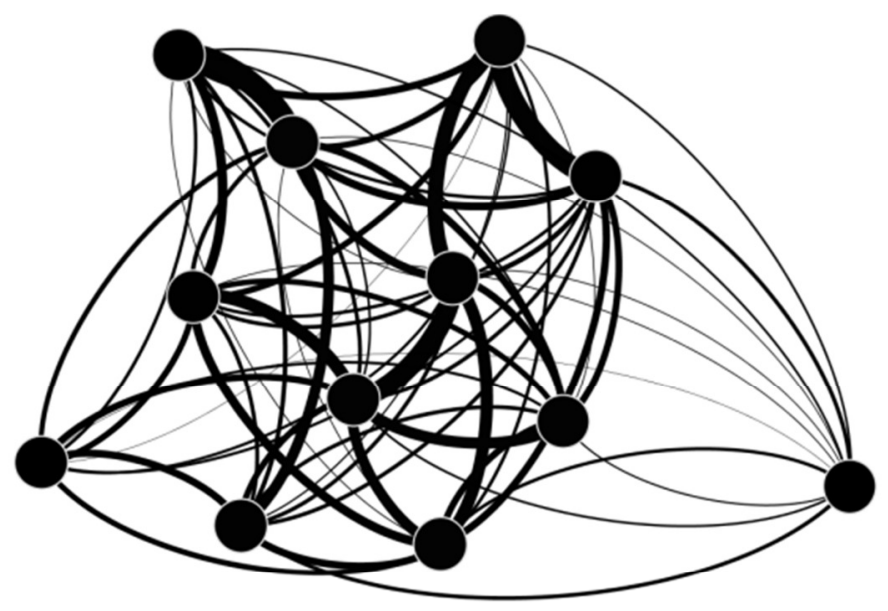

a.

b.

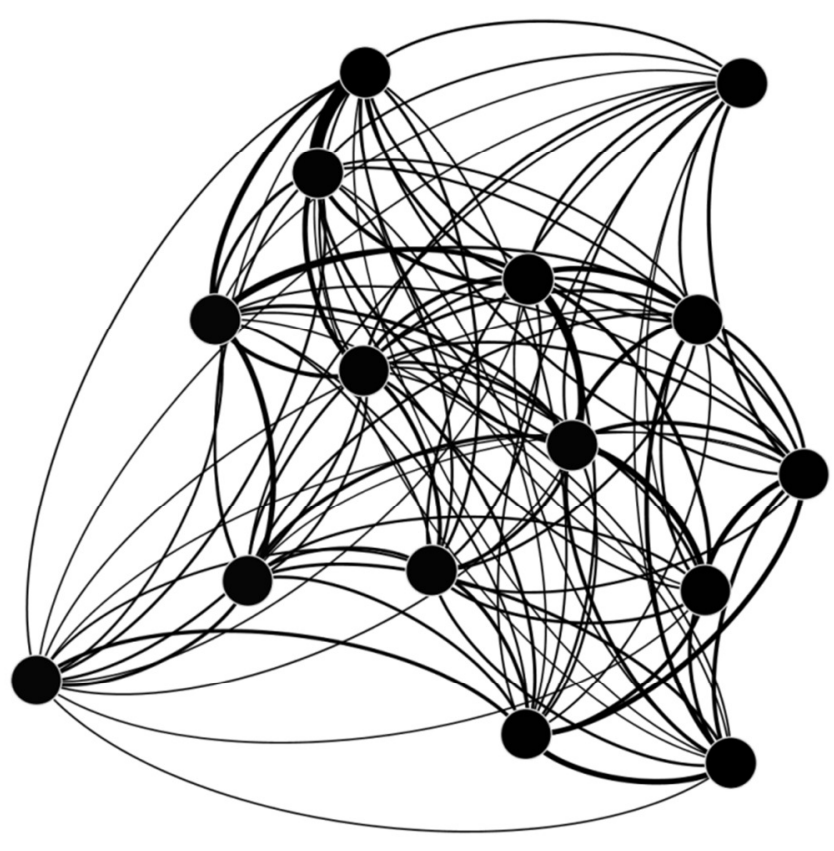

Figure 2. Weighted CSI networks for all females in the group during (a) sampling period 2007-08 and (b) sampling period 2010-11. The thickness of the line indicates the strength of the CSI for that dyad, i.e. the thicker the line the higher the CSI. Both networks were generated by Gephi 0.8.2 (Bastian et al. 2009) using a "Forced Atlas" layout, this process draws strongly linked nodes closer together while pushing weakly linked nodes apart. 
Table 1. Characteristics of female social relationship networks based on CSI, approach, body contact and grooming rates (mins/hr)

\begin{tabular}{lccc}
\hline Networks & Density & Centralisation & $\begin{array}{c}\text { Mean Cluster } \\
\text { Coefficient }\end{array}$ \\
\hline $\begin{array}{l}\text { CSI } \\
\text { (07-08) }\end{array}$ & 1.00 & 0.16 & 1.00 \\
$\begin{array}{l}\text { CSI } \\
(\mathbf{1 0 - 1 1 )}\end{array}$ & 0.99 & 0.16 & 0.98 \\
$\begin{array}{l}\text { Approach } \\
\text { (07-08) }\end{array}$ & 1.00 & 0.14 & 1.00 \\
$\begin{array}{l}\text { Approach } \\
\text { (10-11) }\end{array}$ & 0.99 & 0.28 & 0.98 \\
$\begin{array}{l}\text { Body Contact } \\
\text { (07-08) }\end{array}$ & 0.89 & 0.18 & 0.92 \\
$\begin{array}{l}\text { Body Contact } \\
\text { (10-11) }\end{array}$ & 0.91 & 0.32 & 0.90 \\
$\begin{array}{l}\text { Grooming } \\
\text { (07-08) }\end{array}$ & 0.88 & 0.41 & 0.94 \\
$\begin{array}{l}\text { Grooming } \\
\text { (10-11) }\end{array}$ & 0.90 & 0.48 & 0.88 \\
\hline
\end{tabular}

Stability of Female Social Relationships

Female activity budgets from both sampling periods showed significant variations in the proportion of time allocated to each activity by females across seasons (2007-08: Feeding $X^{2}=$ $15.2, \mathrm{df}=2, \mathrm{p}<0.001$, post hoc $=$ Mating $<$ Pregnancy $\mathrm{p}<0.001$, Pregnancy-Birth $\mathrm{p}=0.06$, MatingBirth $p=0.23$; Resting $X^{2}=11.2, \mathrm{df}=2, \mathrm{p}<0.01$, post hoc $=$ Mating $>$ Pregnancy $p<0.01$, Pregnancy-Birth $p=0.56$, Mating-Birth $p=0.06$; Travel $X^{2}=5.5, \mathrm{df}=2, p=0.06$; Social $X^{2}=4.1$, df $=2, p=0.13$. 2010-11: Feeding $X^{2}=10.1, d f=2, p<0.01$, post hoc $=$ Mating $<$ Pregnancy $p<0.05$, Pregnancy $>$ Birth $p<0.01$, Mating-Birth $p=0.92$; Resting $X^{2}=12.9, \mathrm{df}=2, \mathrm{p}<0.01$, post hoc $=$ Mating $>$ Pregnancy $p<0.05$, Pregnancy<Birth $p<0.01$, Mating-Birth $p=0.91$; Travel $X^{2}=5.7, \mathrm{df}=$ $2, p=0.06$; Social $X^{2}=8.9, d f=2, p<0.05$, post hoc $=$ Mating-Pregnancy $p=0.63$, PregnancyBirth $p=0.11$, Mating-Birth $p<0.01$, Fig. 3). In particular we see a significant rise in the proportion of time spent feeding during the pregnancy period, which in turn appears to be compensated for by a significant dip in resting. Females also spent more time socialising in the mating relative to the birth season in the 2010-11 sampling period. Overall these results indicate that females faced significant changes in the demands for their time throughout the annual breeding cycle.

Despite these changes in the female activity budget female dyadic CSI values remained significantly correlated across seasons (Table 2). This indicates that the relative amount of time females invested in their social relationships remained unchanged throughout the seasons. In 
addition, analysis of the rates of all three social behaviours revealed that there was no significant difference in the rate at which female dyads groomed or were in body contact across seasons, however there was a significant change in the rate of approaches between the mating and birth seasons in the 2010-11 sample (2007-08: Approaches $X^{2}=0.6, \mathrm{df}=2, \mathrm{p}=0.73$; Body Contact $X^{2}=$ 1.3, $\mathrm{df}=2, \mathrm{p}=0.51 ;$ Grooming $X^{2}=1.4, \mathrm{df}=2, \mathrm{p}=0.49$. 2010-11: Approaches $X^{2}=6.3, \mathrm{df}=2, \mathrm{p}<$ 0.05 , post hoc $=$ Mating-Pregnancy $p=0.15$, Pregnancy-Birth $p=0.83$, Mating $<$ Birth $p<0.05$; Body Contact $X^{2}=4.4, \mathrm{df}=2, p=0.11$; Grooming $X^{2}=0.1, \mathrm{df}=2, p=0.98$.). Finally, a row-wise matrix correlation comparing dyadic CSI values, calculated for the full sampling periods, of the ten females that were present in both the 2007-08 and 2010-11 also showed a significant positive correlation $\left(\operatorname{tau}_{\mathrm{rw}, \mathrm{av}}=0.33, \mathrm{p}<0.01\right)$. This indicates that the strength of the relationships between these females in the second sampling period was significantly related to the strength of their relationships three years earlier during the first sampling period despite several demographic changes in the group between the two samples (i.e. two deaths and five immature females reaching adulthood). 
2007-08
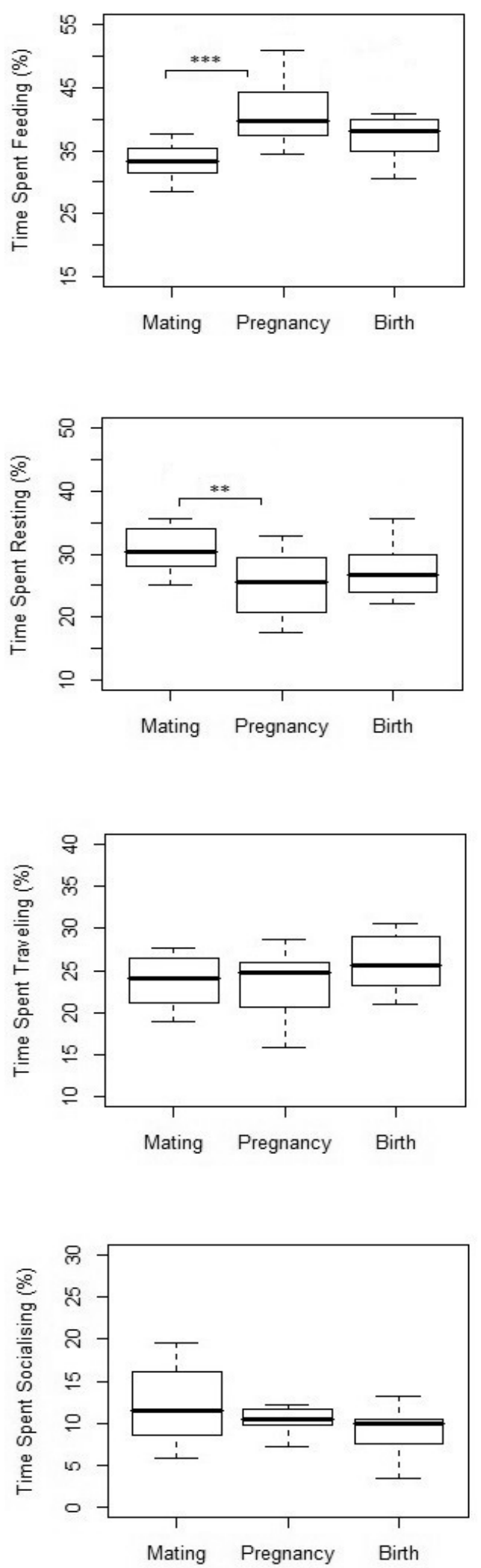

2010-11
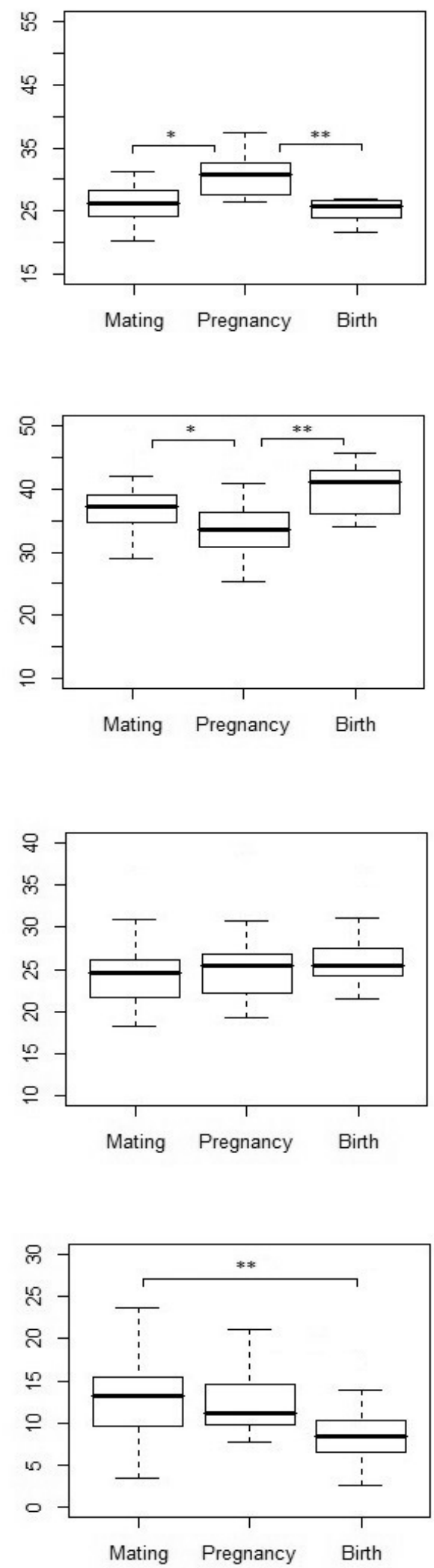

Figure. 3 The proportion of time females spent feeding, resting, traveling and socialising during each sampling period. Each box plot shows the median and 25th and 75th percentiles across individuals; the whiskers indicate the values within 1.5 times the interquartile range (IQR). A significant difference of $\mathrm{p}<0.05$ is indicated by $*, p<0.01$ by $* *, p<0.001$ by $* * *$. 
Table 2. Results of row-wise matrix correlations of female dyadic CSI's across seasons

\begin{tabular}{ll}
\hline Seasons compared & \multicolumn{1}{c}{ Correlation Result } \\
\hline $\begin{array}{l}\text { Mating/Pregnancy } \\
\text { (07-08) }\end{array}$ & $\operatorname{tau}_{\mathrm{rw}, \mathrm{av}}=0.19, \mathrm{p}<0.05$ \\
$\begin{array}{l}\text { Mating/Pregnancy } \\
(\mathbf{1 0 - 1 1 )}\end{array}$ & $\operatorname{tau}_{\mathrm{rw}, \mathrm{av}}=0.32, \mathrm{p}<0.001$ \\
$\begin{array}{l}\text { Pregnancy/Birthing } \\
\text { (07-08) }\end{array}$ & $\operatorname{tau}_{\mathrm{rw}, \mathrm{av}}=0.18, \mathrm{p}<0.05$ \\
$\begin{array}{l}\text { Pregnancy/Birthing } \\
(\mathbf{1 0 - 1 1 )}\end{array}$ & $\operatorname{tau}_{\mathrm{rw}, \mathrm{av}}=0.26, \mathrm{p}<0.001$ \\
$\begin{array}{l}\text { Mating/Birthing } \\
\text { (07-08) }\end{array}$ & $\operatorname{tau}_{\mathrm{rw}, \mathrm{av}}=0.31, \mathrm{p}<0.001$ \\
$\begin{array}{l}\text { Mating/Birthing } \\
(\mathbf{1 0 - 1 1 )}\end{array}$ & $\operatorname{tau}_{\mathrm{rw}, \mathrm{av}}=0.34, \mathrm{p}<0.001$ \\
\hline
\end{tabular}

Stability of Female Social Network

Overall the structural features of the social networks appeared to remain stable across seasons. There are some significant changes in the density of the approach networks, which are then echoed in the CSI networks, however the pattern is not consistent across the two samples (Table 3). In the 2007-08 both the CSI and approach network are significantly denser during the pregnancy versus the birth season, while the 2010-11 networks are found to be significantly denser in the birth season compare to the pregnancy (CSI network only) and mating season. We found no significant seasonal changes in the network centralisation (Table 4) or the mean clustering coefficient (Table 5) for any of the networks.

Table 3. The binary density of all social networks across seasons; mating (M), pregnancy (P) and birthing (B)

\begin{tabular}{lcccccc}
\hline Network & Mating & Pregnancy & Birthing & M vs. P & P vs. B & M vs. B \\
\hline $\begin{array}{l}\text { CSI } \\
\text { (07-08) }\end{array}$ & 0.95 & 0.98 & 0.91 & $\mathrm{p}=0.35$ & $\mathbf{p}<\mathbf{0 . 0 5}$ & $\mathrm{p}=0.33$ \\
$\begin{array}{l}\text { CSI } \\
\text { (10-11) }\end{array}$ & 0.89 & 0.80 & 0.96 & $\mathrm{p}=0.16$ & $\mathbf{p}<0.01$ & $\mathrm{p}<0.05$ \\
$\begin{array}{l}\text { Approach } \\
\text { (07-08) }\end{array}$ & 0.91 & 0.98 & 0.86 & $\mathrm{p}=0.11$ & $\mathrm{p}<0.05$ & $\mathrm{p}=0.51$ \\
$\begin{array}{l}\text { Approach } \\
\text { (10-11) }\end{array}$ & 0.86 & 0.90 & 0.95 & $\mathrm{p}=0.40$ & $\mathrm{p}=0.10$ & $\mathrm{p}<0.05$ \\
$\begin{array}{l}\text { Body Contact } \\
\text { (07-08) }\end{array}$ & 0.47 & 0.52 & 0.64 & $\mathrm{p}=0.71$ & $\mathrm{p}=0.26$ & $\mathrm{p}=0.21$ \\
$\begin{array}{l}\text { Body Contact } \\
\text { (10-11) }\end{array}$ & 0.53 & 0.53 & 0.49 & $\mathrm{p}=1.00$ & $\mathrm{p}=0.56$ & $\mathrm{p}=0.51$ \\
$\begin{array}{l}\text { Grooming } \\
\text { (07-08) }\end{array}$ & 0.53 & 0.65 & 0.55 & $\mathrm{p}=0.20$ & $\mathrm{p}=0.21$ & $\mathrm{p}=0.90$ \\
$\begin{array}{l}\text { Grooming } \\
\text { (10-11) }\end{array}$ & 0.62 & 0.65 & 0.70 & $\mathrm{p}=0.68$ & $\mathrm{p}=0.41$ & $\mathrm{p}=0.21$ \\
\hline
\end{tabular}


Table 4. The network centralisation scores of all social networks across seasons; mating (M), pregnancy (P) and birthing (B)

\begin{tabular}{lcccccc}
\hline Network & Mating & Pregnancy & Birthing & M vs. P & P vs. B & M vs. B \\
\hline $\begin{array}{l}\text { CSI } \\
\text { (07-08) }\end{array}$ & 0.40 & 0.29 & 0.19 & $p=0.93$ & $p=0.99$ & $p=0.99$ \\
$\begin{array}{l}\text { CSI } \\
\text { (10-11) }\end{array}$ & 0.39 & 0.19 & 0.43 & $p=0.99$ & $p=0.99$ & $\mathrm{p}=0.99$ \\
$\begin{array}{l}\text { Approach } \\
\text { (07-08) }\end{array}$ & 0.46 & 0.32 & 0.24 & $p=0.97$ & $p=0.99$ & $\mathrm{p}=0.99$ \\
$\begin{array}{l}\text { Approach } \\
\text { (10-11) }\end{array}$ & 0.29 & 0.36 & 0.25 & $\mathrm{p}=0.96$ & $\mathrm{p}=0.97$ & $\mathrm{p}=0.97$ \\
$\begin{array}{l}\text { Body Contact } \\
\text { (07-08) }\end{array}$ & 0.33 & 0.53 & 0.26 & $\mathrm{p}=0.99$ & $\mathrm{p}=0.99$ & $\mathrm{p}=0.98$ \\
$\begin{array}{l}\text { Body Contact } \\
\text { (10-11) }\end{array}$ & 0.56 & 0.39 & 0.41 & $\mathrm{p}=0.99$ & $\mathrm{p}=0.98$ & $\mathrm{p}=0.95$ \\
$\begin{array}{l}\text { Grooming } \\
\text { (07-08) }\end{array}$ & 0.67 & 0.36 & 0.54 & $\mathrm{p}=0.99$ & $\mathrm{p}=0.98$ & $\mathrm{p}=0.99$ \\
$\begin{array}{l}\text { Grooming } \\
\text { (10-11) }\end{array}$ & 0.51 & 0.38 & 0.63 & $\mathrm{p}=0.99$ & $\mathrm{p}=0.99$ & $\mathrm{p}=0.99$ \\
\hline
\end{tabular}

Table 5. The mean clustering coefficients of all social networks across seasons; mating (M), pregnancy (P) and birthing $(\mathrm{B})$

\begin{tabular}{lcccccc}
\hline Network & Mating & Pregnancy & Birthing & M vs. P & P vs. B & M vs. B \\
\hline $\begin{array}{l}\text { CSI } \\
\text { (07-08) }\end{array}$ & 0.98 & 1.00 & 0.93 & $p=0.52$ & $p=0.68$ & $p=0.73$ \\
$\begin{array}{l}\text { CSI } \\
\text { (10-11) }\end{array}$ & 0.93 & 0.84 & 0.95 & $p=0.97$ & $p=0.81$ & $p=0.92$ \\
$\begin{array}{l}\text { Approach } \\
\text { (07-08) }\end{array}$ & 0.94 & 1.00 & 0.92 & $p=0.25$ & $p=0.83$ & $p=0.87$ \\
$\begin{array}{l}\text { Approach } \\
\text { (10-11) }\end{array}$ & 0.88 & 0.90 & 0.94 & $p=0.81$ & $p=0.64$ & $p=0.76$ \\
$\begin{array}{l}\text { Body Contact } \\
\text { (07-08) }\end{array}$ & 0.65 & 0.64 & 0.81 & $p=0.99$ & $p=0.90$ & $p=0.93$ \\
$\begin{array}{l}\text { Body Contact } \\
\text { (10-11) }\end{array}$ & 0.58 & 0.56 & 0.51 & $p=0.99$ & $p=0.96$ & $p=0.95$ \\
$\begin{array}{l}\text { Grooming } \\
\text { (07-08) }\end{array}$ & 0.56 & 0.71 & 0.82 & $p=0.82$ & $p=0.95$ & $p=0.67$ \\
$\begin{array}{l}\text { Grooming } \\
\text { (10-11) }\end{array}$ & 0.59 & 0.67 & 0.67 & $p=0.99$ & $p=0.99$ & $p=0.99$ \\
\hline
\end{tabular}




\section{Discussion}

Overall our results show that female Assamese macaques form, like females in many other species, strong, differentiated social relationships. More importantly, they show that these relationships remain stable across time despite significant seasonal changes in the female activity budget. In addition we were able to show that the structure of the female social network remained largely stable across seasons and provide some initial evidence that individual relationships between female Assamese macaques can remain stable across multiple years.

Our results provide a detailed picture of the structure of female social relationships in this group. The strong right skew of the CSI distribution indicates that this group contains many weak and few very strong social relationships, i.e. their relationships are strongly differentiated. Females were found on average to form only a few stronger than average social relationships, with dominance rank not significantly influencing the number of stronger than average relationships a female formed. The structural features of all the social networks examined were extremely similar, however they appear to be somewhat atypical compared to similar structural measures from other primate groups. All networks were very dense (Table 3), indicating that while the extent to which females interacted varied widely, the majority of females interacted with each other at some point. High density scores are common in primate social networks, however, the female Assamese macaque networks are arguably considerably denser than the median figure of 0.75 reported for primate social interaction networks in general (Kasper and Voelkl 2009). This is potentially the result of the lower level of differentiation in the female social relationships found in this group compared to other primate species. In terms of network centralisation most networks, with the exception of the grooming networks, showed low centralization scores (Table 4). This is also somewhat unusual for primate social networks, which tend to show relatively high centralization scores around 0.68 (Kasper and Voelkl 2009). However our results do fit with those reported elsewhere specifically for macaques (Sueur et al. 2011b; Brent et al. 2013b), which could be an indication that female social relationships among macaques are more evenly distributed than among other primate groups. Finally the mean clustering coefficient of each network is very high (Table 5), which again appears to be atypical among primates, the average being a relatively low 0.31 (Kasper and Voelkl 2009). However such extremely high clustering coefficients show us yet again that these networks are highly interconnected and as such, rather than divisible into distinct clusters, are in fact one large, extremely interconnected cluster. As such we would argue that these networks have no more major subdivisions in their structure than a less densely connected network with a low clustering coefficient and are therefore not so atypical from other primate social networks. 
Our investigation of the female activity budget shows that females in this group face significantly different demands on their time during different seasons. We included all females in this analysis, although not every female was pregnant, for two reasons: (1) changes in the activity budget of the pregnant females could also impact on the activity budget of the non-pregnant females e.g. if pregnant females must socialise less in order to feed more non-pregnant females may also socialise less as a result of having fewer social partners available to them, and (2) the breeding cycle in this group co-varies with other ecological factors which may have a significant influence on the activity budgets of all females e.g. food availability has already been shown to be significantly lower, in relative terms, during the pregnancy season compared to the birth season in this group (Heesen et al. 2013). The most obvious changes seen in the activity budget were in the proportion of time spent feeding and resting. In both years we see a significant increase in the amount of time females spend feeding during the pregnancy season relative to other times of year. This increase appears to be compensated for in the most part by a significant decrease in the proportion of time spent resting. In addition, we also see an increase in the proportion of time spent socialising during the mating season in the 2010-11 sampling period. This is perhaps explained by an increase in social behaviour between females and males (including grooming) during the mating season (Fürtbauer et al. in revision). The fact that nearly all females (13 out of 15 ) conceived during the 2010-11 sampling period, while less than half conceived during the 2007-08 sampling period, may explain the differences between the two years in this section of the activity budget.

In spite of these significant changes in the female activity budget, we found that the social relationships between females remained largely constant across the breeding seasons. Rates of grooming and body contact remained constant throughout the breeding cycle, as did female dyadic CSI's. Dyadic rates of approaches also remained largely stable, although approaches were found to be significantly lower during the mating season in the 2010-11 sampling period. This, again, may be due to the increase in social behaviour between males and females during this particularly active mating season (see above). The stability of the CSI's and rates of grooming and body contact during the birth season, relative to the rest of the year, also indicates that female Assamese macaque mothers with young infants receive no additional attention from other adult females. This is unusual as interest in young infants and "infant handling" are often a feature of female primate social interactions (MacKinnon 2007).

This overall picture of stability contrasts markedly with the cyclical nature of the female social relationships reported by Henzi et al.(2009) among chacma baboons. This may reflect major differences in the female social relationships of these two species. For example the nutritional pressures faced by chacma baboons in their temperate environments during food 
scarce periods may be much greater than those faced by female Assamese macaques, forcing chacma baboons females to sacrifice the time required to form more constant social relationships. Alternatively social relationships may have more important benefits for female Assamese macaques than female chacma baboons and, as such, they go to greater lengths to preserve them. We are still only just beginning to understand what benefits social relationships may bring for female Assamese macaques. A recent study from the same study group shows that social bonds between females play an important role in the avoidance of feeding competiton in this species (Heesen et al. in revision), however it still remains to be shown if this goes on to have a significant impact on female reproductive success. An important difference between our study and that of Henzi et al 2009, however, is the type of social data used. Henzi et al.(2009) based their analysis solely on association data rather than direct social interactions such as grooming. While these two types of data are of course related, individuals must be within close proximity in order to interact, they are not completely interchangeable. In a later analysis on the same population of baboons significant changes in the structure of a female social network based on association data were found after the death of a high ranking female, however the structure of a female social network based on grooming behaviour remained stable (Barrett et al. 2012). As such these findings open up the possibility that while the association patterns displayed by female chacma baboons show a cyclic pattern, their grooming behaviour, which is arguably a stronger indicator of the strength of the social relationship between females, may still remain stable. Further, findings from both this and other studies (Lehmann and Boesch 2009; Fürtbauer et al. in revision) suggest a similar dissociation between female proximity patterns and grooming patterns exists in other species as well. As such, investigations of social relationships based solely on proximity data should perhaps be interpreted with caution.

Our analysis of the overall structure of the female social networks revealed that, unlike rhesus macaques (Brent et al. 2013b), the structure of the female social relationship networks remain largely stable across seasons. We can see some significant variation in the density of the approach networks (which goes on to create similar differences in the CSI networks), indicating that there were significant changes in the time females spend in close proximity across seasons. However, these variations show no consistent pattern across samples, the birth season being the least sparse of the three seasons in the 2007-08 sampling period while being the densest in the 2010-11 sampling period, and were not accompanied by any significant changes in the social networks based on direct social contact. The contrast in the results between these groups of rhesus and Assamese macaque may indicate an important species difference in the structural stability of female social relationships across breeding seasons. However, it is also possible the differences may be a result from the different volumes of data collected during each study. Our 
study was based on a single group containing a relatively small number of females, ranging from $12-15$, compared to the rhesus groups which contained 21 and 58 females each. This, among other factors, allowed us to gather more hours of data per female during our study, a mean of 81 hours per female compared to 11hours by Brent et al. (2013). SNA measures are in general very sensitive to observation errors, and as a result require large quantities of relational data in order for a reliable network to be produced (James et al. 2009; Voelkl et al. 2011). It is of course always extremely difficult to know when enough data have been collected, however the presence of isolates, i.e. completely unconnected individuals, in the grooming networks produced by Brent et al. (2013) indicates either that some females in their group never groom any other females or, perhaps more likely, that they had never been seen to groom any of the females in their group. If the latter is true then much more data are required before any strong conclusions can be made on the structure or stability of the female social relationships for this group.

Finally, our analysis of the strength of the bonds between the ten females present in both sample periods also provides some initial evidence that social relationships between female Assamese macaques may remain stable for several years. The strength of the relationships between these females in the first sampling period were significantly related to the strength of their relationships three years later in the second sampling period, in spite of several major demographic changes among the females in the group, including two deaths and the maturation of five females from juvenile to adult. We cannot know if these relationships varied in strength in the years between the two sampling periods, however if they did it appears that females later returned to their previously preferred social partners. We do not know at this stage whether relationships between female Assamese macaques remain stable for longer than three years, yet this first evidence indicates that these relationships may be at least as stable over time as those reported among other species displaying "stable" and "enduring" bonds (Langergraber et al. 2009; Lehmann and Boesch 2009; Silk et al. 2010b; Silk et al. 2012).

In sum we have shown that female Assamese macaques like other non-human species form strong, differentiated social relationships. We have also shown that these relationships and the social network they form remain stable despite significant seasonal changes in the female activity budget and may even remain stable for several years. As such we would argue that they do share some fundamental similarities with social relationships among humans, as well as potentially many other non-human species. 


\section{Acknowledgements}

We thank the National Research Council of Thailand (NRCT) and the Department of National Parks, Wildlife and Plant Conservation (DNP) for permission (No. 0004.3/3618; 0002.3/2647) to conduct this study. We are grateful to J. Prabnasuk, K. Nitaya, M. Kumsuk, and K. Kreetiyutanont (PhuKhieo Wildlife Sanctuary) for their cooperation and permission to carry out this research. We also thank A. Koenig and C. Borries (Stony Brook University), who developed the field site at Huai Mai Sot Yai. We are very thankful to all members of team macaque, $\mathrm{N}$. Juntuch, N.Ponganan, D. Bootros, A. Chunchaen, S. Jomhlotwong, T. Kilawit, T. Wisate, P. Saisawatdikul and especially M. Swagemakers for their help in the field. We are also very grateful to W. Nuagchiyo, M. Heesen and S. Rogahn for their help with data collection. We are grateful to B. Voelkl for statistical advice and F.Nowak for technical assistance. We also thank $\mathrm{N}$. Bhumpakphan, W. Eiadthong (Kasetsart University), and W. Brockelman (Mahidol University) for their collaboration. Financial support was provided by the Max Planck Society, the National Geographic Society, the Primate Society of Great Britain and the German Initiative of Excellence to the University of Göttingen. 


\title{
Chapter 3.1
}

\section{The Absence of Grooming for Rank-Related Benefits in Female Assamese Macaques (Macaca assamensis)}

\author{
Sally Macdonald ${ }^{a}$, Oliver Schülke $^{b} \&$ Julia Ostner ${ }^{a}$
}

\footnotetext{
a Primate Social Evolution Group, Courant Research Centre Evolution of Social Behaviour, Georg-August University, Göttingen, Germany.

${ }^{b}$ Courant Research Centre Evolution of Social Behaviour, Georg-August University, Göttingen, Germany.
}

International Journal of Primatology 34: 571-584 (2013) 



\section{Abstract}

Seyfarth's model of social grooming proposes that by grooming females higher ranking than themselves, females can gain access to important rank-related benefits, such as agonistic support. This, in turn, produces a distinctive pattern of grooming in which females direct their grooming up the female dominance hierarchy and compete for access to the highest ranking individuals. In this study we aim to test to what extent the grooming behaviour of female Assamese macaques (Macaca assamensis) fits the assumptions and predictions of Seyfarth's model. During two one-year sampling periods (Oct. 2007 - Sep. 2008, May 2010 - Apr. 2011) we collected over 2100 focal hours of data from a single wild group in their natural habitat at Phu Khieo Wildlife Sanctuary, Thailand. Subjects included all adult female group members ( $N=12$ in 2007/8; N=15 in 2010/11). We collected detailed data on grooming interactions, approaches and departures as well as all aggressive and submissive behaviours between all subjects. We found no evidence that grooming was exchanged for rank-related benefits. In line with this we found no evidence that the grooming of female Assamese macaques fits the pattern predicted by Seyfarth's model. These results are surprising given that such deviations from Seyfarth's model are relatively rare among macaques. We propose that our findings are best explained as a lack of a need for rank-related benefits by females in this group. 



\section{Introduction}

Grooming is a fundamental part of daily life for many primates, with some species dedicating up to $20 \%$ of their day to grooming (Dunbar 1991; Lehmann et al. 2007) and females in particular tending to dedicate more of their time to grooming than males (Mitchell and Tokunaga 1976). One of the most widely cited explanations of this investment in grooming by female primates is Seyfarth's model of social grooming (Seyfarth 1977). This model, also referred to as the "grooming up the hierarchy" model, proposes that by grooming females higher ranking than themselves, lower ranking females can gain access to important rank-related benefits, such as agonistic support, which only higher ranking females can provide. This creates a strong preference among females to groom the highest ranking females in their group, which in turn produces a distinctive pattern of grooming. The model predicts that females direct more of their grooming towards females higher vs. lower ranking than themselves, thereby directing their grooming up the dominance hierarchy. As a result the highest ranking females receive significantly more grooming overall than lower ranking females. Finally, given the limit in terms of time which any female can spend both giving and receiving grooming each day, it is argued that there is strong competition among females to access the highest ranking females in the group (but see Henzi et al. 2003). Assuming that high and middle ranking females are able to exclude lower ranking females from grooming the top ranking individuals, this competition results in the majority of grooming occurring between females who are close in rank.

Meta-analyses of female grooming behaviour across a wide range of primate species have supported the Seyfarth model (Schino 2001) and found that grooming is often significantly linked to agonistic support (Schino 2007).That said, several exceptions have also been found, both within and between species (Hanuman langurs (Presbytis entellus) Borries et al. 1994; Stumptailed macaques (Macaca arctoides) Butovskaya et al. 1994; Olive baboons (Papio anubis) Sambrook et al. 1995; Tufted capuchins (Cebus apella) Parr et al. 1997; Chacma baboons (Papio cynocephalus ursinus) Silk et al. 1999; Hamadryas baboons (Papio hamadryas hamadryas) Leinfelder et al. 2001; Blue monkeys (Cercopithecus mitis) Cords 2002; Chacma baboons (Papio cynocephalus ursinus) Henzi et al. 2003; Tufted capuchins (Cebus apella) Schino et al. 2009b). It has been argued that many of these apparent inconsistencies may be better understood by taking into consideration two important underlying assumptions of the model (Schino et al. 2009b; Tiddi et al. 2012).

First, a recent analysis by Schino and Aureli (2008) has shown that the extent to which females within a given group "groom up the dominance hierarchy" is strongly related to the steepness of the hierarchy (i.e. the steeper the hierarchy the more females direct their grooming towards higher ranking individuals). The authors argue that when a hierarchy is shallow high 
ranking individuals have little influence over their lower ranking group members, devaluing the rank-related services that they can provide, and so grooming up the hierarchy becomes less frequent (Schino and Aureli 2008). It is therefore important to take into account the steepness of the female dominance hierarchy when considering whether we expect rank-related benefits to play an important part in the female grooming patterns of a given group.

A second fundamental, yet often overlooked, assumption of Seyfarth's model is that females derive rank-related benefits from their grooming behavior (Schino et al. 2009b; Tiddi et al. 2012). If high ranking females simply cannot provide or low ranking females do not require rank-related services, then the model's predictions for female grooming behaviour do not hold. Therefore, before testing the predictions of the model, it is again crucial to examine whether there is a significant relationship between the grooming subordinate individuals give and any rank-related benefits they may receive. It is also important to remember that there are often several potential rank-related benefits which subordinates may gain from a dominant (Schino et al. 2009b; Tiddi et al. 2012) all of which, if possible, should be tested.

In this study we aim to test to what extent the grooming behaviour of female Assamese macaques (Macaca assamensis) fits both the assumptions and predictions of Seyfarth's model. The grooming behaviour of female Assamese macaques has been previously examined using data collected from a single provisioned group, living within the grounds of the Tukeswari temple, Assam, India (Cooper and Bernstein 2000). The females at this site showed no signs of the "grooming up the hierarchy" grooming pattern, despite displaying a steep, linear hierarchy and despotic dominance style (as defined by de Waal and Luttrell 1989) compatible with providing rank-related benefits (Cooper and Bernstein 2008). This is a surprising result as grooming for rank-related benefits, with some exceptions (Butovskaya et al. 1994) is commonly found in macaques (Singh et al. 2006; Ventura et al. 2006; Balasubramaniam et al. 2011; Carne et al. 2011; Xia et al. 2012), however there are two potential explanations. First, the rather despotic dominance style of these females may be an artifact of a highly competitive, provisioned environment rather than reflective of the species-typical dominance style. Alternatively, as the second of the underlying assumptions discussed above was not examined in this study, it is unclear whether the exchange of grooming for rank-related benefits, required to trigger grooming up the hierarchy, was taking place.

In this study we aimed to re-evaluate the grooming behavior of female Assamese macaques by testing both of the underlying assumptions as well as the predictions of Seyfath's model. We replicated a range of measures of dominance style used by Cooper and Bernstein (2008) to establish the dominance style and steepness of the dominance hierarchy for this species in an unprovisioned group and also to allow for a direct comparison with the dominance 
style displayed at the Tukeswari Temple site. In addition, we specifically tested for a relationship between the grooming female Assamese macaques gave to higher ranking females and each of the following rank-related benefits: increased agonistic support, reduced aggression during feeding, reduced aggression in general. Finally, we tested the following predictions of Seyfarth's model, 1. that females direct their grooming up the hierarchy i.e. direct more of their grooming towards females higher vs. lower ranking than themselves, 2. that as a result high ranking females receive significantly more grooming than low ranking females and 3 . that females direct their grooming to females close to them in rank due to competition for access to high ranking grooming partners.

\section{Methods}

Study Site and Subjects

We carried out this study at Phu Khieo Wildlife Sanctuary $\left(16^{\circ} 5^{\prime}-35^{\prime} \mathrm{N}, 101^{\circ} 20^{\prime}-55^{\prime} \mathrm{E}\right)$ located in the Chaiyaphum province of north-eastern Thailand. The sanctuary covers $1560 \mathrm{~km}^{2}$, at elevations ranging from $500-1300 \mathrm{~m}$ above sea level, and is part of the contiguous ca. $6500 \mathrm{~km}^{2}$ Western Isaan Forest Complex (Borries et al. 2002). The study site within the sanctuary, "Huai Mai Sot Yai" $\left(16^{\circ} 27^{\prime} \mathrm{N}, 101^{\circ} 38^{\prime} \mathrm{E}\right)$ consists mostly of dry evergreen forest, and bamboo stands (Borries et al. 2002). Vegetation is dense, the terrain hilly and the macaques spend around $60 \%$ of their activity in the middle and upper forest strata (Schülke et al. 2011).

We collected all data from a fully habituated group of wild Assamese macaques over two, one year sampling periods (period 1, October 2007 - September 2008 and period 2, May 2010 April 2011). During these sampling periods the group consisted of a total of 53 individuals, including 12 adult females, and 49 individuals, including 15 adult females, respectively. All adult females were included as subjects in this study. Due to the recent habituation of this study group (completed 2006), the kinship relationships between the adult females remain unknown.

\section{Data Collection}

All females were subject to regular focal animal observations (Altmann 1974) of 30 minute duration, evenly distributed across both time of day and individual. Due to the dense nature of the forest environment occasionally samples could not be completed. All focal observations longer than 3 minutes were included in this analysis giving a total of $841 \mathrm{hrs}$ and $1360.4 \mathrm{hrs}$ of focal data in sampling period 1 and 2 respectively, with a mean of $70 \pm 7.0 \mathrm{hrs}$ of data per female in period 1 and $91 \pm 4$.6hrs in period 2 .

All grooming interactions as well as approaches/departures within $1.5 \mathrm{~m}$ of the focal animal were recorded using continuous sampling (Altmann 1974). In addition all aggressive and 
submissive behaviours (Ostner et al. 2008) given and received were recorded using both continuous sampling during focal observations and ad libitum sampling throughout the day (Altmann 1974). A bout of aggression began with the first aggressive behaviour directed towards any individual and was considered finished when 30 seconds had passed since the last aggressive or submissive behaviour displayed by any individual involved in the conflict. Aggression was considered to have occurred within a feeding context if either of the individuals involved were seen to be feeding immediately before the aggressive bout took place. Counter aggression was defined as any bout of aggression in which the recipient of aggressive behaviour responded with aggressive behaviour. Female-female support was defined as any bout of aggression in which two females directed aggressive behaviours towards any other group member. We identified, where possible, the aggressor, the recipient and the supporter. In cases where two females directed aggression at a third party simultaneously, making it difficult to clearly identify who came to the aid of whom, both females were recorded as supporting each other. Support involving three or more individuals was not considered in the analysis as it was difficult to clearly identify whom, of the multiple individuals involved, a supporter was supporting.

\section{Data Analysis}

Due to a large number of changes in the composition of adult females in the group between the two sampling periods, i.e. two deaths and five previously juvenile females reaching full maturity, each sampling period was analysed separately.

Dominance style: We established the female dominance hierarchies using only decided, dyadic agonistic interactions (i.e. bouts of aggression with only aggression on one side and submission on the other, or spontaneous signals of submission, Hausfater(1975)). We created a winner/loser matrix based on these interactions and reordered this matrix using the I\&SI method as implemented in MATMAN ${ }^{\mathrm{TM}}$ 1.1.4 (Noldus 2003) to give the final female rank order for each sampling period. We then analysed the same winner/loser matrices using the "steepness" package (Leiva and de Vries 2011) in R 2.14.0 (R Development Core Team, 2011) to provide steepness scores for each hierarchy. We report both scores based on Dij indices, which takes into account the frequency of interactions, and $\mathrm{Pij}$, which does not. To allow an easy comparison between the two sites the dominance characteristics for each of the Phu Khieo sampling periods was calculated separately and then averaged to provide a single score for this site (Table 1).

We assessed the proportion of aggressive bouts containing female-female counter aggression and female-female bites using only bouts of aggression recorded during continuous focal observations. In addition we assessed counter aggression using only dyadic bouts of aggression (an aggressive bout involving only two females) in order to exclude counter 
aggression which occurred in the presence of a supporter. We calculated the rate of femalefemale aggression as the number of aggressive bouts per hour of focal observation in which a female was seen to direct an aggressive behaviour toward another female. We used only data from continuous focal observations but did include both dyadic and polyadic bouts (bouts involving three or more individuals) Polyadic bouts made up $13 \%$ of bouts in period 1 and $7.5 \%$ of bouts in period 2 .

Testing of rank-related benefits: We examined rank-related benefits using directed dyadic scores in which A directs the relevant behaviour toward B. Therefore grooming given scores were calculated as the number of minutes per focal hour individual A spent grooming individual $B$. In addition to this score we calculated a grooming difference score where the amount of grooming (mins) individual $B$ gave individual $A$ is subtracted from the amount of grooming A gave individual $B$. This allowed us to subtract the grooming which had already been returned and left us with only the outstanding grooming "debt". We investigated agonistic support by calculating a score based on the number of instances A supported B divided by the number of potential instances A could have supported B (see Schino et al. 2009). We examined reduced aggression during feeding by examining the rate of aggression in a feeding context (the number of bouts of aggression in a feeding context per focal hour) which individual A directed towards individual B, while reduced general aggression was examined using the rate of aggression in any context individual A directed towards individual B. As we are only interested in what subordinates receive from dominants relative to the grooming that they give, only grooming scores where $A$ was subordinate to $B$, and scores of support and aggression where $A$ was dominant over B (i.e. half of all possible dyadic scores) were included in the analysis.

We made use of Generalized Linear Mixed Models (GLMM, Baayen 2008) to test for relationships between grooming given by the subordinate and the three potential rank-related benefits a subordinate could receive. All GLMM's were calculated in R 2.14.0 ( $R$ Development Core Team, 2011) using the function "Imer" within the R package "Ime4" (Bates and Maechler 2012). Separate models were run with agonistic support, reduced aggression during feeding, and general reduced aggression as the dependent variable. Each model included rates of grooming given, grooming difference score, time spent in close proximity $(<1.5 \mathrm{~m})$ and ordinal rank distance as predictor variables. In the feeding aggression model one additional predictor variable was included, the rate of non-feeding related aggression received (the number of bouts of aggression not in a feeding context per focal hour). To allow for comparison with other studies which did not include proximity as a factor we also ran all models with proximity removed as a predictor variable. All GLMM's were fitted with Poisson error structure and log-link function and the identity of the subordinate and dominant individuals were controlled for as random factors. 
The significance of each full model as compared to the null model (comprising only the intercept and the random effects) was established using a likelihood ratio test ( $R$ function anova with argument test set to "Chisq"). Significance of the individual predictor variables were determined based on the $\mathrm{Z}$ scores and $\mathrm{p}$ values provided by the "Imer" function and all appropriate assumptions (multicolinearity, over-dispersion, influential cases) were tested for and met in each analysis. A single dyad was identified as an influential case using DFFit and DFBeta scores in the period 2 data set. We attempted to improve the distribution of the data set using a log transformation however the dyad still remained a strongly influential case. Therefore this dyad was removed from the data set in order for the assumptions of the analysis to be met. The final results of the analysis were not altered by its removal.

Testing of predictions: We tested whether females directed their grooming up the female dominance hierarchy by calculating for each female the proportion of time spent grooming females above and below them in rank, with the highest ranking and lowest ranking female being excluded from the analysis. We then used a Wilcoxon matched-pairs signed-ranks test to make a pairwise comparison of these values. We assessed whether the amount of grooming (in minutes) received by an individual was related to ordinal dominance rank using a standard Spearman rank correlation. Finally, we tested whether, due to competition for access to high ranking grooming partners, females direct most of their grooming towards higher ranking individuals of similar rank in two steps. First we used a matrix correlation to establish whether the absolute rank difference between two females predicted the proportion of grooming they give to each other. We then used a Wilcoxon matched-pairs signed-ranks test to assess whether the proportion of time each female spent grooming the female adjacently above, compared to the female adjacently below her in rank was significantly different, again with the highest and lowest ranking females excluded from the analysis. The matrix correlation was calculated using the row-wise matrix correlation function in MATMAN ${ }^{\mathrm{TM}}$ 1.1.4 (Noldus 2003) (permutations = 10,000), all other statistics were performed in R 2.14.0 (R Development Core Team, 2011).

\section{Results}

\section{Female Dominance Hierarchy and Dominance Style}

The dominance hierarchies established for each sampling period were based on 249 and 393 decided, dyadic agonistic interactions. In period 1 seven (10.6\%) relationships remained unknown and five (7.6\%) were two-way relationships. In period 2 thirteen (12.4\%) relationships remained unknown and seven (6.7\%) were two-way. In terms of linearity (period 1 Landau's index $\left(h^{\prime}\right)=0.91, p<0.001$, period 2 Landau's index $\left.\left(h^{\prime}\right)=0.83, p<0.001\right)$, directional consistency (period $1=0.96$, period $2=0.96$ ) and steepness (Pij: period $1=0.78, p<0.001$, period $2=0.76$, 
$\mathrm{p}<0.001$ Dij: period $1=0.61, \mathrm{p}<0.001$, period $2=0.57, \mathrm{p}<0.001$ ) female Assamese macaques appear to have very similar dominance styles in both provisioned and unprovisioned environments (Table 1).

Table 1. Dominance Style Characteristics of wild and provisioned Assamese macaque females* Figures taken from Cooper and Bernstein (2008), ${ }^{\dagger}$ Figures taken from Balasubramaniam et al. (2012)

\begin{tabular}{lcc}
\hline & $\begin{array}{c}\text { Phu Khieo } \\
\text { Wildlife Sanctuary }\end{array}$ & Tukeswari Temple \\
\hline Corrected Landau's index (h') & 0.87 & $0.89^{*}$ \\
Directional Consistency & 0.96 & $0.99^{*}$ \\
Steepness (Dij) & 0.59 & $0.65^{\dagger}$ \\
$\begin{array}{l}\text { Steepness (Pij) } \\
\text { Counter Aggression (\%) }\end{array}$ & 0.77 & $0.80^{\dagger}$ \\
$\begin{array}{l}\text { Aggression Rate } \\
\text { (bouts per hr) }\end{array}$ & 3.8 & $6.3^{*}$ \\
$\begin{array}{l}\text { Bouts of Aggression } \\
\text { Involving Bites (\%) }\end{array}$ & 0.29 & $0.11^{*}$ \\
\hline
\end{tabular}

\section{Frequency of Grooming, Aggression and Support}

Of the 66 possible female-female dyads in period 1 and the 105 in period 2, 58 (88\%) and $94(90 \%)$ were seen to groom during each sampling period. Each female spent a mean of 1.17 $\pm 0.54 \mathrm{~min} / \mathrm{hr}$ (mean $\pm \mathrm{SD}$, period 1) and $1.50 \pm 0.67 \mathrm{~min} / \mathrm{hr}$ (mean $\pm \mathrm{SD}$, period 2) giving grooming to another female.

In total females were involved in 1286 bouts of aggression $(1.53 / \mathrm{hr})$ in period 1 and 1218 $(0.91 / \mathrm{hr})$ in period 2 respectively. Of these bouts $234(18 \%)$ and $405(33 \%)$ included femalefemale aggression. However, females rarely supported each other (eight times in period 1, seven times in period 2 , i.e. in $0.6 \%$ of all possible bouts of aggression in both sampling periods). 


\section{Testing of Rank-Related Benefits}

Due to the rarity of female-female support, and the resulting small number of data points available, we were unable to run our GLMM for support or any other statistical analysis which would allow us to reliably test for a relationship between grooming and agonistic support. The full models for reduced aggression in a feeding context were not significantly different from the null models in either period (period 1: $X^{2}=3.13, d f=5, p=0.68$, period 2: $X^{2}=2.14, d f=5, p=$ 0.83; without proximity period $1: X^{2}=2.97, d f=4, p=0.56$, period $2: X^{2}=1.79, d f=4, p=0.77$ ), indicating that grooming was not related to reduced aggression during feeding in this group. The full models for reduced general aggression were also not significantly different from their null models (period 1: $X^{2}=3.20, d f=4, p=0.52$, period 2: $X^{2}=3.08, d f=3, p=0.54$; without proximity period 1: $X^{2}=1.55, d f=3, p=0.67$, period $2: X^{2}=2.42, d f=3, p=0.49$ ). Therefore we also found no evidence that females were less aggressive to those females which groomed them the most.

\section{Testing of Predictions}

No significant difference was found in the proportion of time which females spent grooming females higher or lower ranking than themselves (period 1: Wilcoxon matched-pairs signed-ranks test, $V=21, N=10, p=0.91$, period 2: $, V=50.5, N=13, p=0.39 ;$ Fig. 1), indicating that females did not preferentially groom higher ranking individuals. We also, therefore, found no evidence of a relationship between the overall amount of grooming a female received and her rank position (period 1: rho $=0.14, p=0.68$, period 2: rho $=-0.41, p=0.12 ;$ Fig. 2 ) .

We found a significant relationship was found between the absolute rank distance between females and the rate of grooming given (period 1: $\tau \mathrm{rw}$, av $=-0.19, p<0.05$, period 2: $\tau$ $r w, a v=-0.19, p<0.01)$, indicating that female Assamese macaques directed most of their grooming towards females close to them in rank. We found no significant difference between the rate of grooming given by females to the female adjacently above, compared to the female adjacently below them in rank (period 1: Wilcoxon matched-pairs signed-ranks test, $V=28, N=10$, $p=0.55$, period 2:, $V=60, N=13, p=0.33$; Fig. 3), suggesting that females did not direct grooming towards individuals close to them in rank as a result of competition for access to high ranking grooming partners. 


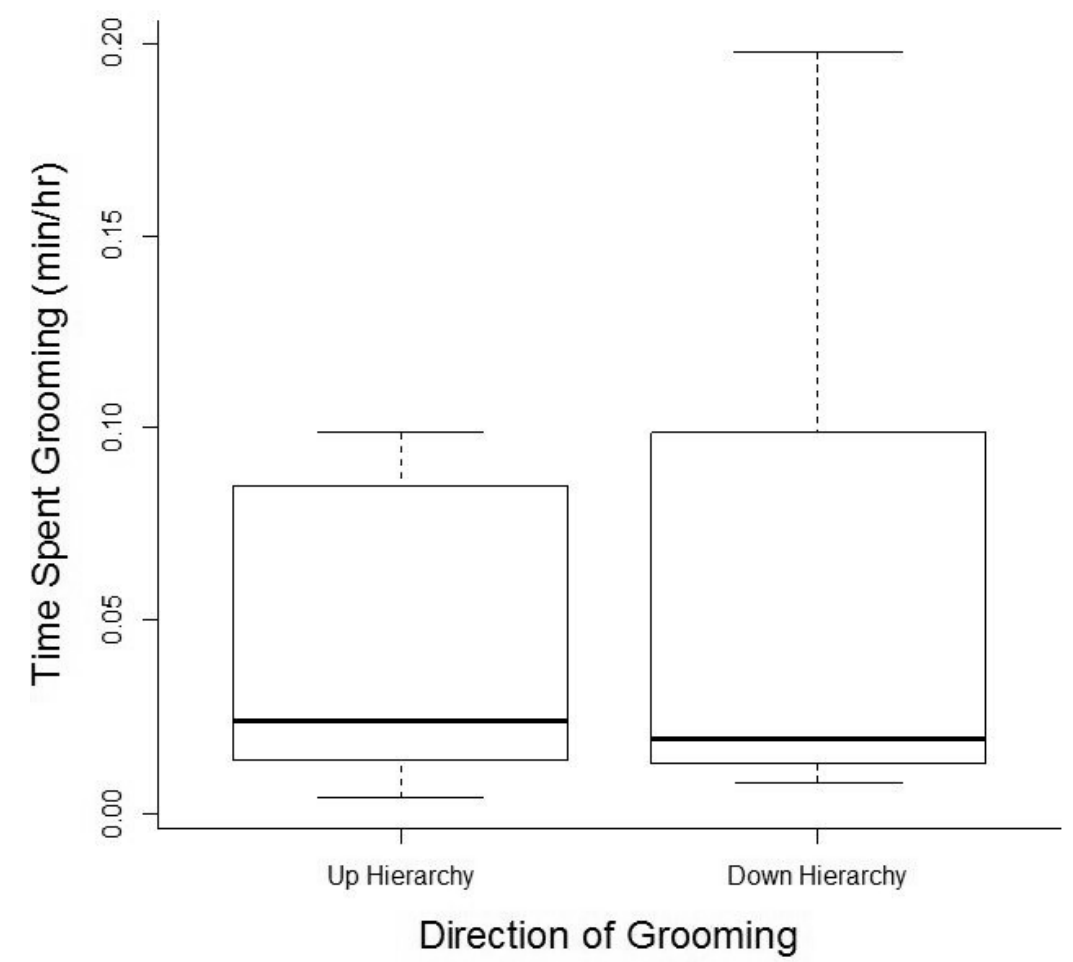

a.

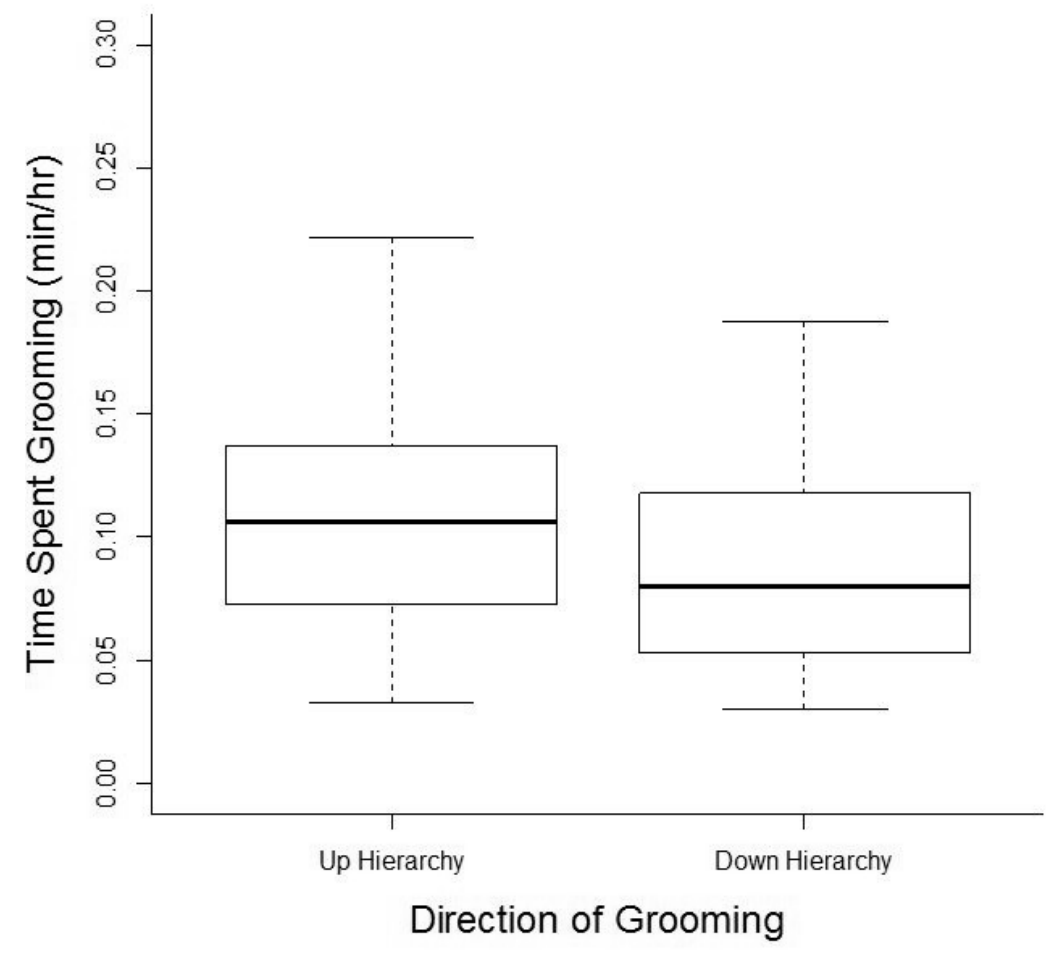

Figure 1 The median proportion of time $(\mathrm{min} / \mathrm{hr}$ ) Assamese macaque females at Phu Khieo Wildlife Sanctuary spent grooming up and down the dominance hierarchy during period1 (2007/08, left) and period 2 (2010/11, right). Each box plot shows the median and 25th and 75th percentiles; the whiskers indicate the values within 1.5 times the interquartile range, IQR. 


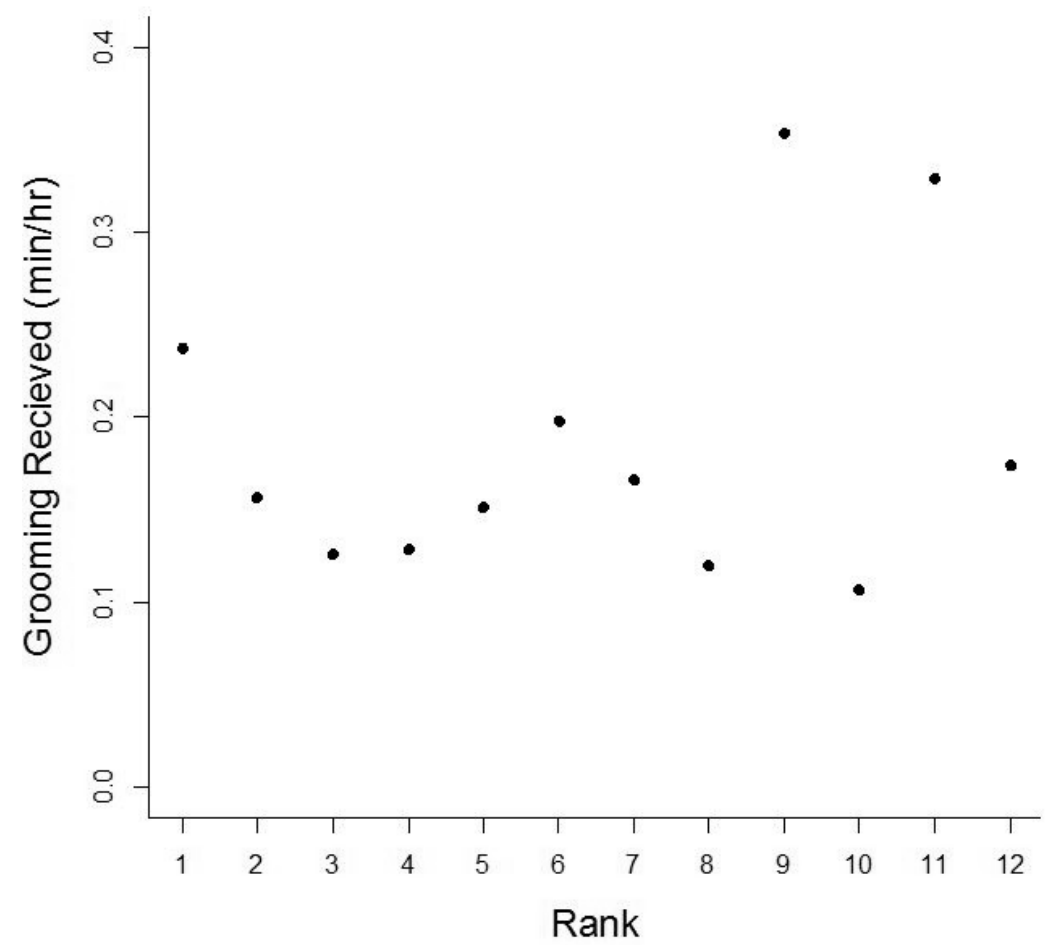

a.

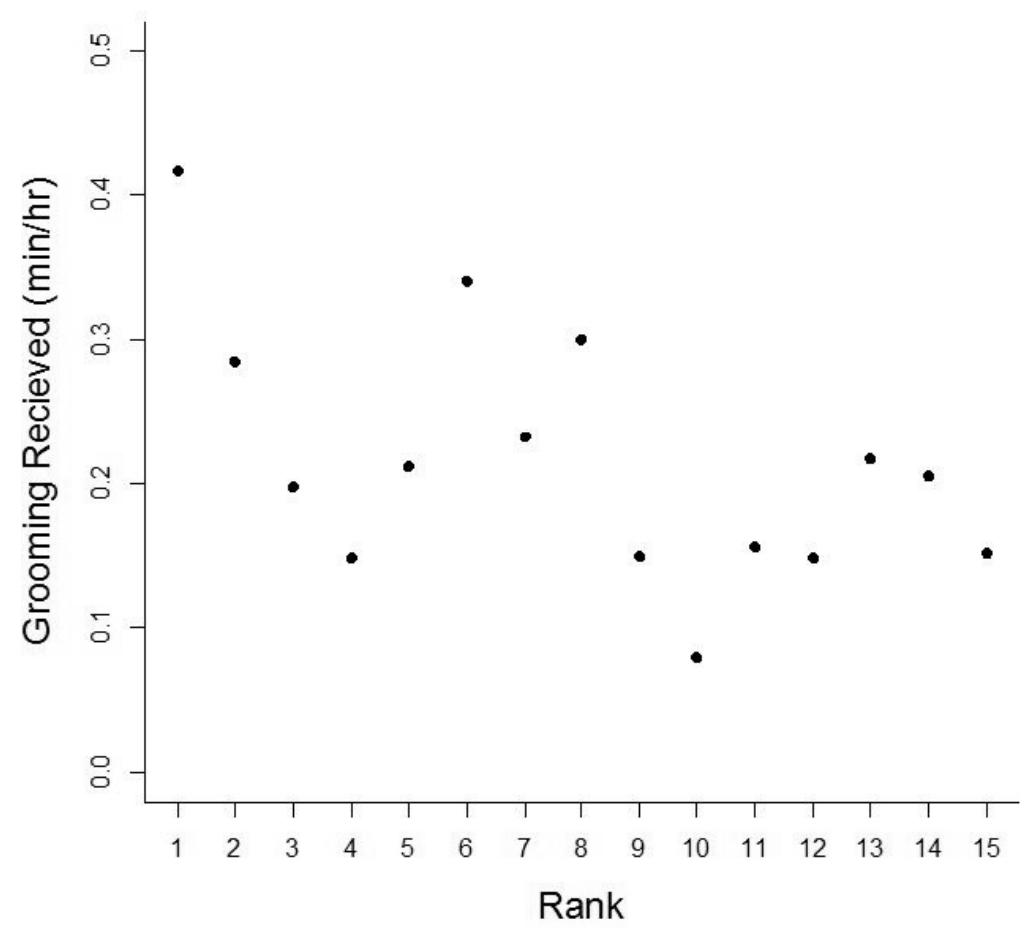

b.

Figure 2 Proportion of grooming received relative to individual rank position by female Assamese macaques at Phu Khieo Wildlife Sanctuary during period1 (2007/08, left) and period 2 (2010/11, right). The highest ranking female was assigned rank 1 


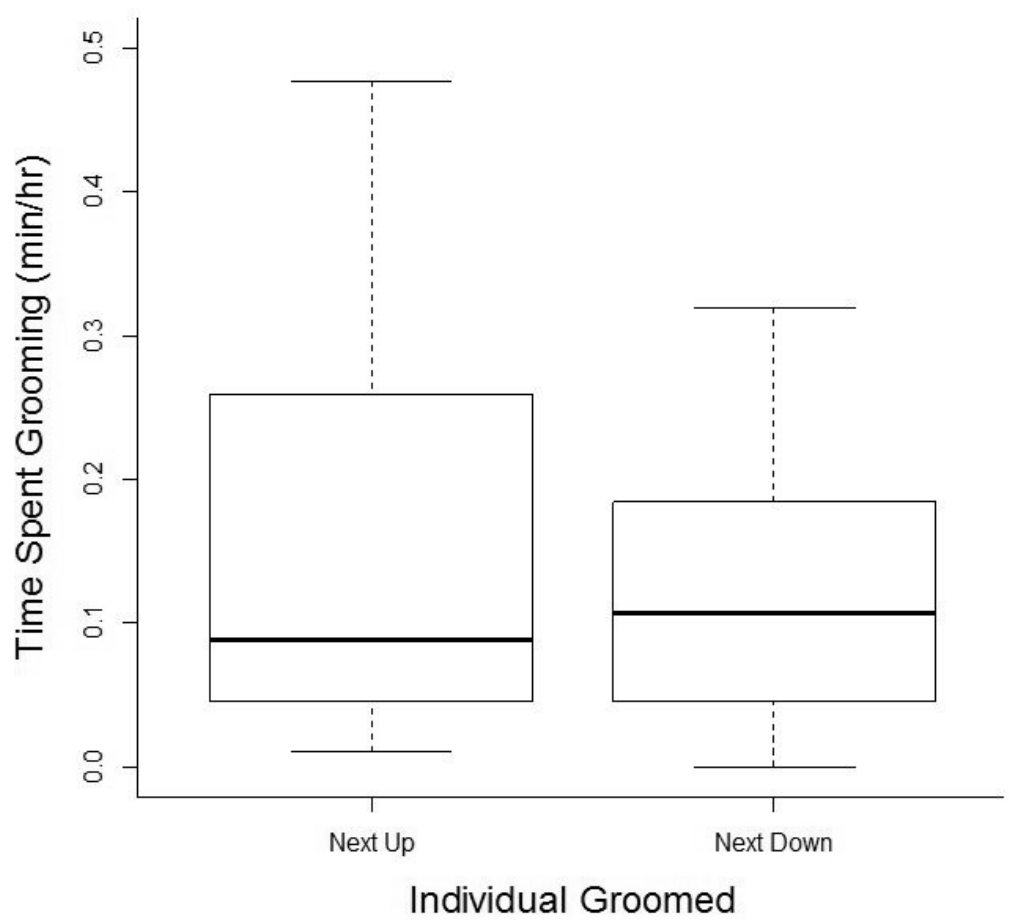

a.

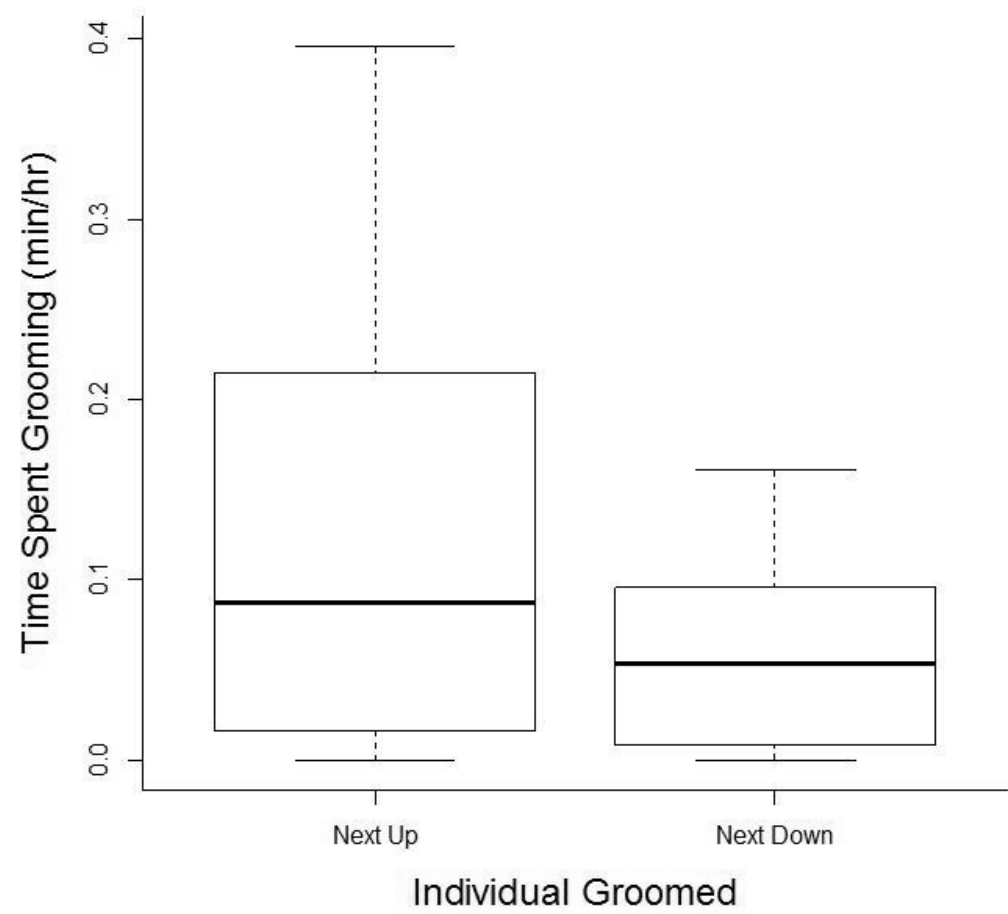

b.

Figure 3 The median proportion of time ( $\mathrm{min} / \mathrm{hr}$ ) Assamese macaque females at Phu Khieo Wildlife Sanctuary spent grooming the female directly above and directly below in rank during period1 (2007/08, left) and period 2 (2010/11, right). Each box plot shows the median and 25th and 75th percentiles; the whiskers indicate the values within 1.5 times the interquartile range, IQR. 


\section{Discussion}

Overall we found no evidence that female Assamese macaques gain rank-related benefits from their grooming. In line with this we also found no evidence that female Assamese macaques met any of the three predictions of Seyfarth's model tested here. Therefore, it appears that female Assamese macaques deviate from the typical "grooming up the hierarchy" pattern of female primates, without, however, challenging the general validity of Seyfarth's model.

We investigated both of the crucial assumptions of the model, the presence of a steep, linear hierarchy and the exchange of grooming for rank-related benefits. In terms of dominance hierarchy we found that females at Phu Khieo had a strikingly similar dominance style compared to the females at Tukeswari Temple. In terms of linearity, directional consistency, and steepness the females at the two sites were almost indistinguishable. There were, however, some distinct differences in terms of the rate of aggression and the proportion of bites between the sites. The overall rate of female-female aggression observed at Phu Khieo was almost 3 times higher than that reported at Tukeswari, ( 0.28 bouts $/ \mathrm{hr}$, period 1 and 0.30 bouts $/ \mathrm{hr}$, period 2 ). While the proportion of aggressive bouts which involved bites was distinctly lower (1.6\% in period 1 and $1.8 \%$ in period 2). Overall, even in their natural environment, it appears that female Assamese macaques display a "despotic" dominance style. Crucially the presence of a steep, linear hierarchy in the Phu Khieo group suggests a potential for rank related benefits. Thus, the absence of "grooming up the hierarchy" cannot be explained by the absence of a suitable power gradient between high and low ranking individuals.

We examined the second of the model's underlying assumptions by investigating whether grooming was related to any of three potential rank-related benefits: agonistic support, reduced aggression during feeding and reduced aggression in general. The first of these three, agonistic support, is the classic ranked-related service associated with Seyfarth's model and has received wide support (Schino 2007, but see Barrett and Henzi 2002). Yet we found female agonistic support to be extremely rare (15 cases in 2100 focal hrs). This rarity could not be explained as a lack of opportunity to provide support as females across both sampling periods were involved, on average, in one aggressive bout per hour, however other potential explanations exist.

The majority of female aggressive bouts (74\%) involved a female against either a juvenile or an adult male. Female agonistic support could be unlikely to occur in both of these instances, but for very different reasons. On the one hand adult females are unlikely to require any help in order to win in their conflicts against juveniles, but on the other hand Assamese macaques are a relatively sexually dimorphic species, (average female $=7 \mathrm{~kg}$, males $11 \mathrm{~kg}$ (Smith and Jungers 1997)) and therefore females may be reluctant to become involved in an aggressive interaction 
involving a male. This dimorphism explanation is backed by the composition of the few bouts of aggression in which female-female agonistic support did occur, 13 out of 15 of which involved females only. Yet a large proportion of female only aggression during which no support was given remains unaccounted for. Low rates of female-female support have been linked elsewhere to the avoidance of conflicts by pregnant or lactating females and relatively small female cohort size (Barrett and Henzi 2002). The first of these is unlikely to apply to strictly seasonal breeders such as Assamese macaques (Fürtbauer et al. 2010), however the average female cohort size of our study group, 13.5, does fall within the range of a "small female cohort" (Barrett and Henzi 2002). Therefore our findings could be considered compatible with the suggestion that there is a threshold in terms of the number of available females that must be passed in order for femalefemale support to be sustainable.

Ultimately the rarity of female agonistic support prevented any statistical tests on the relationship between agonistic support and grooming. It remains a possibility that female agonistic support becomes important only in extremely rare situations, e.g. when the otherwise stable female dominance hierarchy is overthrown. But the rarity of agonistic support observed here may also be taken as an indication that agonistic support is not an important factor shaping the grooming behaviour of females in this group. Overall it appears that agonistic support is a commodity which female Assamese macaques either do not need or are often unwilling to give.

The second potential rank-related benefit investigated was grooming for reduced aggression during feeding. Tolerance during co-feeding is a potential benefit which, while less frequently tested, has been shown to be significantly linked with the distribution of female grooming among multiple primate species, including two species of macaques (Ventura et al. 2006; Carne et al. 2011; Tiddi et al. 2012). In contrast, in our study we found no evidence that grooming was related to tolerance during feeding (indicated in this case as reduced aggression during feeding). However, female rank seems to have little impact on time spent feeding or energy intake among the females of this group (Heesen et al. in revision), suggesting that all females, regardless of their rank, are well able to meet their nutritional needs. Therefore, it could be argued that reduced aggression from high ranking females during feeding has limited value to the lower ranking females in this group.

Finally we assessed whether the amount of aggression a subordinate female received from a higher ranking female was related to the amount of grooming she had given that same female, in an attempt to measure whether grooming allowed females to gain general reduced aggression from high ranking females. As with tolerance during feeding, general reduced aggression is a less frequently tested potential rank-related benefit of social grooming. When tested it has generally been found either to not be an important factor influencing the 
distribution of female grooming (Schino et al. 2009b; Tiddi et al. 2012) or that a significant positive relationship exists (Perry 1996; Schino et al. 2005; Ventura et al. 2006; Carne et al. 2011; McFarland and Majolo 2011). This positive relationship is often interpreted as high ranking individuals attempting to extort grooming from lower ranking individuals by force, and has been reported for several species of macaques in particular (Schino et al. 2005; Ventura et al. 2006; Carne et al. 2011). An important exception to this is a recent study conducted on a group of Tibetan macaques (M. thibetana) (Xia et al. 2012), a species closely related to Assamese macaques, which found a significant negative relationship between grooming given and aggression received among females. Yet, as with the previous potential rank-related benefits, we found no evidence that grooming was related to a reduction in general aggression by higher ranking females in either a positive or negative direction. Again this is perhaps best explained as a lack of need for this commodity. As touched upon above, female-female aggression in this group is relatively uncommon, the average rate being 0.29 bouts per hour, almost half that of the rate reported for Tibetan macaques (Xia et al. 2012). In addition contact aggression, in the form of bites, appears to be extremely rare. As such it could be argued that lower ranking female Assamese macaques are already rarely aggressed by the high ranking females in this group and therefore any additional reduction in aggression would be of limited value.

In summary, overall our results appear to be best explained as a lack of a need for rankrelated benefits by the females of this group. However it could also be argued that they could be explained by the lack of information on the group's kin relationships. Kinship is known to be an important factor shaping the distribution of grooming among female primates, particularly in species where females are the philopatric sex (Silk et al. 2006b). It is possible; for example, that if we controlled for kinship we would remove many of the grooming down dyads and reveal a grooming up the hierarchy pattern that could previously not be seen. However, in his original paper Seyfarth proposed that the attraction of kinship and rank would be additive (Seyfarth 1977). In line with this Seyfarth's model has been tested, and evidence of grooming up the hierarchy found, in several groups for which kinship data were not available, including in Seyfarth's own original studies. Therefore while we cannot rule out that preferences for kin have affected our tests of the model's predictions, we would argued that grooming up the hierarchy, when present, appears to be strong enough to be detected even in the absence of kinship data.

Lastly, there are those who argue that in order to perform a complete evaluation of Seyfarth's model you must not only find grooming up the hierarchy and grooming competition but also show that females operate with an underlying optimal grooming ratio "in mind" (Henzi et al. 2003). This is, however, extremely difficult to test within a single group and therefore was beyond the scope of this study. 
Despite the absence of grooming for rank-related benefits, female-female grooming remains an important behaviour in this group and the groups of other species which deviate from the grooming up the hierarchy pattern. Indeed it has been shown elsewhere that when little opportunities exists for grooming to be exchanged for anything else, females will form balanced partnerships where grooming is exchanged for itself (Barrett et al. 1999). This suggests that there are benefits to female grooming that any female can provide, regardless of rank, the most likely of which is arguably stress reduction (Engh et al. 2006) as well as, of course, the removal of ectoparasites (Akinyi et al. 2013). It could also be argued that such benefits are a more fundamental and/or universal influence on the distribution of grooming behaviour among female primates than rank-related benefits. Yet, Seyfarth's model remains extremely influential in our understanding of female primate grooming behaviour. Our results highlight the importance of closely examining both the underlying assumptions of the model as well it's predictions in order for the implications of results to be fully understood. This is particularly important when trying to interpret instances when female grooming deviates from the predictions made by them model.

\section{Acknowledgements}

We thank the National Research Council of Thailand (NRCT) and the Department of National Parks, Wildlife and Plant Conservation (DNP) for permission (No. 0004.3/3618; 0002.3/2647) to conduct this study. All data collection adhered to the legal requirements of Thailand. We are grateful to J. Prabnasuk, K. Nitaya, M. Kumsuk, and K. Kreetiyutanont (Phu Khieo Wildlife Sanctuary) for their cooperation and permission to carry out this research. We thank A. Koenig and C. Borries (Stony Brook University), who developed the field site at Huai Mai Sot Yai. We also thank N. Bhumpakphan, W. Eiadthong (Kasetsart University), and W. Brockelman (Mahidol University). We are very thankful to all members of team macaque, N. Juntuch, $\mathrm{N}$. Ponganan, D. Bootros, A. Chunchaen, S. Jomhlotwong, T. Kilawit, T. Wisate, P. Saisawatdikul and especially M. Swagemakers for their help in the field. We are also very grateful to W. Nuagchiyo, M. Heesen and S. Rogahn for their help with data collection. We thank B. Tiddi and C. Neumann for helpful discussions and J. Duboscq, F. Nowak, J. Setchell, L. Barrett and an anonymous reviewer for helpful comments on this manuscript. Support was provided by the Max Planck Society, the National Geographic Society and the German Initiative of Excellence to the University of Göttingen. 



\section{Chapter 3.2}

\section{Social Relationship Strength and the Equality of Grooming Reciprocity in Female Assamese Macaques (Macaca assamensis)}

Sally Macdonald ${ }^{a}$, Oliver Schülke ${ }^{b}$ \& Julia Ostner ${ }^{a}$

\footnotetext{
a Primate Social Evolution Group, Courant Research Centre Evolution of Social Behaviour, Georg-August University, Göttingen, Germany.

${ }^{\mathrm{b}}$ Courant Research Centre Evolution of Social Behaviour, Georg-August University, Göttingen, Germany.
} 



\section{Abstract}

Equality in the exchange of both emotional and material services is important for the maintenance of human social relationships. Yet, variation in the strength of a social relationship has been shown to lead to major differences in the time frame over which services are exchanged. It has been suggested that equality is also an important characteristic of non-human social relationships, however very few studies have considered whether social relationship strength influences the time frame of the exchanges of services. The aim of this study is to investigate how equitably grooming is exchanged among female Assamese macaques (Macaca assamensis) and whether social relationship strength has an effect on the equality and time frame of this exchange. We collected over 2100 hours of behavioural observations from a wild group at Phu Khieo Wildlife Sanctuary, Thailand. Data were collected over two one-year sampling periods (Oct. 2007 - Sep. 2008, May 2010 - Apr. 2011) with all adult female group members included in the study ( $\mathrm{N}=12$ 2007-8; $\mathrm{N}=15$ 2010-11). We collected detailed data on all social interactions between females including approaches within $1.5 \mathrm{~m}$, body contact and grooming. Our results indicate that female Assamese macaques have balanced grooming relationships with all females in their group regardless of relationship strength. This balance is not maintained by the immediate reciprocation of grooming, but over a longer time frame. In addition, unlike humans, our results indicate that social relationship strength does not influence the time frame over which grooming is exchanged among females in this species. 



\section{Introduction}

Equality in the exchange of both emotional and material services is important for the maintenance of human social relationships (Rook 1987; Clark and Ayers 1993; Walker 1995; Horwitz et al. 1996; Hendrix 1997; Komter and Schans 2008). However, the strength of the social relationship can lead to major differences in the time frame over which services are expected to be reciprocated. Immediate reciprocation (or the immediate offer of reciprocation in the near future) is generally expected in weaker social relationships, i.e. among strangers or casual acquaintances (Clark and Mills 1979; Clark and Waddell 1985; Shackelford and Buss 1996; Komter and Schans 2008; Xue and Silk 2012) and individuals have been shown to pay closer attention to the contributions of strangers and casual acquaintances to joint tasks compared to individuals they have a strong social relationships with, i.e. close friends or romantic partners (Clark 1984; Clark et al. 1989). Reciprocation between individuals sharing a strong social relationship on the other hand is generally expected to occur over a longer time frame, i.e. an unspecified date in the future (Clark and Mills 1979; Clark and Waddell 1985; Shackelford and Buss 1996; Komter and Schans 2008; Törnblom et al. 2012; Xue and Silk 2012). In fact immediate reciprocation between individuals with a strong social relationship was shown to be potentially interpreted as insulting or even a "betrayal" by the recipient of the reciprocated service, and as a result damaging to the relationship between the individuals involved (Clark and Mills 1979; Shackelford and Buss 1996). Therefore, while strong social relationships do require equality in the exchange of services, the equality is expected to be maintained over the long term.

In recent years it has been repeatedly suggested that non-human animals also form strong social relationships, similar to the strong social relationships, such as friendships, which we see in humans (Massen et al. 2010; Dagg 2011). Studies on the social behaviour of a variety of species have shown that strong social relationships among animals appear to share several important characteristics of strong human social relationships such as stability, strength and equality in the exchange of services (Silk et al. 2006a; Silk et al. 2006b; Lehmann and Boesch 2009; Mitani 2009; Silk et al. 2010b; Silk et al. 2012). Equality in non-human social relationships is usually assessed by examining how equally services such as grooming are exchanged between individuals. It has been found that the overall equality of grooming between individuals varies relative to the strength of the social relationship between those individuals, in that the stronger the social relationship between two individuals the more equal the exchange of grooming is between them (Silk et al. 2006a; Mitani 2009; Silk et al. 2010b). However, it is rarely discussed how this equality between individuals with strong social relationships is achieved, i.e. is the grooming reciprocated immediately or over a longer time frame. We argue that if we wish to understand how similar the role of equality is in the strong social relationships of humans and 
non-human animals it is important that we know more details about the time frame over which equality is achieved.

To date there have only been a handful of studies which have considered social relationship strength when investigating the time frame of grooming reciprocation. In one example, Lewis et al.(2007) found differences in the time frame of the reciprocation of allopreening among breeding pairs and neighbouring pairs in common guillemot (Uria aalge) breeding colonies. The common guillemot breeds in tightly packed colonies, often using the same nest site, next to the same neighboring pairs for multiple breeding seasons. Allopreening between both the breeding pair and between neighbouring pairs was found to have a significant, positive impact on chick survival (Lewis et al. 2007). However, while preening among neighboring pairs of birds, whose relationships last on average 1.5 years, was reciprocated immediately, preening between the breeding pair, whose relationships last on average 5 years, was not. Some other examples of studies examining the influence of relationship strength on the timing of reciprocation come from a range of primate species (Barrett et al. 2000; Fruteau et al. 2011a). These studies consider how the frequency with which individuals groom (a measure of social relationship strength in primates) influences patterns of immediate reciprocity of grooming (Barrett et al. 2000; Fruteau et al. 2011a) (however they do not go as far as to consider whether frequency of grooming influences whether grooming is reciprocated immediately or over a longer time frame). Specifically they considered whether grooming among infrequent groomers is broken down into smaller sub-divisions or "parcels" compared to more frequent groomers (Barrett et al. 2000; Fruteau et al. 2011a). They also examine whether the first parcels in grooming bouts among infrequent groomers might be significantly shorter, subsequently increasing in length as the grooming bout continues and trust builds between the two partners, sometimes referred to as the "raising the stakes" strategy (Roberts and Sherratt 1998). Neither study found any significant effects of grooming frequency on the pattern of grooming reciprocity. However, variation in the frequency with which dyads groomed was measured by dividing groomers into two broad categories, "frequent groomers" and "infrequent groomers". It is possible that a more fine grained measure of variation in relationship strength may uncover significant differences.

In this study we aim to investigate how equitably grooming is exchanged among female Assamese macaques (Macaca assamensis) and whether social relationship strength has an effect on the equality and time frame of this exchange. Grooming (or allopreening among birds) is widely regarded as a valuable, cooperative service, in a range of species (Dunbar 1991; Hart and Hart 1992; Connor 1995; Kimura 1998; Kutsukake and Clutton-Brock 2006; Radford and Plessis 2006; Gill 2012; Radford 2012). It has been found to be exchanged both for itself (Barrett et al. 
2000; Payne et al. 2003; Manson et al. 2004; Pazol and Cords 2005; Gomes et al. 2009; Schino et al. 2009a) or for other services such as agonistic support (Seyfarth 1977; Schino 2007), feeding tolerance (Ventura et al. 2006; Carne et al. 2011; Tiddi et al. 2012), reduced aggression (Löttker et al. 2007; Kutsukake and Clutton-Brock 2010; Xia et al. 2012), assistance in territory defense (Gill 2012; Radford 2012) or opportunities to handle young infants (Henzi and Barrett 2002; Fruteau et al. 2011b). We have previously shown that females in our study group do not appear to exchange grooming for services such as agonistic support, feeding tolerance, reduced aggression (Macdonald et al. 2013) or infant handling (Macdonald et al. to be submitted). Therefore, we predict that grooming is exchanged in a relatively time matched manner for itself by females in this group. We have also previously shown that females in this group form strong, differentiated social relationship with other specific females and that these relationships appear to remain stable for several years, despite significant changes in the female time budget brought about by their seasonal environment (Macdonald et al. to be submitted). As such, these strong social relationships appear to be similar to those described among other primate species, (Silk et al. 2006a; Silk et al. 2006b; Mitani 2009; Silk et al. 2010b). Therefore we predict that, as in these species, equality of grooming among individuals will be positively related to the strength of their social relationship. Lastly, variation in the strength of social relationships among the females in the group also provides us with an opportunity to examine whether the time frame of grooming reciprocation is influenced by relationship strength. If relationship strength influences the time frame of reciprocity as it does among human social relationships we predict that 1 . the stronger the social relationship the more likely it is that a grooming bout will be unidirectional and 2 . that the strength of the social relationship between two individuals will be negatively correlated with the equality of the grooming within reciprocated grooming bouts, i.e. how well time matched grooming is within bouts during which both partners groom.

\section{Methods}

Study Site and Subjects

This study was carried out at Phu Khieo Wildlife Sanctuary $\left(16^{\circ} 5^{\prime}-35^{\prime} \mathrm{N}, 101^{\circ} 20^{\prime}-55^{\prime} \mathrm{E}\right)$ situated in the Chaiyaphum province of north-eastern Thailand. The sanctuary covers $1573 \mathrm{~km}^{2}$ and makes up one of the six sections of the Western Isaan Forest Complex, a continuous, protected area covering ca. $6500 \mathrm{~km}^{2}$ (Borries et al. 2002). We collected data from one habituated group of wild Assamese macaques over two, one year sampling periods, October 2007 - September 2008 (07-08 sample) and May 2010 - April 2011 (10-11 sample). During the first sampling period the group consisted of 53 individuals, 12 of which were adult females, and 49 individuals, 15 of which were adult females during the second. All adult females were included 
as subjects during the study. Maternal kin relationships between the adult females currently remain unknown.

\section{Data Collection}

All adult females were subject to regular focal animal observations (Altmann 1974) of either 20 or 30 minute duration. An effort was made to evenly distribute focal observations across both time of day and individual throughout the study. Due to the dense nature of the forest not all focal observations could be completed for a full 20 or 30 minutes. All focal observations longer than 3 minutes were included in this analysis. This resulted in a total of $841 \mathrm{hrs}$ of focal data collected during the 07-08 sample (mean of 70 $\pm 7.0 \mathrm{hrs}$ per female) and $1360.4 \mathrm{hrs}$ of focal data during the $10-11$ sample (mean of $91 \pm 4.6 \mathrm{hrs}$ per female).

All friendly interactions between females lasting for a minimum of ten seconds were recorded using continuous recording (Martin and Bateson 2007). These interactions included approaches (approaches within 1.5m that did not result in aggression or spontaneous submission from either party), body contact (i.e. body contact that did not involve or occur during aggression or spontaneous submission) and grooming. Grooming bouts were considered to have begun as soon as one individual began to groom another individual and considered finished when all grooming between these two individuals stopped for longer than ten seconds. A grooming bout could be made up of a single or multiple grooming episodes. Grooming episodes were considered to have begun when one individual began to groom another individual and considered finished when that same individuals stopped grooming its partner for longer than 10 seconds.

\section{Data Analysis}

We used the dyadic composite sociality index (CSI) (Silk et al. 2013) to characterise the strength of female social relationships in the study group. The CSI combines rates of correlated, positive, social behaviours between individuals in such a way that it is possible to assess the strength of the relationship between a given dyad relative to the strength of the relationships of all other dyads (for full formula see Silk et al. 2013). The CSI can vary from zero to infinity. The mean CSI value for a group will always be one, therefore any dyad with a score greater than one can be consider as having a stronger than average social relationship, while any dyad with a score less than one can be considered as having a weaker than average social relationship. The behaviours used to calculate the index depend on which social behaviours are most relevant for the given species. We chose six behavioural elements to construct the female Assamese macaque CSI including; the frequency (per hour of observation) of approaches (within $1.5 \mathrm{~m}$ ), body contact and grooming, and the duration (minutes per hour of observation) of time spent 
within $1.5 \mathrm{~m}$, body contact and grooming. Approaches, body contact and grooming are nested behaviors, i.e. one must approach before making body contact and one must make body contact before grooming. Therefore, in an effort to control for pseudoreplication approaches which were followed by body contact or grooming were only included in the analysis if the dyad spent at least 10 seconds in the approach before engaging in the body contact or grooming behaviour. Similarly friendly body contacts were only included in the analysis again if the dyad spent at least 10 seconds in body contact before engaging in grooming.

We assessed how well time matched grooming between two individuals was, both within and across all grooming bouts, by using the grooming equality index (Silk et al. 2013). The grooming equality index takes into consideration the amount each individual within a given dyad groomed the other, returning a score between 1 and 0 , where 1 indicates that grooming between the two individuals is perfectly matched and 0 indicates completely unidirectional grooming between two individuals (for full formula see Silk et al. 2013). We calculated the grooming equality index both across grooming bouts, i.e. taking into consideration all grooming that occur between a given pair of individuals across all their grooming bouts within a given sampling period, and for individual grooming bouts, i.e. taking into consideration only the grooming which occurred between the dyad within a given grooming bout.

\section{Statistical Analysis}

We assessed how well timed-matched grooming was within grooming bouts using a linear mixed model (LMM, Baayen 2008) with a Gaussian error structure. The response variable of the model was grooming received (seconds/log-transformed) by groomer 1 (i.e. the initial groomer) from groomer 2 . The predictor variables were the amount of grooming given by groomer 1 (seconds/log-transformed) and the sampling period (i.e. 07-08, 10-11). Sampling period was included in the model as a predictor variable as it consists of only two levels and therefore could not be included in the model as a random factor. We also included the identity of each groomer (i.e. groomer 1 and groomer 2) as random effects in the model in order to control for individual variation in the tendency of individuals to groom.

We assessed how well timed-matched grooming was within each sampling period using a LMM with a Gaussian error structure. Each groomer in a dyad was assigned as either groomer 1 or groomer 2 alphabetically. The response variable of the model was the grooming given (seconds/log-transformed) by groomer 2. The predictor variables were the amount of grooming given (seconds/log-transformed) by groomer 1 and the sampling period (as above). Again we also included the identity of each groomer as random effects in the model. 
We used a generalized linear mixed model (GLMM, Baayen 2008) with a binomial error structure to assess whether the likelihood that grooming would be reciprocated within the same grooming bout was related to dyadic rank distance or dyadic CSI. The response variable was "is grooming reciprocated during this grooming bout" "yes" or "no". The model included three predictor variables; dyadic rank distance, dyadic CSI and sampling period (as above). As above the identities of each groomer was controlled for as random factors.

We also used LMMs to assess whether the equality of grooming, both within individual grooming bouts and overall across a sampling period, was significantly related to dyadic rank distance and CSI. Each model had a Gaussian error structure. The response variable in the within grooming bouts model was the grooming equality score calculated for each individual grooming bout (unidirectional grooming bouts were not included). The response variable in the grooming across sampling period model was a dyads grooming equality score based on all their observed grooming bouts across the study. Only dyads that were observed to have groomed on at least four occasions during the study were included in the analysis. A cut off of four grooming bouts was based on the analysis of the grooming interactions of a random sample of dyads which indicated that grooming equality scores became reliably stable after 4 or more grooming bouts. The range of the CSI scores of the dyads which remained after this selection procedure was well balanced, range $0.3-7.2$, with $46 \%$ of dyads having a CSI $<=1$. The response variables from both models were left skewed and therefore had to be transformed to match a normal distribution. In order to do this the distribution was first reversed (multiplied by -1 ), creating a right skewed distribution, this right skewed distribution was then square root transformed creating a normal distribution, before finally being multiplied again by -1 to reverse the first reversal of the data. Both models included the same three predictor variables; dyadic rank distance, dyadic CSI and sampling period (as above). Both models were fitted with a Gaussian error structure and the identities of the groomers controlled for as a random factor.

We calculated all the (G)LMMs in R 3.0.1 (R-Core-Team 2013) using the function "Imer" within the R package "Ime4" (Bates and Maechler 2012). We established the significance of each full model by comparing it to a null model (comprising only the intercept and the random effects) using a likelihood ratio test (R function ANOVA with argument test set to "Chisq"). The $p$ values of individual predictor variables in all our LMMs were based on Markov Chain Monte Carlo sampling (Baayen 2008) using the "pvals.fnc" and "aovlmer.fnc" functions found in the "languageR" $R$ package (Baayen 2011). We determined significance of the individual predictor variables in our GLMM based on the $z$ scores and $p$ values provided by the "Imer" function. All appropriate assumptions (i.e. homogeneity of error variances, multicolinearity, over-dispersion) were tested for and met in each model. Seven dyads were identified as influential cases in the LMM assessing 68 
the timed-matching of grooming within each sampling and the LMM assessing influences on the equality of grooming across a sampling period using DFFit and DFBeta scores. These dyads therefore had to be removed from the analysis in order for all assumptions to be met. Their removal did not alter the outcome of the analysis. Finally we calculated $R^{2}$ values for each model using the procedure set out by Nakagawa and Schielzeth (2013) using the "arm" R package (Gelman et al. 2013).

\section{Results}

In total we observed 1187 grooming bouts, 458 during sampling period 07-08 and 729 during sampling period 10-11. The mean length of a grooming bout was 303 seconds. 828 (69\%) of grooming bouts were unreciprocated, i.e. grooming was directed only one-way. Among those bouts in which grooming was reciprocated 59\% consisted of only two grooming episodes, $27 \%$ consisted of three episodes and only $14 \%$ consisting of 4 or more episodes.

Our LMM investigating the relationship between the amount of grooming received and the amount of grooming given within a dyad over the course of each sampling period showed a significant positive relationship between the two variables $\left(X^{2}=33.02, d f=2, p<0.001, R^{2}=0.63\right.$, Table 1). The estimate of the slope of this relationship was 0.52 (Fig. 1) which overall suggest that grooming between individuals was relatively well time matched over the course of each sampling period. However, our LMM examining influences on the equality of grooming exchanged across each sampling period also showed no significant difference between the full and null models $\left(X^{2}=\right.$ $2.44, d f=3, p=0.49, R^{2}=0.21$ ). This indicates that there appears to be no influence of dyadic rank distance or CSI on how equally grooming is exchanged between dyads across each sampling period.

Table 1 LMM examining the relationship between the grooming received (seconds/log transformed) and grooming given (seconds/log transformed) for each dyad across each sampling period.

\begin{tabular}{lcccc}
\hline Predictors & Estimate & Standard Error & t-Value & $p$ Value \\
\hline Intercept & 3.34 & 0.63 & 5.34 & $<0.001$ \\
Grooming Received & 0.52 & 0.08 & 6.27 & $<0.001$ \\
Sampling Period & 0.21 & 0.18 & 1.18 & 0.24 \\
\hline
\end{tabular}




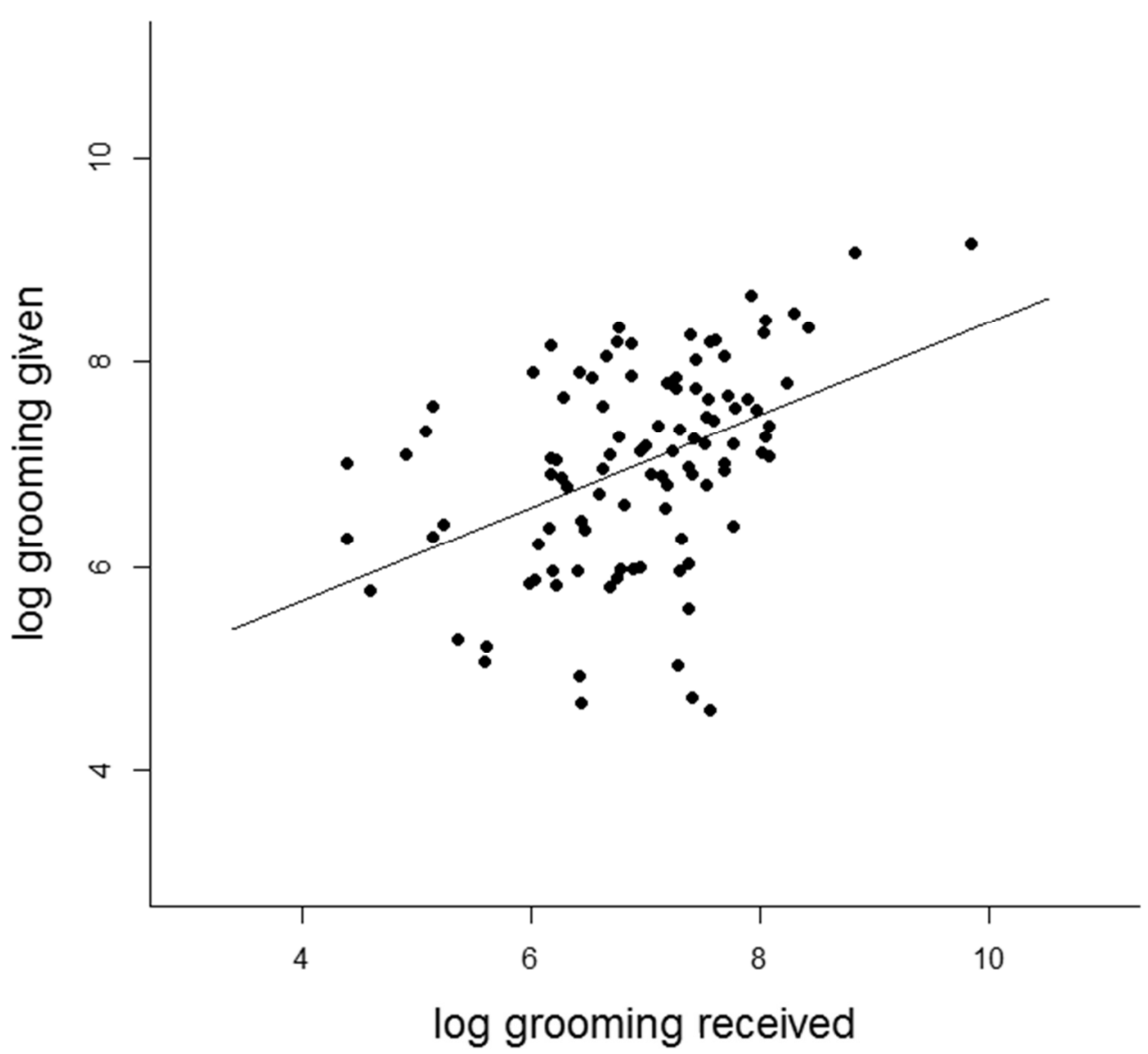

Figure 1. The estimated slope of the relationship between the grooming received (seconds/log transformed) and grooming given (seconds/log transformed) for each dyad across each sampling period.

The LMM investigating the relationship between the amount of grooming returned to a groomer relative to the amount of grooming the initial groomer gave within a reciprocated grooming bouts revealed a significant positive relationship between the two variables $\left(X^{2}=43.39\right.$, $\mathrm{df}=2, \mathrm{p}<0.001, \mathrm{R}^{2}=0.14$, Table 2 ). However, the relatively shallow estimated slope of the relationship (0.30, Fig. 2 ), together with the low $\mathrm{R}^{2}$ for the overall model suggests that grooming was time-matched to relatively low degree within individual grooming bouts. 
Table 2 LMM examining whether the amount of grooming returned is predicted by the amount of grooming given within grooming bouts.

\begin{tabular}{lcccc}
\hline Predictors & Estimate & Standard Error & t-Value & $\boldsymbol{p}$ Value \\
\hline Intercept & 3.62 & 0.26 & 13.85 & $<0.001$ \\
Initial Grooming & 0.30 & 0.05 & 6.46 & $<0.001$ \\
Sampling Period & -0.12 & 0.10 & -1.24 & 0.21 \\
\hline
\end{tabular}

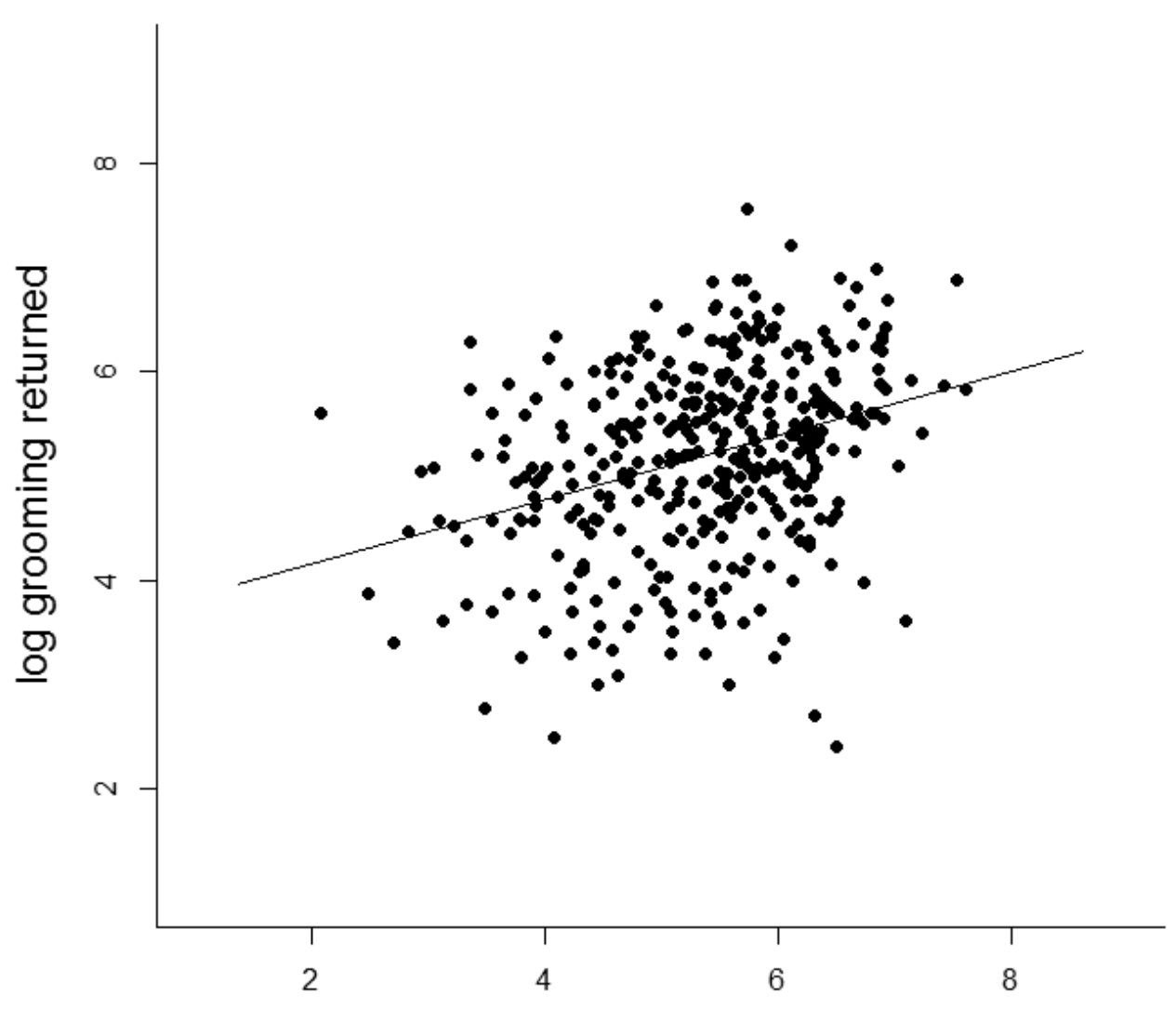

log initial grooming

Figure 2. The estimated slope of the relationship between the grooming returned to the initial grooming (seconds/log transformed) and the initial grooming that they gave (seconds/log transformed).

Our GLMM examining the likelihood that grooming will be reciprocated within the same grooming bout was significantly different from the null model $\left(X^{2}=10.52\right.$, df $=3, p<0.05, R^{2}=$ 0.09). While rank distance was found to have no significant influence on the likelihood that grooming would be reciprocated within an individual grooming bout, a dyads' CSI showed a positive trend with the likelihood of reciprocation, that is the higher the dyad's CSI the more 
likely they are to reciprocate grooming within a grooming bouts (Table 3 ). However the $R^{2}$ for the model is extremely low which suggests this may not be a meaningful relationship.

Table 3 GLMM examining predictors influencing the likelihood of grooming being reciprocated within an individual grooming bout

\begin{tabular}{lcccc}
\hline Predictors & Estimate & Standard Error & z-Value & $p$ Value \\
\hline Intercept & -0.68 & 0.23 & -2.98 & $<0.01$ \\
Rank Distance & -0.02 & 0.03 & -0.86 & 0.39 \\
CSI & 0.08 & 0.05 & 1.68 & 0.09 \\
Sampling Period & -0.33 & 0.15 & -2.18 & $<0.05$ \\
\hline
\end{tabular}

Finally, our LMM examining influences on the equality of grooming exchanged within a reciprocated grooming bout was not significant difference from the null model $\left(X^{2}=3.03, d f=3, p\right.$ $\left.=0.39, R^{2}=0.05\right)$. This indicates that neither dyadic rank distance nor CSI appear to have an influence on how equally grooming is exchanged within an individual grooming bout.

\section{Discussion}

Overall our results indicate that female Assamese macaques have balanced grooming relationships with the other females in their group. This balance is not maintained by the immediate reciprocation of grooming, but appears to be achieved over a longer time frame. In addition, our results indicate that social relationship strength does not influence either how equitably grooming is exchanged between individuals or the time frame over which grooming is exchanged.

As predicted based on our previous findings, grooming appears to be exchanged for itself in a relatively well timed matched manner by females in this group. The estimate of the slope of the relationship between the amount of grooming given and the amount of grooming received across a sampling period was 0.53 , i.e. overall grooming among females was not perfectly time matched, but perfectly matched relationships are rarely seen. A certain amount of error is expected as it is often simply not possible to observe and record every grooming bout that occurred between all dyads throughout the duration of a study. In addition, a certain amount of error is likely to be created due to the fact that it is often not possible to know precisely the time frame over which grooming reciprocated, e.g. a day, a week, a month, a year etc. (unless of course there is evidence that grooming is largely reciprocated immediately). There is also always the possibility that some portion of the grooming may be being traded for another unanticipated 
service. Given these limitations we would argue that overall the grooming among the females in our study population is relatively well balanced.

All female social relationships within our study group were characterised by equality in the exchange of grooming, regardless of their strength. In this respect they differ from those of other primates, specifically female baboons (Silk et al. 2006a; Silk et al. 2010b) and male chimpanzee (Pan troglodytes) (Mitani 2009). In these species the strength of the social relationship between two individuals is positively related to the equality of their grooming exchange, therefore in these species it is concluded that strong social relationships are more equitable than weak social relationships. There are potentially several reasons for the differences between these findings. For example, it is possible that they may result from methodological differences between these studies. In our analysis care was taken to only include dyads that had been observed grooming often enough that a reliable equality score could be obtained. No such precautions are described by Silk et al (2006a; 2010b) or Mitani (2009). Therefore it is possible that the relationship found between relationship strength and grooming equality is the result of biased equality scores calculated from too few observations of interactions of dyads with weaker social relationships. Alternatively, the differences between these findings may represent a difference in the role of equality in the social relationships of these species. This opens up the question, why then would male chimpanzees and female baboons in weak social relationships tolerate inequality in their grooming exchanges. Individuals from other species have been found to make use of simple partner control mechanisms which appear to prevent such inequality (Connor 1995; Barrett et al. 2000). It is possible, that among female baboons and male chimpanzees individuals with weak social relationships exchange grooming for a different service, while individuals with stronger relationships focus on exchanging grooming for itself. This would contrast with reports of human social relationships where the exchange of one service for the same service is a characteristic of weaker social relationships, while among strong social relationships more varied service tend to be exchanged (Clark 1981; Törnblom et al. 2012). Ultimately, further work is required before we can conclude whether the equality we see among all strengths of social relationships in female Assamese macaques is the exception or the rule among primates and other species.

Our observations of the individual grooming bouts suggests that the equality in the exchange of grooming among females in this group is not achieved through immediate reciprocation, but rather exchange over a longer time frame. The majority of grooming bouts (69\%) were completely unreciprocated. Among those bouts in which some grooming was immediately reciprocated the time matching of the grooming given and received was found to be poor. It has been suggested previously that among primates immediate reciprocation of 
grooming is essential for the maintenance of social relationships (Henzi et al. 1997). Parceling, the breaking down of grooming into small reciprocated sections within an individual bout (Connor 1995), has been described as an important feature of this immediate reciprocation (Barrett et al. 2000; Payne et al. 2003; Pazol and Cords 2005). Our results add to a growing number of studies which show that while this may be true in some species, it does not appear to be true for all (Manson et al. 2004; Gomes et al. 2009; Schino et al. 2009a). Indeed there appears to be an extremely wide range of variation in the proportion of grooming bouts which are immediately reciprocated among different species of primates. For example Manson et al. (2004) report immediate reciprocation in only $5-7 \%$ of grooming bouts observed in two groups of bonnet macaques (Macaca radiata), while among sooty mangabeys (Cercocebus atys), $97.8 \%$ of grooming bouts were reported to be immediately reciprocated (Fruteau et al. 2011a). We currently have no good explanation of what drives this variation. It is possible, that variation in the general strength of social relationships within a group may explain some of these interspecies differences. For example, we know that in one population of chacma baboon (Papio cynocephalus ursinus), in which the proportion of grooming bouts which are immediately reciprocated is relatively high (Henzi et al. 1997), female social relationships appear to be in general weak and unstable, changing cyclically depending on the availability of food (Henzi et al. 2009). In turn, the relatively low proportion of immediately reciprocated grooming in female Assamese macaques may be related to the strong and stable social relationships females form with other females in their group (Macdonald et al. to be submitted). If an individual's grooming interactions occur regularly with the same subset of individuals over time there may be less of a need for immediate reciprocation as the chances that you will groom again with this same individual are extremely high. Further studies on a wider range of species would be required to establish whether such a pattern is common for primate in general.

Finally, unlike humans (Clark and Mills 1979; Clark and Waddell 1985; Shackelford and Buss 1996; Komter and Schans 2008; Törnblom et al. 2012; Xue and Silk 2012), variation in the strength of the individual social relationships of the females in this group appears to have little influence on the time frame of grooming reciprocation. A positive trend between the strength of social relationships and the likelihood of grooming being immediately reciprocated within the same bout was found (Table 3), which suggests that the stronger the social relationship between two individuals the more likely it is that they will reciprocate grooming immediately, going against our prediction. However, given the extremely low value of the $\mathrm{R}^{2}$ for the overall model it seems unlikely that this trend is meaningful. In addition, the equality of the exchange of grooming within those grooming bouts during which some grooming was immediately reciprocated was not predicted by the strength of the relationship between the individuals 
involved. Therefore, overall our results indicate that equality in all female Assamese macaque social relationships is maintained through the long term exchange of services regardless of their strength. As a result social relationships among female Assamese macaque do appear to share this important characteristic of human social relationships (Rook 1987; Clark and Ayers 1993; Walker 1995; Horwitz et al. 1996; Hendrix 1997; Komter and Schans 2008). What makes Assamese macaque social relationships unusual relative to human social relationships is that weak social relationships also appear to maintain their equality through long term exchange. It could be argued that this may indicate that all relationships among the females in this group are strong enough that a delay in exchange was considered relatively safe. Among macaques females are born and grow up together in their natal groups, therefore it could be argued that no relationship between any given pair would be so weak as to be equivalent to those the strangers of acquaintances examined in studies of human social relationships (Clark and Mills 1979; Clark and Waddell 1985; Shackelford and Buss 1996; Komter and Schans 2008; Törnblom et al. 2012; Xue and Silk 2012). However, this is also true for many primate species where grooming has been shown to be almost always immediately reciprocated (see above), which suggests that among these species at least knowledge of each other as group members is not enough to allow nonimmediate reciprocation of grooming. Again, further work is required investigating both variation in the immediate reciprocation of grooming and the influence of relationship strength on grooming exchange before we can fully establish the commonality and differences between nonhuman and human social relationships in terms of this characteristic.

\section{Acknowledgements}

We thank the National Research Council of Thailand (NRCT) and the Department of National Parks, Wildlife and Plant Conservation (DNP) for permission (No. 0004.3/3618; $0002.3 / 2647$ ) to conduct this study. All data collection adhered to the legal requirements of Thailand. We are grateful to J. Prabnasuk, K. Nitaya, M. Kumsuk, and K. Kreetiyutanont (Phu Khieo Wildlife Sanctuary) for their cooperation and permission to carry out this research. We thank A. Koenig and C. Borries (Stony Brook University), who developed the field site at Huai Mai Sot Yai. We also thank N. Bhumpakphan, W. Eiadthong (Kasetsart University), and W. Brockelman (Mahidol University). We are very thankful to all members of team macaque, N. Juntuch, $\mathrm{N}$. Ponganan, D. Bootros, A. Chunchaen, S. Jomhlotwong, T. Kilawit, T. Wisate, P. Saisawatdikul and especially M. Swagemakers for their help in the field. We are also very grateful to W. Nuagchiyo, M. Heesen and S. Rogahn for their help with data collection. We thank F. Nowak and M.Heesen for their helpful comments. Support was provided by the Max Planck Society, the National Geographic Society and the German Initiative of Excellence to the University of Göttingen 



\section{Chapter 4}

\section{Primate Social Networks}

Sally Macdonald ${ }^{\mathrm{a}} \&$ Bernhard Voelkl $^{\mathrm{b}}$

${ }^{a}$ Primate Social Evolution Group, Courant Research Centre Evolution of Social Behaviour, Georg-August University, Göttingen, Germany.

${ }^{b}$ The Edward Grey Institute, Department of Zoology, Tinbergen Building, University of Oxford, Oxford, United Kingdom.

In Animal Social Networks: Perspectives and challenges, eds. Krause, J. Croft, D.P. and James, R., Oxford: Oxford University Press. (in press) 



\section{Abstract}

The order of primates shows a remarkable variety in social organization, making it appear almost predestined for social network analysis (hereafter termed SNA). It may also be one of the reasons why primatologists were the first to apply SNA to animal social behaviour. Yet, despite being ripe with opportunities SNA of primates has developed relatively slowly, remaining for most of the part the speciality of a small subset of researchers. As a consequence the goal of this chapter is twofold. First, we want to give a brief summary of the history of SNA in primatology and to discuss in general what we can learn from primatologists' experience with SNA so far. Second, we want to highlight some outstanding questions and problems and by doing so suggest some potentially fruitful applications of SNA in primatology. The chapter is broken down into five sections. The first gives a brief introduction to why SNA is potentially useful for primatologists. The second reviews the history of SNA in primatology to date. The third section discusses how the various levels of SNA can, and have been, applied to primates, while the fourth section takes a look at some of the potential pitfalls and limitations of a network perspective in primatology. Lastly we finish with a tentative sketch of how SNA in primatology may look in the future. 



\section{Why is SNA useful for primatologists?}

The primate order is incredibly diverse. There are currently over 370 recognised species (2005) each of which can vary enormously. In terms of body mass primates can range from around 30g, the Madame Berthe's mouse lemur (Microcebus berthae), to over $200 \mathrm{~kg}$, male Eastern and Western Gorillas (Gorilla beringei, Gorilla gorilla). They make use of extremely varied habitats, from dense rain forests and open savannas to snow covered mountains and arid semideserts, and exploit a huge array of food sources including leaves, fruits, insects, meat, gum, nuts, and roots amongst others (Napier and Napier 1997). But perhaps of greatest interest here is the extreme variety that exists in primate social systems, ranging from the almost completely solitary, Aye-aye (Daubentonia madagascariensis, Sterling 1993), to the complex, multi-level communities of up to 1000 individuals found in Gelada baboons (Theropithecus gelada, SnyderMackler et al. 2012). Analysis and comparisons of this social variation is challenging, even when dealing with a smaller sub-set of the wider range of this variety (Aureli et al. 2008). The SNA approach provides primatology with a new perspective and a new set of tools for approaching these problems.

In applying SNA to primate social behaviour we are taking an approach developed to study the social lives of a very specific primate, Homo sapiens, and broadening it to study the social lives of their closest relatives. Unfortunately we cannot confront non-human primates -or any other animals for that matter- with questionnaires to provide us with the data we need, so we must rely on behavioural observations. Thankfully primates display many different social behaviours which are suitable for network analysis, for example grooming (Sade 1965; Flack et al. 2005; Lehmann and Boesch 2009; MacIntosh et al. 2012), copulations (Cheney 1978a; Lehmann and Ross 2011), displays of aggression and submission (Lehmann and Ross 2011; Flack 2012; Brent et al. 2013a), play (Cheney 1978b; Flack et al. 2006), co-feeding (King et al. 2011), etc.. While the collection of such data is certainly more time consuming (direct observations of behaviour taking much longer to gather than self-report questionnaires) most of these behaviours are easily observed and avoid some disadvantages associated with self-report data. So much so that, as an interesting side-note, we are beginning to see a trend in human studies towards automated behavioural sampling -dubbed "reality mining"- which brings the methods of human and animal network research closer together (Krause et al. 2013). We may never manage to match social scientists in terms of the precision with which they can fine tune their analysis of human social behaviour, but within animal network research primatologists are fortunate in having a larger range of behaviours to work with. Researchers working on other species generally have much more limited options. More importantly, these options often differ not only in quantity but in quality, as many researchers are often forced to base their analysis purely on 
association data alone, e.g. in ungulates (Wittemyer et al. 2005; Sundaresan et al. 2007; Stanley and Dunbar 2013) or cetaceans (Williams and Lusseau 2006; Lusseau 2007). From these associations social relations between animals are then inferred, the argument being that if two individuals spend significantly more time in close proximity to each other than to others, then one can assume some sort of social bond between them. This reasoning may be correct, but it is ultimately only indirect evidence of a relation. Primatologists, on the other hand, can build their networks upon observations of direct interactions (grooming, copulation, aggression etc.). These interactions directly signify a relation between individuals: if two individuals groomed each other, then we can state that they have a 'grooming-relationship' and as such these networks are relationship networks based on direct evidence.

With these networks in hand primatologist can then begin to explore the wide range of analysis SNA has to offer. One of the most widely lauded benefits of SNA is the ability to look beyond the prospect of a single dyad and consider the interactions of individuals (or even subgroups of individuals) within the context of their entire group. This could help primatologists addressing questions about the role of matrilines in determining the social structure of a group, how dominance relates to the integration of individuals into a groups social structure, or whether an individuals' positions in the social structure puts them at a higher risk for diseases. Another commonly praised benefit of SNA is its ability to provide quantitative replacements for verbal classifications of social style and structure. Among primatologist this could help identifying subtle sub-groupings with larger groups or valuable measures of more subtle gradients in species apparently displaying very similar social structures. SNA also has the potential to provide primatologists with an interesting new perspective for phylogenetic comparisons via a range of measures which summarise overall group structure in a variety of ways. These same measures can also be used to make comparisons within species, for example to examine how ecological factors affect the social interactions and structure of the same species at different sites.

\section{A brief history of SNA in primatology}

For many primatologist this apparently new approach of SNA may seem rather familiar. There is a feeling that they have seen a lot of what SNA has to offer before, and to a certain extent this feeling is justified. SNA, or at least some of the elements of SNA, have been around in primatology for a long time. However, a recent surge in computational power and production of ready to use software has now made SNA a much more interesting and accessible tool. In this section we provide a brief history of SNA in primatology in the hope of providing a useful insight into the roots of SNA in primatology and also help primatologists to identify recent changes and developments which might make SNA useful for them today. 
During the 60 's to the mid 70's it became clear that the social structures of non-human primates were much more complex than had previously been suspected. As a result, researchers began to consider whether adapting the concepts and methodologies of the human social science may be both appropriate and necessary to fully understand these non-human primate "societies" (Sade 1972; Hinde 1976). SNA, a thriving field in the human social sciences at this time, appeared to provide the perfect template from which to work (Brent et al. 2011a). One of the first, and most widely adopted, SNA methods used was the sociogram. These useful diagrams allowed primatologists to visualise their observations of the social interactions between individuals within a group. In particular they allowed them to clearly display specific patterns in these interactions that might otherwise be hard to spot. Perhaps the first student of animal behaviour to make use of these diagrams was Hans Kummer (1957) in his detailed study of the social organisation of Hamadryas baboons (Papio hamadryas). Kummer made extensive use of sociograms (Figure 1) throughout this and subsequent studies (e.g. Kummer 1968), to document the structural development of the one male units, as well as changes in the interactions between males and their females during various phases of their reproductive cycle. He would later describe with enthusiasm how he first came to use this tool:

"At first I was most fascinated with the "social structure" of the group. But what that actually was, and how it could be studied, neither my zoology teachers nor the ethological textbooks could tell me. I worried for weeks about this question. The one thing that was clear was that primates -monkeys and apes- treat one another as individuals and not as interchangeable members of a class, as happens among ants and termites, in schools of fish, or in enormous bird colonies. Eventually I thought I had found a solution: by diagramming how often each group member directed a particular signal at each other member, and by doing that for every signal, whether aggressive, caring, sexual, or playful, I must ultimately obtain a picture of the network of social relationships in the group. The complete diagram would then show, for instance, whether Pasha had a sexual preference for one female and whether lower-ranking mothers really punish their children more often than higher-ranking ones. Friendships and enmities would surely be revealed in the graphic network. So that is what I did" (Kummer 1995, page 37).

Unfortunately Kummer published his first report in German, in a supplement to the Swiss Journal of Psychology -a journal, perhaps not closely monitored by primatologists or animal behavioural researchers. 

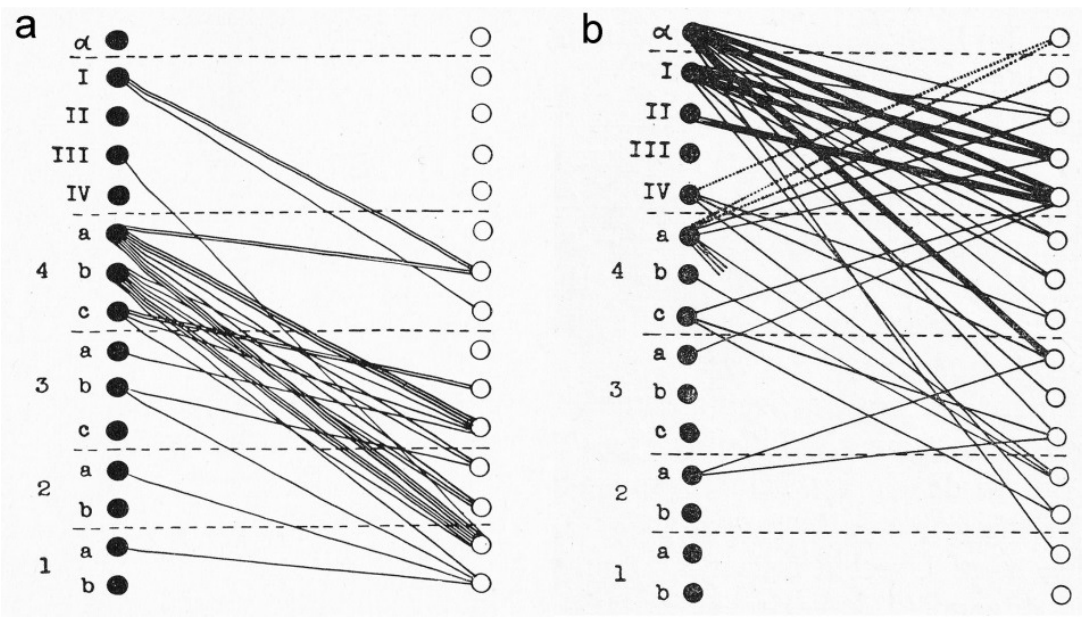

Figure 1: Sociograms for a groop of Hamadryas baboons for (a) 'embracing' and (b) 'brow-lifting' (right). Each line represents one individual: the left side (full circles) shows the individuals as actors, the right side (open circles) as receivers of the behaviour. Reproduced from Kummer (1957): "Soziales Verhalten einer Mantelpavianen-Gruppe." Schweizerische Zeitschrift fuer Psychologie. Beiheft 33: p23 and 40 with friendly permission from Huber Verlag.

In 1965 Donald Sade also began to use sociograms, seemingly independent of Kummer, to visualise the grooming interactions among a free ranging group of rhesus macaques (Macaca mulatta). He used his diagrams to illustrate how grooming relations in the group were focused mainly among related individuals and in particular how the grooming relationships between a mother and her offspring remained strong even once the offspring was fully mature -both novel insights at the time. It is not clear, at which point Sade got to know Kummer's earlier work -there is no reference to Kummer in (Sade 1965), but in a later study (Sade 1972) Kummer's work is cited. After these initial publications and through the influential books by Wilson (1975) and Hinde (1983) sociograms became an increasingly popular way to display all kinds of social interaction data (Ploog et al. 1963; Soczka 1974; Cheney 1978a; Cheney 1978b) before becoming gradually less common in the early 1990's.

Another SNA tool (though not always recognised as such) which became popular among primatologist in the $80^{\prime}$ s and early 90's was cluster analysis. Like sociograms, cluster analysis provided useful diagrams, such as dendrograms, which could be used to display sub-groupings, i.e. clusters, within a group of individuals based on a specific behaviour of interest. However, in addition to being a means of displaying grouping patterns, clustering analysis is also a technique for identifying clusters of more closely connected individuals within a social group. Cluster analysis was mostly used to look for patterns in association data (Chapman 1990; Corradino 1990; Yeager 1990) and grooming data (Chepko-Sade et al. 1989; Byrne et al. 1990) and proved useful for identifying subtle patterns of sub-grouping which otherwise might have been missed. However, there remains a certain arbitrariness in the technique when it comes to determining 
the boundaries of these clusters. As a result different algorithms can produce very different groupings (Scott 2000; Whitehead 2008), and this in turn has led to cluster analysis to fall in and out of fashion over time.

For most primatologists these two methods were the only brushes with SNA at this time. The one major exception to this was Donald Sade and his colleagues. After being one of the first among primatologist to make use of sociograms, Sade went on to write/co-write a series of four interconnected papers which investigated the utility of several SNA measures for the study of primate social structure (Sade 1972; Sade et al. 1988; Chepko-Sade et al. 1989; Sade 1989). His work focused specifically on the social structure and grooming behaviour of a colony of free ranging rhesus macaques living on the island of Cayo Santiago. He made use of a range of different SNA methods and measures, including sociograms, n-cliques (Sade 1972) and clustering analysis (Chepko-Sade et al. 1989), however, the measure which seemed to interest him most was a measure of centrality referred to as "n-path" centrality (Sade 1989) . Like modern eigenvector centrality, n-path centrality calculates an individual's centrality based not only on their own direct connections within the network but also their indirect connection, i.e. the connections of the individuals, individuals are connected to. Sade described the measure as follows:

"Consider the two hypothetical sociograms in table II [here reproduced as Figure 2]. Using grooming statues based on one-step links...it would appear that monkeys $b$ and $d$ have equal status, since each is groomed by one individual. However, the monkey who grooms b is himself groomed by 3 monkeys, but the monkey who grooms $d$ is only groomed by one monkey. Therefore monkey $b$ should be assigned higher grooming status than monkey $d$ because $b$ is chosen by $a$ monkey with higher status than the monkey who chooses d." (Sade 1972).

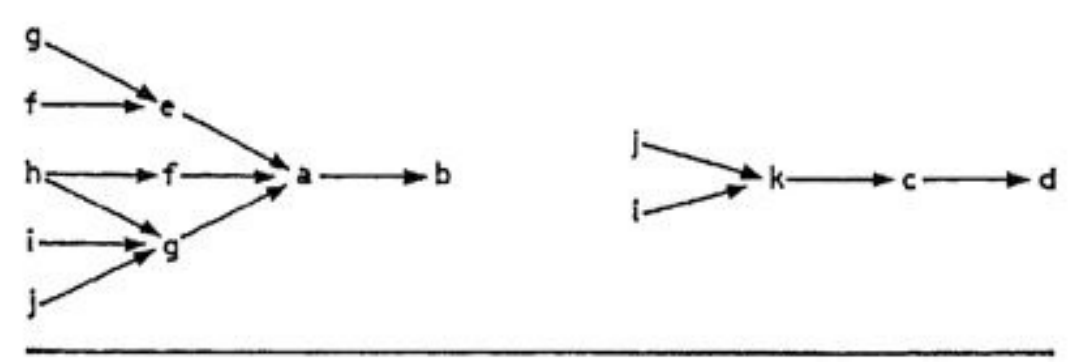

Figure 2: Hypothetical grooming networks. Reproduced from Sade (1972): "Sociometrics of Macaca mulatta I. Linkages and cliques in grooming matrices." Folia Primatologica 18, p. 202, table II with friendly permission from John Wiley \& Sons Inc. 
This example describes "2-path" centrality, as it takes into account two sets of links or "paths", the links that exist between the first individual and other group members and the links between those individual(s) and the rest of the group. Sade went on to investigate the centrality of individuals based on 1 to 3-paths (Sade 1972), later extending this up to 15-paths (Sade 1989), arguing that by increasing the length of the path used to calculate centrality scores one could increase the variation in the scores and therefore better distinguish between the different statuses of individual monkeys. However his analysis in fact showed that while there was a clear increase in the variation of score using 2-paths and 3-paths compared to 1-path there was little increase in the variation of scores using path lengths longer than this. He later went on to use 3path centrality scores to show, what many researcher might intuitively have expected, that in rhesus macaques higher ranking individuals are more central, i.e. more integrated rather than physically central, in their social grooming networks (Sade 1972).

Overall Sade had hoped that these new measures would help primatologists move away from what he believed to be an intuition based analysis of social structure to more objective, comparable methods. However he also admitted that these new methods could be, at this time, computationally burdensome to perform (Sade 1989). And unfortunately, despite successfully attracting interest from those studying human social networks, in the form of a dedicated session on non-human primate networks at the 1988 Sunbelt Social Networks Conference, and a subsequent special issue of the journal "Social Networks", SNA methods would play only a very marginal role in the analysis of primate social behaviour until the beginning of the $21^{\text {st }}$ century.

In 2006 SNA returned to primatology with something of a bang, in the form of a now widely cited study by Jessica Flack and colleagues (Flack et al. 2006). In this study Flack and colleagues used four different network measures (degree, reach, assortativity and mean clustering coefficient) to examine the effect of removing the three highest ranking males from a group of captive pigtailed macaques (Macaca nemestrina) on social networks of grooming, play, contact-sitting and proximity. They were able to show that the removal of these high-ranking males affected the social networks more severely than predicted by simulated removals. From this point onwards a new surge of studies embracing a SNA approach began to appear. While many of these studies focused on what could be considered the traditional topics addressed by SNA, i.e. describing social relationships/structures and their potential functions in primate groups (Sueur and Petit 2008; Henzi et al. 2009; Kasper and Voelkl 2009; Lehmann and Boesch 2009; Lehmann and Dunbar 2009; Ramos-Fernández et al. 2009), many others went on to make use of the network approach to address a broader range of less conventional topics including social learning and information flow (Voelkl and Noë 2008; Franz and Nunn 2009; Franz and Nunn 2010; Hoppit et al. 2010; Kendal et al. 2010; Voelkl and Noë 2010), the influence of social structure on 
cooperation (Voelkl and Kasper 2009; Voelkl 2010) and the welfare of captive groups of primates (McCowan et al. 2008; Beisner et al. 2011a; Clark 2011; Dufour et al. 2011).

\section{Levels of Analysis}

SNA can be split up into three broad levels of analysis; the individual (nodal) level, the sub-group level and the group level. The question of which level of analysis to use usually goes hand in hand with the question of its purpose. In this section we will take a brief look at what analysis can be done at each of these three levels and how it can be of use to primatologists in particular.

\section{Individual level}

The individual level, sometimes also referred to as the nodal level, is where SNA is used to ascribe certain 'nodal properties' to an individual animal. As such this is the level of analysis that allows you to consider an individuals' social position within a group beyond the level of its dyadic interactions, by incorporating its interactions with the group as a whole. This can be done using a single network metric such as a centrality measure or a clustering coefficient, or a list of several different nodal network measures. In the latter case it has been suggested that these measures could even be summarised to form a personality profile for each individual (Crofoot et al. 2011). The purpose of such an individual based approach is usually to correlate these nodal network measures with other biological characteristics of the individuals such as sex, age, social rank, and 'personality scores' (Sade 1972; McCowan et al. 2011; Tiddi et al. 2011), reproductive success (Brent et al. 2013a), parasite load (Maclntosh et al. 2012), or physiological measurements such as fecal gluco-corticoid levels (Brent et al. 2011b). Sade (1972) was one of the first to use nodal measures in this way to show that higher ranking female rhesus macaques were more integrated into their grooming network than lower ranking females. This finding has recently been replicated in a broader study of macaque social structure (Sueur et al. 2011b). The study used eigenvector centrality scores to investigate how female rank was related to female integration into a social network based on body contact (i.e. grooming and contact sitting combined) in 12 groups of macaques from four different species. Their results showed that in socially "intolerant" species of macaques, such as rhesus macaques and Japanese macaques (Macaca fuscata), high ranking females were significantly more central, i.e. more integrated, in the social network than lower ranking females. However the same pattern was not found in two more socially "tolerant" species of macaques, Tonkean macaques (Macaca tonkeana) and crested macaques (Macaca nigra) suggesting a potentially interesting link between social style and network structure in this genus. 
Nodal network measures have also been used to investigate the heritability of social traits in primates. In a seminal study Brent and colleagues (2013a) appeared to show that betweenness and eigenvector centrality of the grooming network, out-strength of the aggression network and eigenvector centrality of the proximity network of the rhesus macaques at Cayo Santiago Island had a significant additive genetic component. An additional quantitative genetic analysis suggests further a correlation between eigenvector centrality for grooming and the genetic variation at two loci involved in serotonergic signalling, hence this is the first study to link genes with nodal network measures.

\section{Subgroup level}

The purpose of analysis at the subgroup level is usually to better understand how a given group is structured, by identifying clusters or subgroups within it, and to identify how these subgroups are connected to each other. This identification process is often referred to as subgroup or community detection (Dow and deWaal 1989; Matsuda et al. 2012). A nice example of this level of analysis in primatology comes from Snyder-Mackler et al. (2012) who studied the multilevel societies of Gelada baboons, which consist of two or more nested levels of organization: one male units, teams, bands, and communities. While the multiple levels of gelada society were described decades ago and are generally accepted, no operational definition existed for the higher levels, i.e. levels above the one-male unit. Making use of clustering analysis methods, the authors were able to find a significant discontinuity at the $50 \%$ association level in their study groups, indicating a sharp distinction between members of the same band and members of the same community, allowing them to provide a meaningful delineation between these two levels of gelada society.

Using hierarchical cluster analysis Zhang and colleagues (2012) could also nicely demonstrate the multi-level character of snub-nosed monkey bands (Rhinopithecus roxellana). Based on a simple ratio association index, using proximity data, they were able to identify nine discrete one male units, in a band of 58 individuals. All members of a one male unit were frequently seen within one meter of each other. Females could also occasionally be seem in close proximity to females from other units, however males were virtually never seen in close proximity to any member of another males' unit. Based on this and sex differences in eigenvector and betweenness centralities, Zhang et al (2012) argued that lactating adult females play a more important social roles than males in connecting the one male units. Contrasting to these results spider monkeys (Ateles geoffroyi) studied by Ramos-Fernandez and colleagues (2009) form groups were usually young males have high centrality scores, and as such appear to act as brokers tying sub-communities together. 
Another useful measure for primatologists at the sub-group level is community modularity. This measure gives an indication of how fragmented a given group is by examining the frequency at which interactions occur within or between subgroups. For example, Sueur et al (2011c) used community modularity to examine how frequently matrilines within different species of macaques interact. They were able to show that "intolerant" species of macaques had significantly higher modularity scores than more "tolerate" species, indicating that intolerant species of macaques concentrate their interactions more within their matrilines than more tolerant macaques. And Beisner and colleagues (2011b) made use of community modularity as a measure of the degree of sub-grouping within matrilines of rhesus macaques. Each matriline was partitioned into all potential arrangements of sub-groupings and community modularity scores were calculated for each sub-grouping arrangement. The arrangements which lead to the highest modularity scores, i.e. the strongest within sub-group interactions and the weakest between subgroup interactions, were chosen. Based on these arrangements the authors were then able to show that the number of sub-groups and the degree of modularity found within matrilines were significantly related to relatedness within those matrilines. That is as relatedness within a matriline decreased the number of subgroups found within the matriline increased, as did the modularity score of the matriline, indicating that these matrilines as a whole were becoming less cohesive.

The sub-group level of analysis can also prove useful for researchers interested in the flow of information, parasites, or disease within a group. For example, Voelkl and Noë (2008; 2010) used simulations of social learning to show that the predicted flow of socially transmitted information can be significantly altered by the social structure of a group. They found that the expected average path length of a transmission process is clearly determined by the community modularity of a group, that is the greater the modularity of a given group the longer the average path length. This clearly shows the importance of incorporating social structure into any predictions of the spread of social information. A similar simulation approach was used by Griffin and Nunn, to show that a stronger subdivision of larger social groups should slow the spread of infectious diseases (Griffin and Nunn 2012; Nunn 2012).

\section{Group level}

The purpose of group level analysis -sometimes referred to as population level analysis- is normally to either compare the properties of different groups or the properties of the same group over different periods of time. The measures used for this sort of analysis are usually either graph-wide measures which describe a property of the whole network -e.g. graph density-, or moments of the distribution of nodal measures like the skewness of the degree distribution or 
edge weight disparity. Group level analyses have been made for different purposes: for descriptively summarizing the structural characteristics of a specific study group (e.g. Sade 1965), for detecting temporal changes -either seasonal long term changes (McCowan et al. 2008; Henzi et al. 2009; Ramos-Fernández et al. 2009; Brent et al. 2013b; Macdonald et al. to be submitted), short term changes due to a specific event, such as individual migration events (Flack et al. 2005; Lehmann and Boesch 2009; Barrett et al. 2012) or habitat changes (Dufour et al. 2011), for comparing different study groups of the same species (Beisner et al. 2011a; Crofoot et al. 2011), or for comparing the group structure of many different species (usually in meta-analyses, e.g. Kasper and Voelkl 2009; Lehmann and Dunbar 2009; Lehmann et al. 2010; Sueur et al. 2011b; Matsuda et al. 2012).

The group level of SNA opens up new interesting perspectives for phylogenetic comparisons. Primates are a well studies group, with a considerable number of species currently being studied, in some case at multiple sites and for several years or even decades. As a result it is entirely possible to construct networks based on the same behavioural categories (e.g. grooming, associations, aggression) for many different species. So far only a few broad comparisons have been attempted; one covering a wide range of primate species (70 groups from 30 different species, Kasper and Voelkl 2009) and another which focused more specifically on macaques (12 groups from 4 different species, Sueur et al. 2011b). In another study Lehmann and Dunbar (2009), examined the relationship between neo-cortex size and social network structure across 11 different primate species. They found that neo-cortex size appears to be negatively correlated with the density and fragmentation of social networks in these species, i.e. the larger the neo-cortices the sparser and more fragmented these networks appear to become. These have all been rather rough initial comparisons with relatively modest sample sizes which may not allow for sensible estimates of within species variance of network measures, and as such there remains a lot of potentially interesting work to be done.

In group level analysis the unit of measurement is the group, thus for studies focusing on a single group the sample size is one. Significance tests are therefore often made with randomization procedures, comparing the observed network metric against a distribution of metrics from randomized networks with the same number of vertices and edges. Yet, the question whether a random network is really a plausible null assumption remains open for now. Intra-specific comparisons of several groups still suffer from relatively modest sample sizes, while large scale inter-specific comparisons come along with the usual problems of meta-analyses (mainly questions of how comparable methods and study designs were between studies). Nevertheless, group level analyses are among the most common network analyses in 
primatology and even in studies that focus on the individual or subgroup level researchers will usually also give some group level summaries of their study groups.

\section{Potential pitfalls and limitations in primate networks}

Compared with other animal social network research, the problems facing studies of primate social networks are in no way special or distinct. There are, however, a few of these general problems which are especially prominent in primatology.

\section{Group size}

Most primate groups are relatively small, which can be a serious limiting factor for certain network measures. While there are a few primate species where group sizes can reach, or even exceed a hundred individuals (e.g. macaques, baboons, mandrills, or snub-nosed monkeys), a comparative study by Kasper and Voelkl (2009), based on published socio-matrices from 70 primate groups from 30 different species, has shown that most primate groups consist of just a dozen or so animals. Group sizes were found to range from 4 to 35 , with a median group size of 9 and an inter-quartile range of $6-16$ individuals. These numbers were close to those found during a rough literature survey of 184 primate species that suggested a median group size for freeliving primates of 9 animals with an inter-quartile range of $4-20$. Such small group sizes can severely limit the scope of a social network analysis, as several metrics show little variation for small groups. For example, community modularity (Newman and Girvan 2004) is a measure defined between zero and one, but if we take 1000 random graphs with $\mathrm{N}=9$ and a density of 0.73 (the observed average density for primate grooming networks) we get community modularity scores ranging only between 0.03 and 0.04 . Likewise clustering coefficient, reach, or characteristic path length will also vary only little for small networks. This problem can be amplified by the dense nature of most primate social networks. In particular networks built on association data are prone to high densities (if one just waits long enough one might see even the biggest rivals close together for a short time) to the point that most group members are directly connected with each other, though some perhaps just very weakly. This reduces variation even further, especially for binary network measures. The problem can be less severe for certain interaction networks, like grooming, though a median density of 0.75 for socio-positive interactions (Kasper and Voelkl 2009) or 0.73 for undirected grooming networks and 0.51 for directed grooming networks ( $\mathrm{N}=77$, Kasper and Voelkl, unpublished data) can still be considered as relatively dense in comparison to the sparse networks reported elsewhere. The recent surge in the development of weighted networks measure goes some way to help combat these problems. 
However researchers should still take time to consider, even when using weighted measures, whether the network measure they wish to use makes sense given the size of their network.

\section{Observation frequency}

Students of animal behaviour usually infer relationships between individuals based on observed interactions between those individuals. As they repeatedly observe the same animals, they can take these repeated observations to quantify the strength of the relationship, i.e. the weights of the edges in such networks. This gives rise to a different problem, the reliable estimation of the edge weights (for discussion of edge weights in this context see e.g. Whitehead 2008; Kasper and Voelkl 2009; Sundaresan et al. 2009; Perreault 2010; Voelkl et al. 2011). With inter-dependent edge weights and no reasonable assumptions about their underlying distribution the best response to this estimation problem is a bootstrap re-sampling plan (Lusseau et al. 2008; Franks et al. 2009; Franks et al. 2010).

It is of course extremely difficult to judge how many observations are needed in order to have an accurate picture of the relationships in a group. It could also be argued that with their small group sizes and the range of easily observable social behaviours available to them, primatologists are unlikely to face serious problems in terms of quantity of observational data. However many primate social behaviours, such as grooming, copulations, aggression etc., are relatively rare. Dunbar (1991) summarized that primates spend on average only $5.2 \%$ of their time grooming, while a cross species comparison of agonistic interactions reported a mean rate of $0.61 \pm 0.09$ agonistic interactions per individual per hour (Wheeler et al. 2013, this studied focused on female agonism). Therefore long hours of detailed observations are still needed to get an accurate picture of these social behaviours. For example, in a study of Chacma baboons (Papio cynocephalus ursinus) Henzi and colleagues (2003) collected during one 17 month study period 278 hours of focal observations during which they observed 263 bouts of grooming between adult females. As the group contained 12 adult females, this gives an average of only two grooming bouts per dyad in the female grooming network. In such a case it would be treacherous to estimate individual edge weights, as many estimates would be based on either just a few or even just a single observation. Furthermore, edge weight distributions based on grooming data are usually skewed (Kasper and Voelkl 2009) which means, that the better part of grooming events will fall on just a few dyads while estimates for the majority of existing edges will be based on very few observations (e.g. Tiddi et al. 2011; Brent et al. 2013a). This is definitively a fact one should worry about and as such we would encourage researchers to give serious consideration to the volume of data available to them before attempting SNA. 
One way to help judge whether enough observations have been collected is to consider the number of isolates in the network (i.e. individuals with no connections at all to any other individual in the network). Large numbers of isolated individuals is generally a clear warning that rather than individuals not interacting, one simply has not seen these individuals interact. There are of course situations where the presence of isolates makes sense. For example in a copulation network certain adult males may be isolated completely from the network as a result of being excluded from virtually all mating by more powerful higher ranking males or in a social play network one might not be surprised to see a large number of isolated adults. However in networks based on more wide spread behaviours such as grooming the presence of even a few isolates can be a strong indication that more data is needed.

Not all network measures are equally sensitive to small samples, thus how much observational data are required to reliably answer a certain question can also depend on the type of network measure used. Voelkl and colleagues (2011) investigated how network measures for networks of 44 primate groups changed under re-sampling and simulated error-attack. By resampling at lower rates from the original data sets they were asking how stable measures were if researchers had collected fewer data. Unsurprisingly, they found that in general networks based on few observations (less than 100) were relatively sensitive to re-sampling, corroborating the general wisdom that larger samples give more robust results. However, the authors could also show that network measures differed in their sensitivity towards re-sampling. Some basic measures, like density, degree variance or edge weight disparity proved to be relatively robust, while other more complex measures, like clustering coefficient, eigenvector centrality or vertex strength variance were much less so.

In summary, the small group sizes and the high density of most primate networks makes it more difficult to find strong, or meaningful, contrasts in network measures between groups. This is especially true when one considers binary network measures. There is hope that weighted network measures can give a more accentuated picture; however researchers must ensure they have large quantities of reliable data in order to obtain good estimates of edge weights, especially if they wish to make use of the more complex network measures.

\section{Specificity}

In section 1 we highlighted the fact that primates are one of those few taxons where researchers are able to build networks based on a variety of different behaviours. This should -in principle- enable them to fine-tune the measure to the specific question. Yet, more often than not the choice of the measure for primate networks seems to be based on practical considerations (i.e. how easy and reliably the behaviour can be observed) than on principal 
considerations (i.e. which type of network would be most relevant for the specific question). When it comes to the transmission of social information a proximity network might be of interest, as one could argue that individuals that spend much time in close proximity are more likely to learn from each other, while an aggression or a copulation network, for example, might be less appropriate. On the other hand, copulation networks might be very informative when one is interested in disease transmission. That the type of network should fit to the question might sound obvious, yet this fallacy has repeatedly slipped its way into primatological research. For example, the membership to a primate group has, in some cases, been exclusively defined by a single behaviour, such as grooming. Disruptions of this network -either observed or simulatedare then interpreted as a group split, neglecting the fact that while these subsets of individuals may not groom each other, they may still continue to roam together, forage together, defend a territory and sleep together at the same site. Speaking in such a case of a "group split" would, in our opinion, be a clear misinterpretation. That is, whenever a social network is built upon a single behaviour, one should keep its specificity in mind. The importance of considering multiple behavioural measures to examine sociality in primates has long been emphasised (Kummer 1968; Hinde 1976) and SNA itself provides primatologists with an excellent means of comparing and integrating multiple social behaviours for this purpose (Lehmann and Ross 2011; Barrett et al. 2012; Brent et al. 2013a; Brent et al. 2013b; Chan et al. 2013a; Macdonald et al. to be submitted). In addition given that network structures for different social behaviours can vary markedly particularly proximity or associations networks (Barrett et al. 2012)- the reliance on single behaviours in general seems unadvisable if multiple social behaviours could be used to give a more rounded and reliable picture.

\section{Outlook: how the future of SNA in primatology might look}

In this final section we take a look at some of the most promising directions for SNA in primatology and sketch out a picture of how the future of primate network analysis might look. This is, of course, quite a speculative endeavour, and our motivation is not to test our magical abilities of foretelling the future, but rather to provide some suggestions of what might be the most fruitful applications of SNA to primate social behaviour in the future.

Our first, almost trivial, prediction would be that grooming will continue playing a prominent role in the construction of primate social networks. As we have mentioned several times primatologists have a distinct advantage over other researchers of animal behaviour when applying SNA, in that their study species show a considerable range of social behaviours that seem to be relatively universal and uniform in their functions. Among these 'universal' social behaviours, grooming is by far the most prominent. It is found in nearly all primate species, is 
easily recognizable, unambiguous, frequent and frequently recorded by field researchers. Regarded as a directed socio-positive interaction, grooming seems predestined for the construction of social networks, and being widespread within primates it positively invites itself as a basis for inter-species comparisons (Kasper and Voelkl 2009; Sueur et al. 2011b).

Our second prediction would be an increase in the development and use of multi-layered social networks. Early discussions of primate sociality often emphasised the importance of incorporating the influences of multiple social behaviours in order to gain a well-rounded view of primate social relationships and social structures (Kummer 1968; Hinde 1976), however the reality of incorporating measures of multiple behaviours has proved challenging. SNA provides primatologists with new opportunities in this regard. Until recently primate social networks have always been constructed based on a single behavioural measure. If researchers were interested in more than one behavioural dimension, then they constructed separate networks for each of them.

Making comparisons between networks based on exactly the same set of individuals is relatively straightforward (Croft et al. 2008) and can allow primatologist to examine and directly contrast subtle differences in the overall structure and the different positions individuals might take in each network (Flack et al. 2006; Lehmann and Ross 2011; Brent et al. 2013a; Brent et al. 2013b; Macdonald et al. to be submitted). Alternatively it is possible to construct a single score which integrates multiple social behaviours, for example the Composite Sociality Index promoted by Silk and colleagues (2006b), and base a single network on this measure (Macdonald et al. to be submitted). However it has been argued that we could gain a much more comprehensive picture of primate sociality by combining separate behavioural networks to form a single multi-layered network (Barrett et al. 2012). Such a multi-dimensional graph object has the potential to give a much more accurate and detailed picture of an animals' social niche. Barrett and colleagues constructed their multi-layered network based on aggressive and grooming behaviour as well as spatial proximity data for all adult females from a troop of baboons in the De Hope Nature Reserve in South Africa. The resulting three-layered multi-dimensional network was characterised in terms of its information entropy. Using both natural and simulated "knock-outs" this case study suggests that the overall entropy of the network changes more after the disappearance of a high ranking individual than after the disappearance of a low ranking female (Barrett et al. 2012). Another method to integrate information from multiple single-behaviour networks was recently introduced by Chan and colleagues (Chan et al. 2013a), who used a multidimensional framework based on joint probabilities of edge co-occurrences from four different behavioural networks to extract patterns of relationships (via constraint functions). Using this approach they compared the social structure of a rhesus macaque group during a period of rank 
stability and during a period leading up to a major rank disruption. They were able to show that during the period leading up to the rank disruption subtle structural properties, linked to a stable social structure, appeared to have disintegrated, resulting in a simpler, yet arguably less stable, social structure. Such multi-layered approaches are still in an early stage of development, however they appear to be very promising and given the range of easily observable types of behavioural interactions, primates seem to be a well suited taxonomic group for developing such an approach further.

Another interesting topic that we predict will receive more attention is the question of how animal social networks change over time. Here, again, primates would be a well suited model system as they are relatively long-lived and tend to form stable social groups that often persist over several generations. At some study sites groups of chimpanzees, macaques, or baboons have been continuously monitored for up to five decades, and while not all the historic data will be suitable for a detailed re-construction of the animals' social networks, the recent interest in networks may convince researchers to change their observational protocols in order to collect network fit data. There have been some interesting initial studies that have focused on temporal changes of primate social networks. The first, published by Henzi and colleagues (2009) could show, a clear cyclicity in the degree to which female baboons maintained differentiated associations. Similarly a recent study of free-ranging rhesus macaques by Brent and colleagues showed that female social network structure varied around the species breeding cycle, being more centralized and more clustered in the mating season than in the birth season (Brent et al. 2013b). This contrasts with a study by Macdonald et al (to be submitted) which shows relative stability in the social relationships of females Assamese macaques (Macaca assamensis) despite significant changes in their social and ecological environment. For sure, these will not be the last studies to focus on temporal changes in primate networks.

In a recent review Brent et al (2011a) envisage that SNA may allow a new quantitative approach to social role theory that might be especially useful for nonhuman primate research. Role theory was originally developed by social psychologists but later also adopted by some primatologists (Bernstein 1964; Reynolds 1970; Fedigan 1972). It largely fell out of favour in the 1980ies (for a review see Roney and Maestripieri 2003) which, according to Brent and colleagues, was ultimately due to three reasons: first, role theory was criticised for producing little more than descriptions of activity patterns of members of given age or sex classes, second, its implications were partly misunderstood, and third, it was criticised for lacking clear operational definitions. As some of these misconceptions -especially concerning the link between role theory and group selection could now be cleared out (Roney and Maestripieri 2003) and social network measures offer a way to define roles operationally via nodal properties of the individuals, Brent and 
colleagues (2011a) predict a revival of role theory in primatology. Time will tell to what extend this will be the case, but we would predict that primatologists and-more general- behavioural ecologists will begin to embrace network analysis as a tool for quantitatively describing the 'social niche' of an individual or defining 'socio-behavioural phenotypes'.

Another recent trend in behavioural ecology which we predict is likely to also effect primatology is the increased use of automated recording techniques, i.e. where individuals are fitted with either geo-location loggers or with radio frequency identification (RFID) tags (Rutz et al. 2012). These devices usually record the geographical position and sometimes motion parameters (direction and acceleration) or further physiological parameters of the animals with a high spatial and temporal resolution, generating huge amounts of data. For example, by using passive integrated transponder (PIT) tags on a population of great tits and an array of antennas sampling at a rate of more than one Hertz, Garroway and colleagues (this book) could record several million observations and more than ten thousand co-occurrences of birds during a five months period. This is clearly something that would not be possible with a classical bootsbinocular-pen-and-paper approach still practiced by many primatologists. With such enormous data sets it is possible to construct accurate weighted networks, however this technique is of course limited to addressing questions based on association data. Despite this drawback this technique has the potential to be an extremely useful tool for primatologist by helping them to address important topics where traditional data collection methods often struggle, such as large scale group movements/ranging patterns, intergroup encounters, ranging among fission-fusion societies, dispersal patterns etc.

Finally, researchers have started, with the help of SNA, to begin to investigate the genetic basis of social behaviours. As it can be assumed that behavioural traits have a highly polygenetic background, one needs two things to tackle this topic: first, high resolution sequencing techniques that allow the construction of detailed QTL maps and, second, good quantitative descriptors for the social behaviour of an individual. For the latter SNA has the potential to offer valuable contributions. Having nodal network measures for single individuals describing their particular social niche, allows one to then relate these measures to the genetic data. Such an approach has been recently attempted by Brent and colleagues (2013a). The authors appear to find both additive genetic variance for several network measures as well as a link between centrality in the grooming network and a gene complex in the serotonin pathway. This is the first study of its kind to take this direction. Given its reception, no magical skills are required to predict that more studies along these lines are to come and that this will be a hot topic for the near future. 


\section{Concluding Remark}

Despite several enthusiastic reviews directly aimed at primatologists (Brent et al. 2011a; Jacobs and Petit 2011; Sueur et al. 2011a) the SNA approach has been slow to develop in this field. This is likely in part due to the barrage of new jargon that accompanies it and in part due to the somewhat unfamiliar statistical techniques required to adequately deal with the extremely dependent data. For some primatologists there is also a sense that this approach isn't actually providing them with anything very new. We hope that by giving a realistic overview of what SNA of primate groups can and cannot achieve, and by clarifying what is and is not new in the approach, this chapter will encourage more primatologist to embrace SNA in their research and help establish SNA as a useful tool for investigating questions of primate social behaviour. 
Chapter 5

General Discussion 

The overall aim of this thesis has been to establish the characteristics of social relationships among female Assamese macaques and consider how closely they resemble the characteristics of strong social relationships among humans and other non-human species. By doing so, I hope to improve our understanding of the evolutionary origins of both strong human and non-human social relationships. The thesis focused primarily on investigating three major characteristics of strong social relationships: differentiation in strength, stability and equality. In addition, the thesis evaluated the potential benefits social network analysis (SNA) may bring to our understanding of both primate social relationships and primate social behaviour in general. In this general discussion I will bring together the findings reported in each of the chapters and consider their implications for our understanding of 1. the social lives of Assamese macaques, 2. the study of non-human social relationships, and 3 . the evolution of human social relationships. I will conclude with some suggests of possible future directions for the study non-human social relationships.

\section{The characteristics of social relationships among female Assamese macaques}

\subsection{Differentiation in strength}

The first of the three characteristics of strong social relationships I investigated in this species was differentiation in strength. Strong social relationships among both humans and nonhuman species are by definition stronger than other social relationships i.e. individuals with strong social relationships associate/interact with each other more frequently and/or for longer durations than individuals with weak social relationships (1987; Dainton and Aylor 2002; Laursen and Collins 2003; Silk et al. 2006b; Lehmann and Boesch 2009; Mitani 2009; Silk et al. 2010b; Kerth et al. 2011; Roberts and Dunbar 2011a). Therefore, in order to show that strong social relationships exist within a given group it is necessary to show that individuals within that group associate/interact with some individuals more regularly than they associate/interact with others, i.e. that there is differentiation in the strength of social relationships within the group (Silk et al. 2006b; Lehmann and Boesch 2009; Mitani 2009; Silk et al. 2010b; Kerth et al. 2011). Differentiation in social relationship strength is commonly found among non-human species (horses: Kimura 1998; e.g. bottlenose dolphins: Connor et al. 2000; blue monkeys: Cords 2000; sperm whales: Whitehead 2000; guppies and sticklebacks: Croft et al. 2005; elephants: Archie et al. 2006; yellow baboons: Silk et al. 2006b; house mice: Weidt et al. 2008; kangaroos: Carter et al. 2009; Langergraber et al. 2009; Lehmann and Boesch 2009; chimpanzees: Mitani 2009; male Assamese macaques: Schülke et al. 2010; chacma baboons: Silk et al. 2010b; bats: Kerth et al. 2011; great tits: Aplin et al. 2013; giraffes: Carter et al. 2013; feral goats: Stanley and Dunbar 2013) and the results from Chapter 2 indicate that female Assamese macaques are no exception. 
As has been shown in other primate species (Silk et al. 2006b; Schülke et al. 2010; Silk et al. $2010 \mathrm{~b}$; Young et al. to be submitted) the distribution of the strength of the social relationships in our study group was extremely skewed, with many weak and only a few strong social relationships. Females were found to have, on average, 4.7 stronger than average social relationships, i.e. with a CSI $>1$, and 1.3 very strong social relationships, with a CSI $>2$. A females' dominance rank did not predict the number stronger than average social relationships she had.

The average number of strong and very strong social relationships described above suggests that female Assamese macaques social relationships may show a similar nested structure as found among human social relationships (Zhou et al. 2005) as well as a range of other non-human species (Hill et al. 2008). At the centre of this structure would be the 1.3 very strong social relationships each female has on average, these would then be nested within the 4.7 strong social relationships, which would be nested within the 11-14 social relationships each female has with all female group members. As such, this structure, like those described by Hill (2008) appears to scale at each level by a factor somewhere between 3-4, i.e. the number of individuals in each level increases by a multiple of 3-4. This is perhaps the first hint that such nested structures, which to date have only ever been identified among species living in highly structured social groups, such as elephants (Loxodonta africana), gelada (Theropithecus gelada) and hamadryas (Papio hamadryas hamadryas) baboons (Hill et al. 2008), may also occur among individuals living in more fluid social groups. It is of course debatable whether these divisions in social relationship strength have any meaning for the macaques themselves. There is also a large amount of individual variation in the number of relationships individuals have at each of these levels. Yet, these results do provide some further tempting evidence that such nested hierarchical structures may be a common characteristic among both human and non-human social relationships.

\subsection{Stability}

The second characteristic of strong social relationships I addressed was stability. Previous studies had provided evidence that social relationships in general, among a wide range of nonhumans species remain stable over time (Connor et al. 2000; Silk et al. 2006a; Lehmann and Boesch 2009; Mitani 2009; Silk et al. 2010b; Moss and Lee 2011; Silk et al. 2012; Stanley and Dunbar 2013). However, much of this work has been based solely on association data, which is not always a good proxy for social interaction data (Barrett et al. 2012). In addition, it has been argued the apparent stability shown in many of these studies may simply be a byproduct of stability in the short term needs of individuals (Henzi et al. 2009). The data set used in Chapter 2 contained detailed data on a range of social behaviours, over two full cycles of seasonal change 
within a group. As a result it allowed this study to specifically address both of these limitations of previous studies examining the stability of social relationships in non-human animals.

Overall, the results from Chapter 2 provide strong evidence that female Assamese macaque social relationships, including strong social relationships, are stable over time. The results indicate that in spite of significant changes in the short term needs of the females (assessed by examining changes in the female activity budget) no significant changes in the relative strength of the social relationships (measured by the CSI) among females was found. In addition, no significant changes in the actual rates of grooming or body contact among females during these periods were found. The results also indicate that, unlike the findings reported for rhesus macaques (Brent et al. 2013b), the overall structure of the female social network remains stable throughout the breeding cycle. Lastly, while it was not within the scope of this thesis to provide conclusive evidence that the social relationships of female Assamese macaques remain stable for multiple years, analysis in Chapter 2 provided initial evidence that this may be the case. The relative strength of the social relationships (i.e. the CSI's) among the ten females which were present in both years of data were found to be significantly, positively correlated. This is in spite of several demographic changes in the female population of the group, including two deaths and five maturations of juvenile females to full adults. Ultimately, long term data, from consecutive years is required before any definitive conclusions can be made. However, these results provide a first insight into the potential long term stability of female social relationships in this species.

\subsection{Equality}

Equality in the exchange of services has been shown to be an important characteristic of strong human social relationships (Rook 1987; Clark and Ayers 1993; Walker 1995; Horwitz et al. 1996; Hendrix 1997; Komter and Schans 2008). More specifically, the way in which equality in the exchange of services is maintained in strong social relationship differs from the way it is maintained in weak social relationships in two ways. The types of services exchanged can be very different in strong social relationships, while in weak social relationships they tend to be very similar (Clark 1981; Törnblom et al. 2012). In addition, the time frame over which services are exchanged tends to be longer in strong social relationships, while services in weak social relationships tend to be exchanged immediately or as soon as possible (Komter and Schans 2008; Törnblom et al. 2012; Xue and Silk 2012). To date, when examining the equality of non-human social relationships researchers have paid little attention to the status of individuals, focusing instead almost exclusively on examining the equality of the exchange of services (Silk et al. 2006a; Mitani 2009; Silk et al. 2010b). Within these studies, however, little attention has been given to differences in the content or time frame of exchanges relative to social relationships 
strength. Therefore, the results of this thesis provide important insights into the role of equality in non-human social relationships by examining the influence of social relationship strength on the content and time frame of exchanges of services.

Overall these results indicate that the role of equality in social relationships of female Assamese macaques bares some similarities to the role of equality in strong human social relationships, but also important differences. Female Assamese macaque grooming behaviour revealed that grooming was not exchanged for rank related services, i.e. agonistic support, feeding tolerance and reduced aggression (Chapter 3.1). In addition, the stability in the relative strength of the social relationships across the breeding cycle suggests that female Assamese macaques do not exchange grooming for infant handling (Chapter 2). Rather, female Assamese macaques appear to exchange grooming largely for itself (Chapter 3.2). Therefore, unlike humans, the content of exchanges between female Assamese macaques remains largely the same regardless of social relationship strength. Further analysis revealed that exchanges of grooming for itself were, like exchanges in human social relationships, relatively well balanced, regardless of social relationship strength (Chapter 3.2). This balance was not maintained through immediate reciprocation but over a longer time frame, again regardless of social relationship strength, therefore, unlike humans, social relationship strength appears to have no influence on the time frame of exchanges (Chapter 3.2).

\subsection{Summary}

Overall these results provide evidence that female Assamese macaques form strong, stable social relationships which share some, but not all, the features of equality found in human social relationships. These findings also provide further insights into this relatively understudied species of macaque, providing a contribution to the gradually improving picture of their social lives. We now have evidence that both males and females in this species form strong social relationships with preferred social partner's (Chapter 2; Schülke et al. 2010), although it still remains to be seen whether male strong social relationships are similar to female social relationships in terms of stability and equality. We also now have further evidence that while the species' seasonal breeding cycle has a significant influence on male-female social relationships (including their grooming behaviour) (Fürtbauer et al. in revision) female-female social relationships are largely unaffected. Lastly, when combined with previous findings (Heesen et al. 2013; Heesen et al. in revision) the results of this thesis adds to growing evidence that dominance rank has a limited influence on the behaviour of female Assamese macaques. As such, female Assamese macaques do not appear to fit easily into some of the conventional schemes used to 
understand the social behaviour of both macaques and primates in general (Sterck et al. 1997; Thierry et al. 2004).

\section{Social network analysis and non-human social relationships}

One of the major problems limiting our ability to make firm conclusions in the study of nonhuman social relationships is the lack of consensus on how best to quantify these social relationships, their various characteristics and the structures that they form. Social network analysis (SNA) has been widely promoted in the last 5-6 years as a valuable tool for quantitatively addressing a whole range of social behaviours in non-human species (Krause et al. 2007; Croft et al. 2008; Wey et al. 2008; Krause et al. 2009; Brent et al. 2011a; Pinter-Wollman et al. 2013). In this thesis I reviewed the potential benefits and limitations of SNA in the study of primate social behaviour in general (Chapter 4). In addition, I made use of a range of SNA measures in my description of the structure of the social relationships of female Assamese macaques (Chapter 2). Based on the conclusions and findings of these chapters I will use this section of the general discussion to briefly discuss the potential benefits SNA can bring specifically to the study of nonhuman social relationships.

Many of the potential applications of SNA discussed in Chapter 4 highlight the usefulness of SNA as a means of quantifying the structure of social networks, i.e. the patterning of the connections within a given network. In terms of a social relationship network these measures, therefore, offer a means of quantitatively measuring the "patterning" of social relationships, i.e. to address the upper level of Hinde's framework of social structure (Hinde 1976). In Chapter 2 of this thesis I made use of such measures to examine the patterning of female Assamese macaque social relationship networks. For example, I used network centralisation, a measure of how focused ties in a network are around a small number of individuals, to demonstrate that social relationships in female Assamese macaques are relatively evenly distributed among all individuals. This is relatively atypical for primates in general (Kasper and Voelkl 2009), but appears to be a common feature of macaque social relationship networks (Sueur et al. 2011b; Brent et al. 2013b). I also used the clustering coefficient, a measure indicating how clustered into sub-groups a network is, to demonstrate that social relationship networks among females in this species are not highly centralised. This is a typical feature of primate social relationship networks in general (Kasper and Voelkl 2009), but is somewhat atypical for a female-bonded, old world monkey species (Lehmann and Dunbar 2009). Currently our ability to make comparisons, both between and within species, using these measures is ultimately limited by a lack of reported figures. However, by building up more information, from a wider range of species we could use 
these measures to begin to create a collection of quantitatively based characteristics of nonhuman social relationships.

SNA also has the potential to help with the challenges of quantifying the first level of Hinde's model, i.e. combining and quantifying social interactions into measures of social relationships (Hinde 1976). It is generally accepted that in order to quantify social relationships we need to combine information from a number of different interactions, from a variety of different behaviours. There is a relative consensus on which behaviours are most relevant, e.g. approaches, grooming etc., however there is little agreement on how best to transform measurements of these behaviours into meaningful representations of social relationships (Silk et al. 2013). As a result researchers often focus on one particular behaviour, either because they consider it to be a particularly important indicator of a social relationship, or simply because it is the easiest and/or most convenient to measure. Others have attempted to combine measurements of multiple behaviours into a single composite score, such as the CSI (Silk et al. 2013) or the CRI (Crockford et al. 2013), although currently there is again no clear consensus on how best to form such scores. The recent developments within SNA towards "multi-layered" or "multi-dimensional" networks (Barrett et al. 2012; Chan et al. 2013b), highlighted in Chapter 4, may provide an important third option, by allowing researchers to combine networks based on several individual behaviours into a single object. The development of these multi-dimensional networks is still very much at an early stage, with only a few studies attempted so far (Barrett et al. 2012; Chan et al. 2013b). Yet, if this method succeeds in becoming more well established, quantifying non-human social relationships is perhaps one of the best examples of the many benefits it may bring to primate and other non-human social behavioural research.

Ironically, given that it was first developed in the human social sciences, SNA may not be a useful means of improving comparisons of human and non-human social relationships. Human and non-human social relationship networks are likely to be difficult to compare as, while nonhuman social networks typically encompass all, or virtually all, the relationships of the individuals within a group, those studying human social networks tend to focus on specific subgroups of social relationships, e.g. social relationships in the work place (Cole et al. 2002; Barrett et al. 2012), religious groups (Mckenzie 2004) or at university (Saltz et al. 2004), rather than complete social relationship networks. Yet, in turn, this could be beneficial as SNA may become instead a means of quantifying and measuring characteristics of non-human social relationships which may be less meaningful for human social relationships, e.g. the relationship between rank and the patterning of social relationships described above. As such, SNA may help to encourage those studying non-human social relationships to move away from anthropocentric and anthropomorphic interpretations of these relationships. 


\section{The evolution of non-human social relationships}

The main findings of this thesis provide further evidence that non-human species can form strong, stable social relationships, as such they have implications for our understanding of the potential value of non-human social relationships. The approach taken to examine the stability of female Assamese macaques' social relationships in Chapter 2 is very similar to that taken by Dunbar and colleagues to investigate the impact of time constraints on the activity budgets of old world monkeys (Dunbar and Sharman 1984; Dunbar and Dunbar 1988). Like Dunbar and colleagues this analysis found that while the time allocated to some behaviours, such as feeding, tends to vary depending on external conditions, the amount of time dedicated to other behaviours, specifically social behaviours, is much more constant. As such, these results provide further support for the proposal that among some highly social, large-brained species, social relationships hold a certain value, and that individuals, when necessary, will adjust the amount of time they devote to other activities in order to maintain them (Dunbar 1998). In contrast, these results do not fit with the biological market approach to social relationships promoted by Barrett and Henzi (Henzi and Barrett 2002; Barrett and Henzi 2006). Female Assamese macaques live in what potentially could be considered a very changeable market place. As touched upon above, their annual breeding cycle is related to significant changes in the amount of time they dedicate to various daily activities, as well as intersexual social interactions (Fürtbauer et al. in revision). Yet, despite these short term variations in their social and ecological environment there was no evidence that female Assamese macaques changed the "goods" that they traded or the partners that they traded with (Chapter $2 \&$ Chapter 3). Rather they appear to invest in maintaining long-term relationships with the same individuals, potentially for several years.

The results of this thesis also have implications for the importance placed on rank in the study of non-human social relationships. There is a tendency, particularly among those studying non-human primates, to focus on dominance interactions when examining non-human social relationships or "social styles" (Thierry 2004) (a social relationship in this context including both friendly and agonistic social behaviours). For example, the socioecological model (Sterck et al. 1997), which aims to explain variation in female social relationships among non-human primates, focuses almost exclusively on establishing the nature of female dominance relationships, while paying very little attention to affiliative behaviours. Similarly, in his classification system of macaque social styles, Thierry (2004) outlines 14 behavioural characteristics used to assign species of macaques into one of four possible grades. Nine of these characteristics assess dominance and agonistic behaviours, while only one addresses affiliative behaviours. As far back as the $70^{\prime}$ s researchers have been trying to guide the study of non-human social relationships 
away from the "well-worn paths" of social dominance (Hinde 1976) towards a fuller appreciation of the complexities of non-human social lives. In recent years there have been renewed calls for a shift in the study of non-human social behaviour away from aggression and competition and towards affiliation and cooperation (Sussman et al. 2005). There has also been mounting evidence that the fitness benefits which social relationships can provide are gained independent of dominance rank (Silk et al. 2003; Cameron et al. 2009; Silk et al. 2009; Silk et al. 2010a). The results of this thesis add to this by providing evidence that dominance rank in general has little influence on the social relationships of female Assamese macaques. Dominance rank was shown not to influence the number of stronger than average social relationships a female had (Chapter 2). No evidence was found that grooming was exchanged for rank related benefits (Chapter 3.1), nor did rank distance influence the immediate reciprocation of grooming exchanged for itself (Chapter 3.2). Finally, both the overall structure of the female social relationship network and individual females' positions within this network were also found not to be affected by dominance rank. While there are flaws in some of the reasoning presented for a shift toward a greater emphasis on affiliative behaviours (Koenig et al. 2006), it is becoming increasingly clear that important aspects of non-human social relationships function independently of dominance interactions.

\section{The evolution of human social relationships}

By providing further evidence that non-human social relationships can share important characteristics with strong human social relationships, the results of this thesis also provide evidence that strong human and non-human social relationships share common evolutionary origins. This in turn has implications for our understanding of the evolution of strong human social relationships. The evolution of strong human social relationships, and their underlying benefits, is still widely debated (Silk 2002b). Attempts to identify the benefits of these relationships, particularly friendship, have tended to focus on the material and/or physical support, e.g. the exchange of goods or support during conflict, that these relationships potentially bring (Kenrick and Trost 2000; DeScioli and Kurzban 2009). However, social psychologists' data on the nature of reciprocity in strong human social relationships does not always fit well with the underlying theories, such as reciprocal altruism (Trivers 1971), that these explanations are based on (Silk 2002b; DeScioli and Kurzban 2009). If we accept, as the results of this thesis suggests, that strong human social relationships share a common evolutionary history with non-human social relationships, strong human social relationships may be better understood by considering the benefits social relationships provide to extant non-human species. 
A range of potential benefits of strong social relationships have been examined in nonhuman species. Some of them are similar to those considered in human social relationships, including the exchange of support/formation of cooperative alliances (Connor et al. 2000; Schülke et al. 2010; Young et al. in press). Others are perhaps less familiar, such as vigilance against predators (Micheletta et al. 2012), or tolerance during co-feeding (Heesen et al. in revision). One of the most prominent potential benefits of social relationships investigated in non-human species is the reduction of stress (Engh et al. 2006; Wittig et al. 2008; Fürtbauer et al. in revision; Young et al. to be submitted). While stress, or more specifically glucocorticoids released in response to stressful stimuli, has been found to be adaptive in the short term, chronic stress has been found to impair immune, cognitive, and reproductive function (McEwen and Wingfield 2003; Sapolsky 2004; Sapolsky 2005). Strong, focused social relationships, particularly the grooming associated with these relationships, appears to play an important role in reducing stress in a range of primate species (Engh et al. 2006; Crockford et al. 2008; Wittig et al. 2008; Fürtbauer et al. in revision; Young et al. to be submitted). Therefore, it has been suggested that these relationships may have evolved in order to help reduce the negative impacts of stress (Crockford et al. 2008; Wittig et al. 2008; Fürtbauer et al. in revision; Young et al. to be submitted). Several studies, focusing on the health benefits of human social relationships have found similar results, linking the presence of social support to stress reduction (Uchino 2006). Yet currently, these results do not appear to have been given much consideration by those investigating the evolutionary origins of strong human social relationships.

\section{Outlook}

A recent editorial in the International Journal of Primatology (IJP) discussed the outcomes of a survey launched to identify the top 10 questions that remain unanswered in primatology. Questions relating to "The evolution of sociality and social behavior", including questions regarding the benefits of social relationships, were ranked number two on this list (Setchell 2013). Primatologists do not appear to be alone in this interest, a growing number of papers asking very similar questions about the nature and potential benefits of social relationships, among a range of species are accumulating in the animal behaviour literature (König 1994; Moses and Millar 1994; Weidt et al. 2008; Cameron et al. 2009; Frére et al. 2010). One of the challenges in this area of research is obtaining suitable quantities of good quality, social interaction data. This thesis has been able to make a useful contribution in this regard by providing detailed social data on a relatively understudied species of macaque. More importantly it has provided valuable insights into the similarities and differences between human and non-human social relationships. 
Yet, as the topics rating in the IJP editorial suggests, there are still many challenging questions which remain unanswered.

One potential direction for the future is to continue to attempt to identify common characteristics between strong human and non-human social relationships, such as compatibility. Compatibility is another important characteristic common to strong human social relationships. One of the classic findings of friendship research is that close friendships tend to be formed by individuals of the same gender, race and age (Adams and Allan 1998). The strength of friendships has also been found to be positively correlated with similarity in hobbies, moral beliefs and sense of humor (Curry and Dunbar 2013a; Curry and Dunbar 2013b). Similarly, satisfaction in romantic relationships has been shown to be positively correlated with the degree to which individuals share common values and opinions (Coombs 1966; Cramer 2002). Even among relatives compatibility is important for the maintenance of strong family ties, particularly compatibility of values. For example, one of the most widely studied causes of the breakdown of family relationships is the rejection of a family member due to their sexual orientation. These isolated individuals often go on to form what are referred to as "families of choice", where they relay almost exclusively on close friends and romantic partners for both emotional and material needs and support (Dewaele et al. 2011). Attempts have been made to investigate the role of compatibility in non-human social relationships, however the definitions and measures used are not always well matched to those in human social relationship research. As described above, compatibility in human social relationships is generally established by assessing how similar individuals are in terms of their beliefs, interests, sense of humor etc., as well as more basic qualities such as age and gender. However, studies of non-human species have tended to use definitions of compatibility such as "the general tenor of social interactions" (Cords and Aureli 2000; Fraser and Bugnyar 2010) and "the level of tolerance between two individuals" (Fraser and Bugnyar 2010). As a result measures of compatibility in these studies resemble measures used elsewhere in the literature to establish the strength of social relationship. That is, the more time two individuals spent in close proximity and less aggression they directed towards each other the more compatible they are considered to be (Cords and Aureli 2000; Fraser and Bugnyar 2010). More recent studies have started to approach compatibility in a way more in line with the concept used by those studying human social relationships. For example, Aplin et al. (2013) and Massen and Koski (2014) have been able to show that great tits and chimpanzee, respectively, prefer to socially interact with individuals which share the same personality traits. It remains to be seen if these findings can be extended to other species and/or to similarities in other attributes. 
Another possible future direction for the study of non-human social relationships would be to broaden our ideas on the characteristics of these social relationships and consider whether they display characteristics not found in human social relationships. The work of Sueur et al. (2011b) investigating the "embeddedness" of individual macaques within their social relationship network relative to their dominance status provide one example of a characteristic of social relationships which perhaps is more meaningful among non-human species than humans. Silk et al. (2013) provide a list of a range of potential characteristics which may be relevant to nonhuman social relationships, some of which are characteristic which have been found to be shared with human social relationships and some of which have not yet been properly assessed. These characteristics are perhaps somewhat over simplistic, particularly in the dimension in which they are proposed to vary, however this list may act as a good starting point to begin from. As always there will be the on-going challenge, both for the characteristics proposed by Silk and any other that may arise, of how to effectively measure and compare these characteristics. However by taking a less human focused perspective of non-human social relationships we may begin to gain a better understanding of the nature and complexity of non-human social relationships in their own right.

Lastly, it is perhaps important for our understanding of non-human social relationships to turn away in the future from examining strong and enduring social relationships and to give greater attention to weaker and dynamic social relationships (Barrett per.com.). The results of this thesis as well as other studies have shown that the majority of social relationships between individuals in a group are often relatively weak (Chapter 2; Silk et al. 2006b; Schülke et al. 2010; Silk et al. 2010b), yet we have little understanding of what function these weaker social relationships serve. One example of the potential importance of weak social relationships comes from bottlenose dolphins (Connor et al. 2000). When bottlenose dolphin calves are young their mothers must remain with them near the surface of the water, while the rest of the group dives deeper to feed. This can leave both the female and her young calf exposed to predators and the dangers of harassing males. The chances that one of the few females with whom the mother has a strong social relationship with will also have a calf at the same time is relatively low. Therefore, Connor et al. (2000) suggests, that females may maintain weak social relationships with a large number of females in the group in order to increase the chances of having a friendly female to associate with, and jointly defend themselves and their young, during this stage of their reproductive cycle. Strategies like this may be common among non-human species, providing important fitness benefits for the individuals involved, however there is currently a distinct lack of data and measures specifically addressing the nature of weak and dynamic social relationships. SNA may again be able to provide useful tools to assist in the measuring and tracking of weak, 
dynamic social relationships in non-human species. A recent review by Pinter-Wollman et al. (2013) highlights a range of concepts and measures which address the dynamics of social networks, currently underused by those studying non-human species, which they argue are both adaptable and useful for the study of non-human social behaviour. Ultimately, it may only be by putting an equal amount of effort into examining both weak and strong social relationships that we will gain a full understanding of the benefits of non-human social relationships. 


\section{References}

Adams RG, Allan G (1998) Placing Friendship in Context. Cambridge University Press, Cambridge

Adams RG, Blieszner R, de Vries B (2000) Definitions of friendship in the third age: age, gender, and study location effects. Journal of Aging Studies 14:117-133

Akinyi MY, Tung J, Jeneby M, Patel NB, Altmann J, Alberts SC (2013) Role of grooming in reducing tick load in wild baboons (Papio cynocephalus). Animal Behaviour 85:559-568

Alberts SC (2010) Primatology: A faithful friend is the medicine of life Current biology : CB 20:R632-R634

Altmann J (1974) Observational study of behavior: sampling methods. Behaviour 49:227267

Aplin LM, Farine DR, Morand-Ferron J, Cole EF, Cockburn A, Sheldon BC (2013) Individual personalities predict social behaviour in wild networks of great tits (Parus major). Ecology Letters 16:1365-1372

Archie EA, Moss CJ, Alberts SC (2006) The ties that bind: genetic relatedness predicts the fission and fusion of social groups in wild African elephants. Proceedings of the Royal Society B: Biological Sciences 273:513-522

Aureli F, Schaffner CM, Boesch C, Bearder SK, Call J, Chapman CA, Connor R, Di Fiore A, Dunbar RIM, Henzi PS, Holekamp K, Korstjens AH, Layton R, Lee P, Lehmann J, Manson JH, Ramos-Fernandez G, Strier KB, van Schaik CP (2008) Fission-fusion dynamics. Current Anthropology 49:627-654

Baayen RH (2008) Analyzing Linguistic Data. Cambridge University Press, Cambridge

Baayen RH (2011) R package languageR - Data sets and functions with "Analyzing Linguistic Data: A practical introduction to statistics". . http://cran.at.r-project.org/

Balasubramaniam KN, Berman CM, Ogawa H, Li J (2011) Using biological markets principles to examine patterns of grooming exchange in Macaca thibetana. American Journal of Primatology 73:1269-1279

Balasubramaniam KN, Dittmar K, Berman CM, Butovskaya M, Cooper MA, Majolo B, Ogawa H, Schino G, Thierry B, de Waal FBM (2012) Hierarchical steepness and phylogenetic models: phylogenetic signals in Macaca. Animal Behaviour 83:12071218

Barrett L, Henzi S, Weingrill T, Lycett J, Hill R (1999) Market forces predict grooming reciprocity in female baboons. Proceedings of the Royal Society London B 266:665-670

Barrett L, Henzi SP, Weingrill T, Lycett JE, Hill RA (2000) Female baboons do not raise the stakes but they give as good as they get. Animal Behaviour 59:763-770

Barrett L, Henzi SP (2002) Constraints on relationship formation among female primates. Behaviour 139:263-289

Barrett L, Henzi S (2006) Monkeys, markets and minds: biological markets and primate sociality. In: Kappeler P, van Schaik C (eds) Cooperation in primates and humans. Springer, Heidelberg, pp 209-232

Barrett L, Henzi P, Rendall D (2007) Social brains, simple minds: does social complexity really require cognitive complexity? Philosophical Transactions of the Royal Society B: Biological Sciences 362:561-575

Barrett L (2011) Beyond the Brain: How body and environment shape animal and human minds. Princeton University Press, Princeton 
Barrett L, Henzi PS, Lusseau D (2012) Taking sociality seriously: the structure of multidimensional social networks as a source of information for individuals. Proceedings of the Royal Society London B 367:2108-2118

Bastian M, Heymann S, Jacomy M (2009) Gephi: An Open Source Software for Exploring and Manipulating Networks

Bates D, Maechler M (2012) R package lme4 - linear mixed effects models using S4 classes. . URL:http://lme4.r-forge.r-project.org/

Beisner BA, Jackson ME, Cameron A, McCowan B (2011a) Effects of natal male alliances on aggression and power dynamics in Rhesus macaques. American Journal of Primatology 73:790-801

Beisner BA, Jackson ME, Cameron AN, McCowan B (2011b) Detecting Instability in Animal Social Networks: Genetic Fragmentation Is Associated with Social Instability in Rhesus Macaques. PLoS ONE 6:e16365

Berkman LF, Syme SL (1979) Social networks, host resistance, and mortality: A nine-year follow-up study of alameda county residents. American Journal of Epidemiology 109:186-204

Berkman LF, Melchior M, Chastang J-F, Niedhammer I, Leclerc A, Goldberg M (2004) Social Integration and Mortality: A Prospective Study of French Employees of Electricity of France-Gas of France: The GAZEL Cohort. American Journal of Epidemiology 159:167-174

Bernstein IS (1964) Role of the dominant male rhesus monkey in response to external challenges to the group. Journal of Comparative and Physiological Psychology 57:404-406

Borgatti SP, Everett MG, Freeman LC (2002) Ucinet for windows: Software for social network analysis. MA: Analytic Technologies, Harvard

Borries C, Sommer V, Srivastava A (1994) Weaving a tight social net: Allogrooming in free-ranging female langurs (Presbytis entellus). International Journal of Primatology 15:421-443

Borries C, Larney E, Kreetiyutanont K, Koenig A (2002) The diurnal primate community in a dry evergreen forest in Phu Khieo Wildlife Sanctuary, Northeast Thailand. Natural History Bulletin of the Siam Society 50:75-88

Brent LJN, Lehmann J, Ramos-Fernández G (2011a) Social network analysis in the study of nonhuman primates: A historical perspective. American Journal of Primatology 73:720-730

Brent LJN, Semple S, Dubuc C, Heistermann M, MacLarnon A (2011b) Social capital and physiological stress levels in free-ranging adult female rhesus macaques. Behaviour 102:76-83

Brent LJN, Heilbronner SR, Horvath JE, Gonzalez-Martinez J, Ruiz-Lambides A, Robinson AG, Skene JHP, Platt LM (2013a) Genetic origins of social networks in rhesus macaques. Scinetific Reports 3:1042

Brent LN, MacLarnon A, Platt M, Semple S (2013b) Seasonal changes in the structure of rhesus macaque social networks. Behavioral Ecology and Sociobiology 67:349359

Butovskaya M, Kozintsev A, Kozintsev B (1994) The structure of affiliative relations in a primate community: allogrooming in stumptailed macaques (Macaca arctoides). Human Evolution 9:11-23

Butts CT (2013) Tools for social network analysis. http://cran.r-project.org/web/packages/sna/, R package version 3.0.1 
Byrne RW, Whiten A, Henzi SP (1990) Social relationships of mountain baboons: Leadership and affiliation in a non-female-bonded monkey. American Journal of Primatology 20:313-329

Cameron EZ, Setsaas TH, Linklater WL (2009) Social bonds between unrelated females increase reproductive success in feral horses. Proceedings of the National Academy of Sciences 106:13850-13853

Carne C, Wiper S, Semple S (2011) Reciprocation and interchange of grooming, agonistic support, feeding tolerance, and aggression in semi-free-ranging Barbary macaques. American Journal of Primatology 73:1127-1133

Carter AJ, Macdonald SL, Thomson VA, Goldizen AW (2009) Structured association patterns and their energetic benefits in female eastern grey kangaroos, Macropus giganteus. Animal Behaviour 77:839-846

Carter KD, Seddon JM, Frère CH, Carter JK, Goldizen AW (2013) Fission-fusion dynamics in wild giraffes may be driven by kinship, spatial overlap and individual social preferences. Animal Behaviour 85:385-394

Chan S, Fushing H, Beisner BA, McCowan B (2013a) Joint modeling of multiple social networks to elucidate primate social dynamics: I. Maximum entropy

principle and network-based interactions. PLoS one 8:e51903

Chan S, Fushing H, Beisner BA, McCowan B (2013b) Joint Modeling of Multiple Social Networks to Elucidate Primate Social Dynamics: I. Maximum Entropy Principle and Network-Based Interactions. PLoS ONE 8:e51903

Chapman CA (1990) Association patterns of spider monkeys: The influence of ecology and sex on social organization. Behavioral Ecology and Sociobiology 26:409-414

Cheney D, Seyfarth R, Smuts B (1986) Social relationships and social cognition in nonhuman primates. Science 234:1361-1366

Cheney D, Seyfarth R (2005) Constraints and preadaptations in the earliest stages of language evolution. The Linguistic Review 22:135

Cheney DL (1978a) Interactions of immature male and female baboons with adult females. Animal Behaviour 26:389-408

Cheney DL (1978b) The play partners of immature baboons. Animal Behaviour 26:10381050

Chepko-Sade BD, Reitz KP, Sade DS (1989) Sociometrics of Macaca mulatta IV: Network analysis of social structure of a pre-fision group. Social Networks 11:293-314

Clark FE (2011) Space to choose: Network analysis of social preferences in a captive chimpanzee community, and implications for management. American Journal of Primatology 73:748-757

Clark ML, Ayers M (1993) Friendship Expectations and Friendship Evaluations: Reciprocity and Gender Effects. Youth \& Society 24:299-313

Clark MS, Mills J (1979) Interpersonal attraction in exchange and communal relationships. Journal of Personality and Social Psychology 37:12-24

Clark MS (1981) Noncomparability of Benefits Given and Received: A Cue to the Existence of Friendship. Social Psychology Quarterly 44:375-381

Clark MS (1984) Record keeping in two types of relationships. Journal of Personality and Social Psychology 47:549-557

Clark MS, Waddell B (1985) Perceptions of Exploitation in Communal and Exchange Relationships. Journal of Social and Personal Relationships 2:403-418

Clark MS, Mills JR, Corcoran DM (1989) Keeping Track of Needs and Inputs of Friends and Strangers. Personality and Social Psychology Bulletin 15:533-542 
Cole MS, Schaninger WS, Harris SG (2002) The Workplace Social Exchange Network: A Multilevel, Conceptual Examination. Group \& Organization Management 27:142167

Connor RC (1995) Impala allogrooming and the parcelling model of reciprocity. Animal Behaviour 49:528-530

Connor RC, Wells RS, Mann J, Read AJ (2000) The Bottlenose Dolphin: Social relationships in a fission-fusion society. In: Mann J, Conner RC, Tyack PL, Whitehead H (eds) Cetacean Societies: Field studies of dolphins and whales. The University of Chicago Press, Chicago

Coombs RH (1966) Value Consensus and Partner Satisfaction among Dating Couples. Journal of Marriage and Family 28:166-173

Cooper MA, Bernstein IS (2000) Social grooming in assamese macaques (Macaca assamensis). American Journal of Primatology 50:77-85

Cooper MA, Bernstein IS (2008) Evaluating dominance styles in assamese and rhesus macaques. International Journal of Primatology 29:225-243

Cords M (2000) Agonistic and afilliative relationships in a blue monkey group. In: Whitehead P, Jolly C (eds) Old World Monkeys. Cambridge University Press, Cambridge, pp 453-479

Cords M, Aureli F (2000) Reconciliation and relationship qualities. In: Aureli F, De Waal F (eds) Natural conflict resolution. University of California Press, Berkley, pp 177198

Cords M (2002) Friendship among adult female blue monkeys (Cercopithecus mitis). Behaviour 139:291-314

Corradino C (1990) Proximity structure in a captive colony of Japanese monkeys (Macaca fuscata fuscata): An application of multidimensional scaling. Primates 31:351-362

Costanzo ES, Lutgendorf SK, Sood AK, Anderson B, Sorosky J, Lubaroff DM (2005) Psychosocial factors and interleukin-6 among women with advanced ovarian cancer. Cancer 104:305-313

Cramer D (2002) Relationship Satisfaction and Conflict Over Minor and Major Issues in Romantic Relationships. The Journal of Psychology 136:75-81

Crockford C, Wittig RM, Whitten P, Seyfarth RM, Cheney DL (2008) Social stressors and coping mechanisms in wild female baboons (Papio hamadryas ursinus). Hormones and Behavior 53:254-265

Crockford C, Wittig RM, Langergraber K, Ziegler TE, Zuberbühler K, Deschner T (2013) Urinary oxytocin and social bonding in related and unrelated wild chimpanzees. Proceedings of the Royal Society B: Biological Sciences 280

Crofoot MC, Rubenstein DI, Maiya AS, Berger-Wolf TY (2011) Aggression, grooming and group-level cooperation in White-faced capuchins (Cebus capucinus): Insights from social networks. American Journal of Primatology 73:821-833

Croft D, James R, Krause J (2008) Exploring animal social networks. Princeton University Press, Princeton

Croft DP, James R, Ward AJW, Botham MS, Mawdsley D, Krause J (2005) Assortative interactions and social networks in fish. Oecologia 143:211-219

Curry O, Dunbar RM (2013a) Do Birds of a Feather Flock Together? Human Nature 24:336-347

Curry OS, Dunbar RIM (2013b) Sharing a joke: The effects of a similar sense of humor on affiliation and altruism. Evolution and Human Behavior 34:125-129

Dagg AI (2011) Animal Friendships. Cambridge University Press, Cambridge

Dainton M, Aylor B (2002) Patterns of communication channel use in the maintenance of long-distance relationships. Communication Research Reports 19:118-129 
de Vries H (1998) Finding a dominance order most consistent with a linear hierarchy: a new procedure and review. Animal Behaviour 55:827-843

de Vries H, Stevens J, Vervaecke H (2006) Measuring and testing the steepness of dominance hierarchies. Animal Behaviour 71:585-592

de Waal FBM, Luttrell LM (1989) Toward a comparative socioecology of the genus Macaca: different dominance styles in rhesus and stumptailed macaques. American Journal of Primatology 19:83-109

de Waal FBM (1997) The Chimpanzee's service economy: food for grooming. Evolution and Human Behavior 18:375-386

DeScioli P, Kurzban R (2009) The Alliance Hypothesis for Human Friendship. PLoS ONE 4:e5802

Dewaele A, Cox N, Van den Berghe W, Vincke J (2011) Families of Choice? Exploring the Supportive Networks of Lesbians, Gay Men, and Bisexuals1. Journal of Applied Social Psychology 41:312-331

Dindia K, Baxter LA (1987) Strategies for Maintaining and Repairing Marital Relationships. Journal of Social and Personal Relationships 4:143-158

Dow MM, deWaal FBM (1989) Assignment methods for the analysis of network subgroup interactions. Social Networks 11:237-255

Dufour V, Sueur C, Whiten A, Buchanan-Smith HM (2011) The impact of moving to a novel environment on social networks, activity and wellbeing in two new world primates. American Journal of Primatology 73:802-811

Dunbar R (1991) Functional significance of social grooming in primates. Folia Primatologica 57:121- 131

Dunbar R (1998) The social brain hypothesis. Evolutionary Anthropology 6:178-190

Dunbar RIM, Sharman M (1984) Is Social Grooming Altruistic? Zeitschrift für Tierpsychologie 64:163-173

Dunbar RIM, Dunbar P (1988) Maternal time budgets of gelada baboons. Animal Behaviour 36:970-980

Dunbar RIM, Bever J (1998) Neocortex Size Predicts Group Size in Carnivores and Some Insectivores. Ethology 104:695-708

Engh A, Beehner J, Bergman T, Whitten P, Hoffmeier R, Seyfarth RM, Cheney DL (2006) Behavioural and hormonal responses to predation in female chacma baboons (Papio hamadryas ursinus). Proceedings of the Royal Society London B 273:707-712

Erickson DH, Beiser M, Iacono WG, Fleming JAE, Lin T (1989) The role of social relationships in the course of first-episode schizophrenia and affective psychosis. The American Journal of Psychiatry 146:1456-1461

Everson-Rose SA, Lewis TT (2005) Psychosocial factors and cardiovascular diseases. Annual Review of Public Health 26:469-500

Fedigan LM (1972) Roles and activities of male Geladas (Theropithecus gelada). Behaviour 41:82-90

Flack JC, Krakauer DC, de Waal FBM (2005) Robustness mechanisms in primate societies: a pertubation study. Proceedings of the Royal Society London B 272:1091-1099

Flack JC, Girvan M, de Waal FBM, Krakauer DC (2006) Policing stabilizes construction of social niches in primates. Nature 439:426-429

Flack JC (2012) Multiple time-scales and the developmental dynamics of social systems. Philosophical Transactions of the Royal Society B 367:1802-1810

Franks D, Ruxton G, James R (2010) Sampling animal association networks with the gambit of the group. Behavioral Ecology and Sociobiology 64:493-503 
Franks DW, James R, Noble J, Ruxton GD (2009) A foundation for developing a methodology for social network sampling. Behavioral Ecology and Sociobiology 63:1079-1088

Franz M, Nunn C, L. (2009) Network-based diffusion analysis: a new method for detecting social learning. Proceedings of the Royal Society London B 276:18291836

Franz M, Nunn C, L. (2010) Investigating the impact of observation errors on the statistical performance of network-based diffusion analysis. Learning and Behavior 38:235-242

Fraser ON, Bugnyar T (2010) The quality of social relationships in ravens. Animal Behaviour 79:927-933

Frére CH, Krützen M, Mann J, Connor RC, Bejder L, Sherwin WB (2010) Social and genetic interactions drive fitness variation in a free-living dolphin population. Proceedings of the National Academy of Sciences 107:19949-19954

Friedman EM, Hayney MS, Love GD, Urry HL, Rosenkranz MA, Davidson RJ, Singer BH, Ryff CD (2005) Social relationships, sleep quality, and interleukin-6 in aging women. Proceedings of the National Academy of Sciences of the United States of America 102:18757-18762

Fruteau C, Lemoine S, Hellard E, van Damme E, Noe R (2011a) When females trade grooming for grooming: testing partner control and partner choice models of cooperation in two primate species. Animal Behaviour 81:1223-1230

Fruteau C, van de Waal E, van Damme E, Noë R (2011b) Infant access and handling in sooty mangabeys and vervet monkeys. Animal Behaviour 81:153-161

Fürtbauer I, Schülke O, Heistermann M, Ostner J (2010) Reproductive and life history parameters of wild female Assamese macaques (Macaca assamensis). International Journal of Primatology 31:501-517

Fürtbauer I, Heistermann M, Schülke O, Ostner J (in revision) Low female stress levels are predicted by same- or opposite-sex relationships depending on season in wild Assamese macaques.

Galili T (2010) Post hoc analysis for Friedman's test ( $\mathrm{R}$ code). In. http://www.rstatistics.com/2010/02/post-hoc-analysis-for-friedmans-test-r-code/

Gelman A, Su Y, Ya-jima M, Hill J, Pittau MG, Kerman J, Zheng T, Dorie V (2013) R package arm - Data Analysis Using Regression and Multilevel/Hierarchical Models. http://CRAN.R-project.org/package=arm

Gill S (2012) Strategic use of allopreening in family-living wrens. Behavioral Ecology and Sociobiology 66:757-763

Gomes CM, Mundry R, Boesch C (2009) Long-term reciprocation of grooming in wild West African chimpanzees. Proceedings of the Royal Society B 276:699-706

Griffin RH, Nunn C, L. (2012) Community structure and the spread of infectious disease in primate social networks. Evolutionary Ecology 26:779-800

Groves CP (2005) Order primates. In: Wilson DE, Reeder DM (eds) Mammal Species of the World, 3rd edn. Johns Hopkins University Press, Baltimore, pp 111-184

Harrison RS, Boyle SW, Farley OW (1999) Evaluating the Outcomes of Family-Based Intervention for Troubled Children: A Pretest-Posttest Study. Research on Social Work Practice 9:640-655

Hart BL, Hart LA (1992) Reciprocal allogrooming in impala, Aepyceros melampus. Animal Behaviour 44:1073-1083

Hausfater G (1975) Dominance and reproduction in baboons (Papio cynocephalus): a quantitative analysis. Contributions to Primatology 7:1-68 
Heesen M, Ostner J, Schülke O (2013) Food abundance affects energy intake and reproduction in frugivorous female Assamese macaques. Behavioral Ecology and Sociobiology

Heesen M, Rogahn S, Macdonald S, Ostner J, Schülke O (in revision) Predictors of food related aggression in wild Assamese macaques and the role of conflict avoidance. Behavioral Ecology and Sociobiology

Hendrix L (1997) Quality and Equality in Marriage: A Cross- Cultural View. CrossCultural Research 31:201-225

Henrich J, Heine SJ, Norenzayan A (2010) Most people are not WEIRD. Nature 466:29

Henzi S, Lusseau D, Weingrill T, van Schaik C, Barrett L (2009) Cyclicity in the structure of female baboon social networks. Behavioral Ecology and Sociobiology 63:10151021

Henzi SP, Lycett JE, Weingrill T (1997) Cohort size and the allocation of social effort by female mountain baboons. Animal Behaviour 54:1235-1243

Henzi SP, Barrett L (1999) The value of grooming to female primates. Primates 40:47-59

Henzi SP, Barrett L (2002) Infants as a commodity in a baboon market. Animal Behaviour 63:915-921

Henzi SP, Barrett L, Gaynor D, Greeff J, Weingrill T, Hill RA (2003) Effect of resource competition on the long-term allocation of grooming by female baboons: evaluating Seyfarth's model. Animal Behaviour 66:931-938

Hill RA, Bentley RA, Dunbar RIM (2008) Network scaling reveals consistent fractal pattern in hierarchical mammalian societies. Biology Letters 4:748-751

Hinde R (1976) Interactions, relationships and social structure. Man 11:1-17

Hinde RA (1983) A conceptual framework. In: Hinde RA (ed) Primate Social Relationships. Blackwell Scientific Publications, Oxford, pp 1-7

Holt-Lunstad J, Smith TB, Layton JB (2010) Social Relationships and Mortality Risk: A Meta-analytic Review. PLoS Med 7:e1000316

Hoppit W, Kandler A, Kendal JR, Laland KN (2010) The effect of task structure on diffusion dynamics: Implications for diffusion curve and network-based analyses. Learning and Behavior 38:243-251

Horsten M, Mittleman MA, Wamala SP, Schenck-Gustafsson K, Orth-Gomer K (2000) Depressive symptoms and lack of social integration in relation to prognosis of CHD in middle-aged women. The Stockholm Female Coronary Risk Study. European Heart Journal 21:1072-1080

Horwitz AV, Reinhard SC, Howell-White S (1996) Caregiving as Reciprocal Exchange in Families with Seriously Mentally Ill Members. Journal of Health and Social Behavior 37:149-162

House JS, Robbins C, Metzner HL (1982) The association of social relationships and activities with mortality: Prospective evidence from the Tecumseh community health study

American Journal of Epidemiology 116:123-140

House JS (2001) Social Isolation Kills, But How and Why? Psychosomatic Medicine 63:273-274

Hultman CM, Wieselgren I-M, Öhman A (1997) Relationships Between Social Support, Social Coping and Life Events in the Relapse of Schizophrenic Patients. Scandinavian Journal of Psychology 38:3-13

Humphrey NK (1976) The social function of intellect. In: Hinde RA (ed) Growing points in ethology. Cambridge University Press, Cambridge

Jacobs A, Petit O (2011) Social network modeling: A powerful tool for the study of group scale phenomena in primates. American Journal of Primatology 73:741-747 
James R, Croft D, Krause J (2009) Potential banana skins in animal social network analysis. Behavioral Ecology and Sociobiology 63:989-997

Jolly A (1966) Lemur Social Behavior and Primate Intelligence. Science 153:501-506

Kasper C, Voelkl B (2009) A social network analysis of primate groups. Primates 50:343356

Kendal RL, Custance DM, Kendal JR, Vale G, Stoinski TS, Rakotomalala NL, Rasamimanana H (2010) Evidence for social learning in wild lemurs (Lemur catta). Learning and Behavior 38:220-234

Kenrick D, Trost M (2000) An evolutionary perspective on human relationships. In: Ickes W, Duck S (eds) The social psychology of personal relationships. John Wiley and Sons, New York

Kerth G, Perony N, Schweitzer F (2011) Bats are able to maintain long-term social relationships despite the high fission-fusion dynamics of their groups. Proceedings of the Royal Society B: Biological Sciences 278:2761-2767

Kimura R (1998) Mutual grooming and preferred associate relationships in a band of freeranging horses. Applied Animal Behaviour Science 59:265-276

King AJ, Clark FE, Cowlishaw G (2011) The dining etiquette of desert baboons: The roles of social bonds, kinship, and dominance in co-feeding networks. American Journal of Primatology 73:768-774

Knox SS, Adelman A, Ellison RC, Arnett DK, Siegmund K, Weidner G, Province MA (2000) Hostility, social support, and carotid artery atherosclerosis in The National Heart, Lung, and Blood Institute Family Heart Study. The American Journal of Cardiology 86:1086-1089

Koenig A, Borries C, Doran-Sheehy DM, Janson CH (2006) How important are affiliation and cooperation? A reply to Sussman et al. American Journal of Physical Anthropology 131:522-523

Komter AE, Schans D (2008) Reciprocity Revisited: Give and Take in Dutch and Immigrant Families. Journal of Comparative Family Studies 39:279-298

König B (1994) Components of lifetime reproductive success in communally and solitarily nursing house mice - a laboratory study. Behavioral Ecology and Sociobiology 34:275-283

Krause J, Butlin RK, Peuhkuri N, Pritchard VL (2000) The social organization of fish shoals: a test of the predictive power of laboratory experiments for the field. Biological Reviews 75:477-501

Krause J, Croft D, James R (2007) Social network theory in the behavioural sciences:potential applications. Behavioral Ecology and Sociobiology

Krause J, Lusseau D, James R (2009) Animal social networks: an introduction. Behavioral Ecology and Sociobiology 63:967-973

Krause J, Krause S, Arlinghaus R, Psorakis I, Roberts S, Rutz C (2013) Reality mining of animal social systems. Trends in Ecology and Evolution 28:541-551

Krause J, Croft DP, James R (in press) Animal Social Networks: Perspectives and challenges. In. Oxford University Press, Oxford

Kulik L (2002) Equality in Marriage, Marital Satisfaction, and Life Satisfaction: A Comparative Analysis of Preretired and Retired Men and Women in Israel. Families in Society: The Journal of Contemporary Social Services 83:197-207

Kummer H (1957) Soziales Verhalten einer Mantelpavianen-Gruppe. Schweizerische Zeitschrift fuer Psychologie. Beiheft 33:1-91

Kummer H (1968) Social Organization of Hamadryas Baboons. University of Chicago Press, Chicago 
Kummer H (1978) On the value of social relationships to nonhuman primates: A heuristic scheme. Social Science Information 17:687-705

Kummer H (1995) In the Quest of the Sacred Baboon. Princeton University Press, Princeton, New Jersey

Kuper H, Singh-Manoux A, Siegrist J, Marmot M (2002) When reciprocity fails: effortreward imbalance in relation to coronary heart disease and health functioning within the Whitehall II study. Occupational and Environmental Medicine 59:777784

Kutsukake N, Clutton-Brock T (2006) Social functions of allogrooming in cooperatively breeding meerkats. Animal Behaviour 72:1059-1068

Kutsukake N, Clutton-Brock TH (2010) Grooming and the value of social relationships in cooperatively breeding meerkats. Animal Behaviour 79:271-279

Langergraber K, Mitani J, Vigilant L (2009) Kinship and social bonds in female chimpanzees (Pan troglodytes). American Journal of Primatology 71:840-851

Laursen B, Collins WA (2003) Parent-child communication during adolescence. In: Family Communication. Lawrence Erlbaum Associates, Mahwah

Lehmann J, Korstjens AH, Dunbar RIM (2007) Group size, grooming and social cohesion in primates. Animal Behaviour 74:1617-1629

Lehmann J, Boesch C (2009) Sociality of the dispersing sex: the nature of social bonds in West African female chimpanzees, Pan troglodytes. Animal Behaviour 77:377387

Lehmann J, Dunbar RIM (2009) Network cohesion, group size and neocortex size in female-bonded Old World primates. Proceedings of the Royal Society B: Biological Sciences 276:4417-4422

Lehmann J, Andrews K, Dunbar RIM (2010) Social networks and social complexity in female-bonded primates. Proceedings of the British Academy 158: 57-82

Lehmann J, Ross C (2011) Baboon (Papio anubis) social complexity-A network approach. American Journal of Primatology 73:775-789

Lehner PN (1998) Handbook of ethological methods, 2nd edn. Cambridge University Press, Cambridge

Leinfelder I, de Vries H, Deleu R, Nelissen M (2001) Rank and grooming reciprocity among females in a mixed-sex group of captive Hamadryas baboons. American Journal of Primatology 55:25-42

Leiva D, de Vries H (2011) steepness: Testing Steepness of Dominance Hierarchies. http://CRAN.R-project.org/package=steepness

Lewis S, Roberts G, Harris MP, Prigmore C, Wanless S (2007) Fitness increases with partner and neighbour allopreening. Biology Letters 3:386-389

Löttker P, Huck M, Zinner DP, Heymann EW (2007) Grooming relationships between breeding females and adult group members in cooperatively breeding moustached tamarins (Saguinus mystax). American Journal of Primatology 69:1159-1172

Lusseau D (2007) Evidence for social role in a dolphin social network. Evolutionary Ecology 21:357-366

Lusseau D, Whitehead H, Gero S (2008) Incorporating uncertainty into the study of animal social networks. Animal Behaviour 75:1809-1815

Macdonald S, Schülke O, Ostner J (2013) The absence of grooming for rank-related benefits in female Assamese macaques (Macaca assamensis). International Journal of Primatology 34:571-584

Macdonald S, Schülke O, Ostner J (to be submitted) The structure and stability of female social relationships in Assamese macaques (Macaca assamensis). 
MacIntosh AJJ, Jacobs A, Garcia C, Shimizu K, Mouri K, Huffman MA, Hernandez AD (2012) Monkeys in the middle: Parasite transmission through the social network of a wild primate. PLoS one 7:e51144

MacKinnon K (2007) Social beginnings: the tapestry of infant and adult interactions. In: Campbell C, Fuentes A, MacKinnon K, Panger M, Bearder S (eds) Primates in Perspective. Oxford University Press, New York, pp 571-591

Manson JH, David Navarrete C, Silk JB, Perry S (2004) Time-matched grooming in female primates? New analyses from two species. Animal Behaviour 67:493-500

Martin P, Bateson P (2007) Measuring Behaviour, Third Edition edn. Cambridge University Press, Cambridge

Massen J, Sterck E, de Vos H (2010) Close social associations in animals and humans: functions and mechanisms of friendship. Behaviour 147:1379-1412

Massen JJM, Koski SE (2014) Chimps of a feather sit together: chimpanzee friendships are based on homophily in personality. Evolution and Human Behavior 35:1-8

Matsuda I, Zhang P, Swedell L, Mori U, Tuuga A, Bernard H, Sueur C (2012) Comparisons of intraunit relationships in nonhuman primates living in multilevel social systems. International Journal of Primatology 33:1038-1053

McCowan B, Anderson K, Heagarty A, Cameron A (2008) Utility of social network analysis for primate behavioral management and well-being. Applied Animal Behaviour Science 109:396-405

McCowan B, Beisner BA, Capitanio JP, Jackson ME, Cameron AN, Seil S, Attwil ER, Fushing H (2011) Network stability is a balancing act of personality, power, and conflict dynamics in rhesus macaque societies. PLoS one 6:e22350

McEwen BS, Wingfield JC (2003) The concept of allostasis in biology and biomedicine. Hormones and Behavior 43:2-15

McFarland R, Majolo B (2011) Grooming coercion and the post-conflict trading of social services in wild Barbary macaques. PLoS ONE 6:e26893

Mckenzie BD (2004) Religious Social Networks, Indirect Mobilization, and AfricanAmerican Political Participation. Political Research Quarterly 57:621-632

Mechakra-Tahiri S, Zunzunegui MV, Préville M, Dubé M (2009) Social relationships and depression among people 65 years and over living in rural and urban areas of Quebec. International Journal of Geriatric Psychiatry 24:1226-1236

Micheletta J, Waller BM, Panggur MR, Neumann C, Duboscq J, Agil M, Engelhardt A (2012) Social bonds affect anti-predator behaviour in a tolerant species of macaque, Macaca nigra. Proceedings of the Royal Society B: Biological Sciences 279:4042-4050

Mitani JC (2009) Male chimpanzees form enduring and equitable social bonds. Animal Behaviour 77:633-640

Mitani JC, Call J, Kappeler PM, Palombit RA, Silk JB (2012) The Evolution of Primate Societies. In. The University of Chicago Press, Chicago

Mitchell G, Tokunaga DH (1976) Sex differences in nonhuman primate grooming. Behavioural Processes 1:335-345

Moses R, Millar J (1994) Philopatry and mother-daughter associations in bushy-tailed woodrats: space use and reproductive success. Behavioral Ecology and Sociobiology 35:131-140

Moss CJ, Lee PC (2011) Female Social Dynamics: Fidelity and flexibility. In: Moss CJ, Croze H, Lee PC (eds) The Amboseli Elephants: A long-term perspective on a long-lived mammal

Nakagawa S, Schielzeth H (2013) A general and simplemethod for obtaining R2 from generalized linearmixed-effectsmodels. Methods in Ecology and Evolution 4 
Napier JR, Napier PH (1997) The Natural History of the Primates. The MIT Press, Cambridge, Massachusetts

Newman MEJ, Girvan M (2004) Finding and evaluating community structure in networks. Physical Review E 69

Noë R, Hammerstein P (1994) Biological markets: supply and demand determine the effect of partner choice in cooperation, mutualism and mating. Behavioral Ecology and Sociobiology 35:1-11

Noë R, Hammerstein P (1995) Biological markets. Trends in Ecology \& Evolution 10:336-339

Noë R, Van Hooff JARAM, Hammerstein P (2001) Economics in Nature - Social dilemmas, mate choice and biological markets. Cambridge University Press, Cambridge

Norman RMG, Malla AK, Manchanda R, Harricharan R, Takhar J, Northcott S (2005) Social support and three-year symptom and admission outcomes for first episode psychosis. Schizophrenia Research 80:227-234

Nunn C, L. (2012) Primate disease ecology in comparative and theoretical perspective. American Journal of Primatology 74:497-509

Opsahl T (2013) tnet: Software for analysis of weighted, two-mode, and longitudinal networks. http://cran.r-project.org/web/packages/tnet/, R package version 3.0.1

Ostner J, Heistermann M, Schülke O (2008) Dominance, aggression and physiological stress in wild male Assamese macaques (Macaca assamensis). Hormones and Behavior 54:613-619

Oswald DL, Clark EM (2003) Best friends forever?: High school best friendships and the transition to college. Personal Relationships 10:187-196

Parr LA, Matheson MD, Bernstein IS, De Waal FBM (1997) Grooming down the hierarchy: allogrooming in captive brown capuchin monkeys,Cebus apella. Animal Behaviour 54:361-367

Patterson TL, Shaw W, Semple SJ, Moscona S, Harris MJ, Kaplan RM, Grant I, Jeste DV (1997) Health-related quality of life in older patients with schizophrenia and other psychoses: relationships among psychosocial and psychiatric factors. International Journal of Geriatric Psychiatry 12:452-461

Payne H, Lawes M, Henzi SP (2003) Competition and the Exchange of Grooming Among Female Samango Monkeys (Cercopithecus Mitis Erythrarchus). Behaviour 140:453-471

Pazol K, Cords M (2005) Seasonal variation in feeding behavior, competition and female social relationships in a forest dwelling guenon, the blue monkey (Cercopithecus mitis stuhlmanni), in the Kakamega Forest, Kenya. Behavioral Ecology and Sociobiology 58:566-577

Peirce RS, Frone MR, Russell M, Cooper ML, Mudar P (2000) A longitudinal model of social contact, social support, depression, and alcohol use. Health Psychology 19:28-38

Perreault C (2010) A note on reconstructing animal social networks from independent small-group observations. Animal Behaviour 80:551-562

Perry S (1996) Female-female social relationships in wild white-faced capuchin monkeys, Cebus capucinus. American Journal of Primatology 40:167-182

Pinter-Wollman N, Hobson EA, Smith JE, Edelman AJ, Shizuka D, de Silva S, Waters JS, Prager SD, Sasaki T, Wittemyer G, Fewell J, McDonald DB (2013) The dynamics of animal social networks: analytical, conceptual, and theoretical advances. Behavioral Ecology 
Ploog DW, Blitz J, Ploog F (1963) Studies on Social and Sexual Behavior of the Squirrel Monkey (Saimiri sciureus). Folia Primatologica 1:29-66

Prell C (2012) Social network analysis: history, theory and methodology. Sage, London

R-Core-Team (2013) R: A language and environment for statistical computing. R Foundation for Statistical Computing, Vienna, Austria. URL http://www.Rproject.org/. In:

Radford A, Plessis MA (2006) Dual function of allopreening in the cooperatively breeding green woodhoopoe, Phoeniculus purpureus. Behavioral Ecology and Sociobiology $61: 221-230$

Radford AN (2012) Post-allogrooming reductions in self-directed behaviour are affected by role and status in the green woodhoopoe. Biology Letters 8:24-27

Ramos-Fernández G, Boyer D, Aureli F, Vick LG (2009) Association networks in spider monkeys (Ateles geoffroyi). Behavioral Ecology and Sociobiology 63:999-1013

Reynolds V (1970) Roles and role change in monkey society: The consort relationship of rhesus monkeys. Man 5:449-465

Roberts G, Sherratt TN (1998) Development of cooperative relationships through increasing investment. nature 394:175-179

Roberts SGB, Dunbar RIM (2011a) Communication in social networks: Effects of kinship, network size, and emotional closeness. Personal Relationships 18:439-452

Roberts SGB, Dunbar RIM (2011b) The costs of family and friends: an 18-month longitudinal study of relationship maintenance and decay. Evolution and Human Behavior 32:186-197

Roney JR, Maestripieri D (2003) Social development and affiliation. In: Maestripieri D (ed) Primate psychology. Harvard University Press, Cambridge, MA

Rook KS (1987) Reciprocity of social exchange and social satisfaction among older women. Journal of Personality and Social Psychology 52:145-154

Rutz C, Burns ZT, James R, Ismar SMh, Burt J, Otis B, Bowen J, St Clair JJH (2012) Automated mapping of social networks in wild birds. .Current Biology 22:R669R671

Sade DS (1965) Some aspects of parent-offspring and sibling relations in a group of rhesus monkeys, with a discussion of grooming. American Journal of Physical Anthropology 23:1-17

Sade DS (1972) Sociometrics of Macaca mulatta I. Linkages and Cliques in Grooming Matrices. Folia Primatologica 18:196-223

Sade DS, Altmann M, Loy J, Hausfater G, Breuggeman JA (1988) Sociometrics of Macaca mulatta: II. Decoupling centrality and dominance in rhesus monkey social networks. American Journal of Physical Anthropology 77:409-425

Sade DS (1989) Sociometrics of Macaca Mulatta III: n-path centrality in grooming networks. Social Networks 11:273-292

Salokangas RKR (1997) Living situation, social network and outcome in schizophrenia: a five-year prospective follow-up study. Acta Psychiatrica Scandinavica 96:459-468

Saltz JS, Hiltz SR, Turoff M (2004) Student social graphs: visualizing a student's online social network. In: Proceedings of the 2004 ACM conference on Computer supported cooperative work. ACM, Chicago, Illinois, USA

Sambrook TD, Whiten A, Strum SC (1995) Priority of access and grooming patterns of females in a large and a small group of olive baboons. Animal Behaviour 50:16671682

Sapolsky R (2005) The influence of social hierarchy on primate health. Science 308:648652

Sapolsky RM (2004) Why zebra's don't get ulcers. Henry Holt and Company, New York 
Schino G (2001) Grooming, competition and social rank among female primates: a metaanalysis. Animal Behaviour 62:265-271

Schino G, Ventura R, Troisi A (2005) Grooming and aggression in captive Japanese macaques. Primates 46:207-209

Schino G (2007) Grooming and agonistic support: a meta-analysis of primate reciprocal altruism. Behavioral Ecology 18 115-120

Schino G, Aureli F (2008) Grooming reciprocation among female primates: a metaanalysis. Biology Letters 4:9-11

Schino G, Di Giuseppe F, Visalberghi E (2009a) The Time Frame of Partner Choice in the Grooming Reciprocation of Cebus apella. Ethology 115:70-76

Schino G, Di Giuseppe F, Visalberghi E (2009b) Grooming, Rank, and Agonistic Support in Tufted Capuchin Monkeys. American Journal of Primatology 71:101-105

Schülke O, Bhagavatula J, Vigilant L, Ostner J (2010) Social bonds enhance reproductive success in male macaques. Current Biology 220:2207-2210

Schülke O, Pesek D, Whitman B, Ostner J (2011) Ecology of Assamese macaques (Macaca assamensis) at Phu Khieo Wildlife Sanctuary. Journal of Wildlife in Thailand 18:1-15

Scott J (2000) Social network analysis: a handbook. Sage, London

Seeman TE, Lusignolo TM, Albert M, Berkman L (2001) Social relationships, social support, and patterns of cognitive aging in healthy, high-functioning older adults:

MacArthur Studies of Successful Aging. Health Psychology 20:243-255

Setchell J (2013) Editorial: The Top 10 Questions in Primatology. International Journal of Primatology 34:647-661

Seyfarth R (1977) A model of social grooming among female monkeys. Journal of Theoretical Biology 65:671-698

Shackelford TK, Buss DM (1996) Betrayal in Mateships, Friendships, and Coalitions. Personality and Social Psychology Bulletin 22:1151-1164

Shultz S, Dunbar RIM (2006) Both social and ecological factors predict ungulate brain size. Proceedings of the Royal Society B: Biological Sciences 273:207-215

Silk J, Seyfarth R, Cheney D (1999) The structure of social relationships among female savanna baboons in moremi reserve, botswana. Behaviour:679-703

Silk J (2002a) Females, Food, Family, and Friendship. Evolutionary Anthropology 11:8587

Silk J (2002b) Using the 'F'-word in primatology. Behaviour 139:421-446

Silk J, Alberts S, Altmann J (2003) Social bonds of female baboons enhance infant survival. Science 302:1231- 1234

Silk J, Alberts S, Altmann J (2006a) Social relationships among adult female baboons (Papio cynocephalus) II. Variation in the quality and stability of social bonds. Behavioral Ecology and Sociobiology 61:197-204

Silk J, Altmann J, Alberts S (2006b) Social relationships among adult female baboons (Papio cynocephalus) I. Variation in the strength of social bonds. Behavioral Ecology and Sociobiology 6:183-195

Silk J (2007) The adaptive value of sociality in mammalian groups. Philosophical Transectiens of the Royal Society B 362:539-559

Silk J, Beehner J, Bergman T, Crockford C, Engh A, Moscovice L, Wittig R, Seyfarth R, Cheney D (2009) The benefits of social captial: close social bonds among female baboons enhance offspring survival. Proceedings of the Royal Society B 276:30993104 
Silk J, Beehner J, Bergman T, Crockford C, Engh A, Moscovice L, Wittig R, Seyfarth R, Cheney D (2010a) Strong and consistent social bonds enhance the longevity of female baboons. Current biology 20:1359-1361

Silk J, Beehner J, Bergman T, Crockford C, Engh A, Moscovice L, Wittig R, Seyfarth R, Cheney D (2010b) Female chacma baboons form strong, equitable, and enduring social bonds. Behavioral Ecology and Sociobiology 64:1733-1747

Silk J, Alberts S, Altmann J, Cheney D, Seyfarth R (2012) Stability of partner choice among female baboons. Animal Behaviour 83:1511-1518

Silk J, Cheney D, Seyfarth R (2013) A practical guide to the study of social relationships. Evolutionary Anthropology 22:213-225

Singh M, Krishna BA, Singh M (2006) Dominance hierarchy and social grooming in female lion-tailed macaques (Macaca silenus) in the Western Ghats. Journal of Bioscience 31:369-377

Smuts BB (1985) Sex and friendship in baboons. Aldine Publishing Company, New York

Snyder-Mackler N, Beehner JC, Bergman TJ (2012) Defining higher levels in the multilevel societies of Geladas (Theropithecus gelada). International Journal of Primatology 33:1054-1068

Soczka L (1974) Ethologie sociale et sociometrie: analyse de la structures d'un groupe de singes crabiers (Macaca fascicularis) en captivite. Behaviour 50:254-269

Stanley CR, Dunbar RIM (2013) Consistent social structure and optimal clique size revealed by social network analysis of feral goats, Capra hircus. Animal Behaviour 85:771-779

Sterck EHM, Watts DP, van Schaik CP (1997) The evolution of female social relationships in nonhuman primates. Behavioral Ecology and Sociobiology 41:291-309

Sterling EJ (1993) Patterns of range use and social organization in aye-ayes (Daubentonia madagascariensis) on Nosy Mangabe. In: M. KP, U. GJ (eds) Lemur social systems and their ecological basis. Plenum, New York, pp 1-10

Sueur C, Petit O (2008) Organization of group members at departure is driven by social structure in Macaca. International Journal of Primatology 29:1085-1098

Sueur C, Jacobs A, Amblard F, Petit O, King AJ (2011a) How can social network analysis improve the study of primate behavior? American Journal of Primatology 73:703719

Sueur C, Petit O, De Marco A, Jacobs AT, Watanabe K, Thierry B (2011b) A comparative network analysis of social style in macaques. Animal Behaviour 82:845-852

Sueur C, Petit O, DeMarco A, Jacobs AT, Watanabe K, Thierry B (2011c) A comparative network analysis of social style in macaques. Animal Behaviour 82:845-852

Sundaresan SR, Fischhoff IR, Dushoff J, Rubenstein DI (2007) Network metrics reveal differences in social organization between two fission-fussion species, Grevy's zebra and onager. Oecologia 151:140-149

Sundaresan SR, Fischhoff IR, Dushoff J (2009) Avoiding spurious findings of nonrandom social structure in association data. Animal Behaviour 77:1381-1385

Sussman RW, Garber P, Cheverud J (2005) Importance of cooperation and affiliation in the evolution of primate sociality. American Journal of Physical Anthropology 128:84-97

Thierry B (2004) Social epigenesis. In: Thierry B, Singh M, Kaumanns W (eds) Macaque societies - a model for the study of social organization. Cambridge University Press, Cambridge, pp 267-289

Thierry B, Singh M, Kaumanns W (2004) Macaque societies - a model for the study of social organization. Cambridge University Press, Cambridge 
Thierry B (2007) The macaques - A double-layered social organization In: Campbell C, Fuentes A, MacKinnon K (eds) Primate in Perspective. Oxford University Press, New York, Oxford, pp 224- 239

Tiddi B, Aureli F, Schino G, Voelkl B (2011) Social relationships between adult females and the alpha male in wild tufted capuchin monkeys American Journal of Primatology 73:812-820

Tiddi B, Aureli F, Schino G (2012) Grooming Up the Hierarchy: The Exchange of Grooming and Rank-Related Benefits in a New World Primate. PLoS ONE 7:e36641

Törnblom K, Kazemi A, Fredholm E (2012) Attribution of Friendship: The Influence of the Nature and Comparability of Resources Given and Received. In: Törnblom K, Kazemi A (eds) Handbook of Social Resource Theory. Springer New York, pp $119-132$

Trivers RL (1971) The evolution of reciprocal altruism. The Quarterly Review of Biology 46:35-57

Uchino B (2006) Social Support and Health: A Review of Physiological Processes Potentially Underlying Links to Disease Outcomes. Journal of Behavioral Medicine 29:377-387

van Schaik CP (1989) The ecology of social relationships amongst female primates. In: Standen V, Foley RA (eds) Comparative socioecology. The behavioural ecology of humans and other mammals. Blackwell Scientific Publications, Oxford, pp 195218

Vanderhorst RK, McLaren S (2005) Social relationships as predictors of depression and suicidal ideation in older adults. Aging \& Mental Health 9:517-525

Ventura R, Majola B, Koyama N, Hardie S, Schino, G (2006) Reciprocation and interchange in Wild Japanese Macacques: Grooming, Cofeeding, and Agonistic Support. American Journal of Primatology 68:1138-1149

Voelkl B, Noë R (2008) The Influence of Social Structure on the Propagation of Social Information in Artificial Primate Groups: A Graph-based Simulation Approach. Journal of Theoretical Biology 257:77-86

Voelkl B, Kasper C (2009) Social structure of primate interaction networks facilitates the emergence of cooperation. Biology Letters 5:462-464

Voelkl B (2010) The 'Hawk-Dove' game and the speed of the evolutionary process in small heterogeneous populations. Games 1:103-116

Voelkl B, Noë R (2010) Simulation of information propagation in real-life primate

networks: longevity, fecundity, fidelity. Behavioral Ecology and Sociobiology 64:14491459

Voelkl B, Kasper C, Schwab C (2011) Network measures for dyadic interactions: stability and reliability. American Journal of Primatology 73:731-740

Walker K (1995) "Always there for me": Friendship patterns and expectations among middle- and working-class men and women. Sociological Forum 10:273-296

Wang H-X, Mittleman MA, Orth-Gomer K (2005) Influence of social support on progression of coronary artery disease in women. Social Science \& Medicine 60:599-607

Weidt A, Hofmann SE, König B (2008) Not only mate choice matters: fitness consequences of social partner choice in female house mice. Animal Behaviour 75:801-808

Welin L, Svärdsudd K, Ander-Peciva S, Tibblin G, Tibblin B, Larsson B, Wilhelmsen L (1985) Prospective study of social influences on mortality: The study of men born in 1913 and 1923. The Lancet 325:915-918 
Wey T, Blumstein DT, Shen W, Jordán F (2008) Social network analysis of animal behaviour: a promising tool for the study of sociality. Animal Behaviour 75:333344

Wheeler BC, Scarry CJ, Koenig A (2013) Rates of agonism among female primates: a cross-taxon perspective. Behavioral Ecology:in press

Whitehead H (2008) Analyzing Animal Societies: Quantitative methods for vertebrate social analysis. The University of Chicago Press, Chicago

Whitehead HaW, L. (2000) The Sperm Whale: Social females and roving males. In: Mann J, Conner, R.C., Tyack, P.L., and Whitehead, H. (ed) Cetacean Societies: Field studies of dolphins and whales. The University of Chicago Press, Chicago

Wikberg EC, Ting N, Sicotte P (2013) Kinship and similarity in residency status structure female social networks in black-and-white colobus monkeys (colobus vellerosus). American Journal of Physical Anthropology 153:365-376

Williams R, Lusseau D (2006) A killer whale social network is vulnerable to targeted removals. Biology Letters 2:497-500

Wilson EO (1975) Sociobiology: The New Synthesis. Harvard University Press, Cambridge, MA

Wittemyer G, Douglas-Hamilton I, Getz WM (2005) The socioecology of elephants: analysis of the processes creating multitiered social structures. Animal Behaviour 69:1357-1371

Wittig R, Crockford C, Lehmann J, Whitten P, Seyfarth R, Cheney D (2008) Focused grooming networks and stress alleviation in wild female baboons. Hormones and Behavior in press

Wrangham RW (1980) An ecological model of female-bonded primate groups. Behaviour 75:262-300

Xia D, Li J, Garber PA, Sun L, Zhu Y, Sun B (2012) Grooming reciprocity in female Tibetan macaques (Macaca thibetana). American Journal of Primatology 74:569579

Xue M, Silk JB (2012) The role of tracking and tolerance in relationship among friends. Evolution and Human Behavior 33:17-25

Yeager CP (1990) Proboscis monkey (Nasalis larvatus) social organization: Group structure. American Journal of Primatology 20:95-106

Young C, Majolo B, Schülke O, Ostner J (in press) Male social bonds and rank predict supporter selection in cooperative aggression in wild Barbary macaques. Animal Behaviour

Young C, Majolo B, Heistermann M, Schülke O, Ostner J (to be submitted) Responses to social and environmental stress are attenuated by strong male bonds in wild macaques.

Zhang P, Li B, Qi X, MacIntosh AJJ, Watanabe K (2012) A proximity-based social network of a group of Sichuan snub-nosed monkeys. International Journal of Primatology 33:1081-1095

Zhou W, Sornette D, Hill R, Dunbar R (2005) Discrete hierarchical organization of social group sizes. Proceedings of the Royal Society London B 272:439-444 



\section{Acknowledgements}

First of all I would like to Julia Ostner and Oliver Schülke for giving me this fantastic opportunity. I would also like to thank them for teaching me how to have confidence in myself and my work and for always having an open door when I needed it. I am grateful to Peter Kappeler for acting as the co-supervisor of this thesis and to Antje Engelhardt, Bernhard Fink, Julia Fischer and Eckhard Heymann for taking the time to act as my defense committee. I am also grateful to the German Initiative of Excellence to the University of Göttingen for providing funding for this project.

I would like to thank the National Research Council of Thailand (NRCT) and the Department of National Parks, Wildlife and Plant Conservation (DNP) for permission (No. 0004.3/3618; 0002.3/2647) to conduct this work. I am grateful to J. Prabnasuk, K. Nitaya, M. Kumsuk, and K. Kreetiyutanont (PhuKhieo Wildlife Sanctuary) for their cooperation and permission to carry out this research. I would also like to thank Andreas Koenig and Carola Borries (Stony Brook University), who developed the field site at Huai Mai Sot Yai, for their kind words and encouragement.

I am extremely grateful to all members of Team Macaque, Kun Moo, Khun Sayaan, Khun Tam, Khun Wat, Khun Piya for all their kindness and hard work, especially to Khun Wet and Sabastian Rogahn for their help with data collection. You are an amazing team and I feel very lucky to have had the chance to meet and work with you all!

Special thanks has to go to Marlies Heesen and Miranda Swagemakers for being there through all the very literal blood, sweat and tears in the field and for all the tea, wise words and support back in Germany. I particularly have to thank Miranda for making running camp look easy, our lives in the forest run so smoothly and for showing me how to laugh when the stats don't work. For Marlies I am not really sure where to begin...You've been calming me down and propping me up since the day we met at the MPI BBQ, right up until the last hours of formatting of the final thesis. I can't thank you enough for all the crazy memories, we danced the night away in so many cities, in so many countries, on so many continents! I only hope we can keep it up...

I was warned by several people at the beginning of my $\mathrm{PhD}$ that it was probably going to be a lonely and isolating experience. Clearly these people had never worked anywhere like the CRC or the DPZ! I am so grateful to all the amazing colleagues I've met at both institutes over the last 5 years. For the dancing and laughing and wine fueled debates about life, stats and monkeys. 
This is the point where traditionally we insert a long list of names... I am going to break with tradition out of fear that I will inevitably miss someone. You know who you are, you all know that you are wonderful and I am incredibly sad that many of you are now far, far away. Having said all that I would like to specifically thank Marlies Heesen, Cédric Girard-Buttoz and Chris Young for their proof-reading and pep talks in the final weeks of writing, I really appreciate it.

I would like to give a special thanks to Ulrike Mälzig for her help in unconventional and often inconvenient circumstances, and Astrid Bellmund-Soller for her incredible guidance and support. Throughout my PhD I have been battling recurring bouts of clinical depression. It is no exaggeration to say that the greatest achievement of $\mathrm{my} \mathrm{PhD}$ will be to stand on the day of my defense, in front of my defense committee un-medicated and free of depression. I worked hard to get to this point, but without the help of these kind and patient women all the hard work in the world would not have been enough.

I have to also give a huge thanks to my parents and my sister for all their patience, love and support during my PhD. For sending all the teabags and sweeties, and for always being at the end of a phone whenever I needed you, wherever I was. It has been hard to spend so much time away from you all over the last 5 years, and I am looking forward to spending a bit more time closer to home soon.

Lastly, I an incredibly grateful to Frederic Nowak for supporting me in every conceivable way over the last couple of years. From extracting data and proofreading manuscripts (and virtually every word of this thesis), to rubbing my sore shoulders and doing the dishes. You'll probably find it a bit over the top if I say I couldn't have done it without you, I guess I would have found a way, but the thought of it sends a shudder right through me. Thank you so, so much. I would also like to say a big thank you to Frederic's family for all the laughter, chips and sekt and for making me feel so at home here in Germany. 


\section{Sally Macdonald}

\section{CURRICULUM VITAE}

\section{Address}

Groner Landstr. 55b

37081, Göttingen

Germany

Email: sallymacd@gmail.com

Date of Birth $5^{\text {th }}$ December 1983

\section{ACADEMIC CAREER}

2010 - Current $\quad$ PhD Behavioural Biology, Georg-August Universität Göttingen

Thesis Title: "Female social relationships among wild Assamese macaques (Macaca assamensis)"

Supervisor: Prof. Dr. Julia Ostner

2008 - $2010 \quad$ Research Assistant: Social Evolution in Primates Research Group, Phu Khieo Wildlife Sanctuary, Thailand

2007-2008

Msc. Evolutionary Anthropology, Durham University

Dissertation: "Biological markets and infant handling among Barbary macaques (Macaca sylvanus)"

Supervisor: Dr. Russell Hill

Research Assistant: Fongoli Savanna Chimpanzee Project, Kedougou, Senegal

Bsc. Psychology (Hons), 2.1, University of St Andrews

Honors Project: “An experimental study of the diffusion of traditions in chimpanzees (Pan troglodytes)."

Supervisor : Prof. Andrew Whiten 


\section{GRANTS}

2012 German Excellence Initiative, Georg-August-Universität Göttingen, Conference Travel Grant - $€ \mathbf{1 7 0 0}$

2012 DAAD RISE Internship, held with Samual Shry - $€ 1950$

2011 Primate Society of Great Britain, General Research Grant - £750

\section{TEACHING EXPERIENCE}

2012 Bachelor Project/DAAD Internship Supervisor, Samual Shry, "Fluctuations in spatial cohesion in Assamese macaques (Macaca assamensis)"

2012 Bachelor Project Supervisor, Sandra Granzow, "The effect of dominance rank on a social network in rhesus macaques."

2006 Teaching Assistant, Primate Behaviour and Conservation Field School, El Zota Biological Field Station, Costa Rica

\section{CONFERENCE CONTRIBUTIONS}

2013 "Parasite Load in Female Assamese Macaques: A Cost of Sociality" (Poster) Göttinger Freilandtage, Göttingen, Germany

2012 "Rank and Grooming Relationships Among Female Assamese Macaques" International Primatological Society Congress, Cancun, Mexico

2012 "Female Social Relationships of Wild Assamese Macaques" (Poster) Primate Society of Great Britain, Spring Meeting, Kent, UK

2011 "The Effect of Rank on Female Social Relationships in Female Assamese Macaques" (Poster)

Göttinger Freilandtage, Göttingen, Germany

$2010 \quad$ "Female-Female Social Structure of Wild Assamese Macaques (Macaca assamensis) at Phu Khieo Wildlife Sanctuary" (Poster) Thai Wildlife Conference, Bangkok, Thailand 


\section{SOCIETY MEMBERSHIP}

2013 Association for the Study of Animal Behaviour

2007 International Primatological Society

2007 Primate Society of Great Britain

\section{PUBLICATIONS}

\section{Journal Articles}

Macdonald, S., Schülke, O. \& Ostner, J. (2013). The absence of grooming for rank-related benefits in female Assamese macaques (Macaca assamensis). International Journal of Primatology $34,571-584$.

Heesen, M., Rogahn, S., Macdonald, S., Ostner, J. \& Schülke, O. (in revision). Predictors of food related aggression in wild Assamese macaques and the role of conflict avoidance. Behavioural Ecology and Sociobiology

Heesen, M., Rogahn, S., Macdonald, S., Ostner, J. \& Schülke, O. (under review). Ecological and social determinants of group cohesiveness and within-group spatial position in wild Assamese macaques. Ethology

\section{Book Chapters}

Macdonald, S. and Voelkl, B. (in press). Primate social networks. In Animal Social Networks: Perspectives and challenges, eds. Krause, J. Croft, D.P. and James, R., Oxford: Oxford University Press. 